\title{
WestVirginiaUniversity
}

THE RESEARCH REPOSITORY @ WVU

Graduate Theses, Dissertations, and Problem Reports

2017

\section{Three Essays on Time-Varying Risk Aversion and Investor Sentiment}

Denghui Chen

Follow this and additional works at: https://researchrepository.wvu.edu/etd

\section{Recommended Citation}

Chen, Denghui, "Three Essays on Time-Varying Risk Aversion and Investor Sentiment" (2017). Graduate Theses, Dissertations, and Problem Reports. 7071.

https://researchrepository.wvu.edu/etd/7071

This Dissertation is protected by copyright and/or related rights. It has been brought to you by the The Research Repository @ WVU with permission from the rights-holder(s). You are free to use this Dissertation in any way that is permitted by the copyright and related rights legislation that applies to your use. For other uses you must obtain permission from the rights-holder(s) directly, unless additional rights are indicated by a Creative Commons license in the record and/ or on the work itself. This Dissertation has been accepted for inclusion in WVU Graduate Theses, Dissertations, and Problem Reports collection by an authorized administrator of The Research Repository @ WVU.

For more information, please contact researchrepository@mail.wvu.edu. 
Three Essays on Time-Varying Risk Aversion and Investor Sentiment

\author{
Denghui Chen \\ Dissertation submitted to the \\ College of Business and Economics \\ at West Virginia University \\ in partial fulfillment of the requirements for the degree of
}

Doctor of Philosophy in Finance

Victor Chow, Ph.D., Chair

Alexander Kurov, Ph.D.

Eric Olson, Ph.D.

Gulnara Zaynutdinova, Ph.D.

Department of Finance

Morgantown, West Virginia

2017

Keywords: Risk aversion; Financial crisis; Risk premium; Monetary policy; Fed funds rate; Investor sentiment; Macroeconomic announcements; Market response; Intraday data

\title{
Copyright 2017 Denghui Chen
}




\section{Abstract \\ Three Essays on Time-Varying Risk Aversion and Investor Sentiment}

\section{Denghui Chen}

This dissertation explores issues regarding the effect of investor risk aversion and sentiment on financial markets. It is widely considered that a risk averse investor requires risk premium to hold risky assets, and the required risk premium is proportional to the riskiness of the underlying assets. From the myopic loss aversion perspective, investors, who get utility by frequently evaluating their portfolios and are more sensitive to losses, will require a higher risk premium as compensation for the fear of a major drop in financial wealth. Recent literature has shown that large tail jumps are often contributed to such major drop in financial markets. Rare events, which often accompanied with tail jumps, have a more drastic impact on risk averse investor, and the compensation for rare events accounts for a large fraction of the equity risk premium. However, there is no theoretical framework that has been developed to separate the risk aversion component of rare events from daily volatility.

In this work, I continue to argue the importance of the rare events have different impact on investors decision regarding to equity risk premium. Rational investor risk aversion should spike and require higher risk premium to compensate for higher risk when rare events happen. I develop a theoretical framework to decompose the risk aversion component with rare events from the part associated with daily volatility and prove that they have varying impact on risk premium. Specifically, I first extend the jump-diffusion model incorporated with disaster models and develop a theoretical framework to decompose the risk aversion component of rare events from frequent events. Then I attempt to use monetary surprises as empirical application of the theoretical framework. Bernanke and Kuttner (2005) show that the effect of monetary surprises on expected excess returns can be related to the impact of monetary policy on investor risk aversion or the riskiness of stocks. Finally I test how market response to macroeconomic news surprises conditional on investor sentiment. The results are arranged in the following order.

Chapter 1 of the dissertation makes the argument that investors should treat rare events differently from frequent events. Intuitively, a rare event (disaster) reduces the fundamental value of a stock by a time-varying amount. A rise in disaster probability lowers the expected rate of return on equity, and it also motivates investors to shift toward the risk-free asset or buy deep out-of-themoney puts. Comparing to previous models, I extend the general jump-diffusion model by decomposing investor risk aversion towards frequent and rare events separately. I show that investor treats frequent volatility (quadratic variations) and rare events (tail variations) differently, and decompose representative agent's risk aversion into volatility risk aversion and tail risk aversion. The model implicates that tail risk aversion can be considered as a tractable way to model changes in expectation of rare events and equity risk premium.

In Chapter 2 of the dissertation, I apply the model implication by using monetary surprises and decomposed risk premium from the VIX. Monetary surprises are not only likely to influence stock prices, but also to affect the degree of uncertainty and risk aversion faced by investors. This paper examines the interdependence of stock market, tail risk aversion, and monetary shocks across conventional and unconventional monetary policy periods. The empirical sample is from January 
1998 to October 2014. During conventional monetary policy period, I find that there is contemporaneous response among stock market, time-varying risk aversion, and monetary policy under a VAR analysis. Generally, both volatility and tail risk aversion components respond negatively to a positive stock market and monetary policy shock. It indicates that a bullish stock market decreases investor risk aversion, and a positive monetary shock also decreases investor risk aversion as increasing interest rate is considered a good indicator of the economy. During unconventional times, we find that a surprise decline in the expected short-term rate leads to an increase in stock prices and a mixed effect on tail risk aversion. A plausible explanation is that investors believe a surprise drop in expected short-term rate reflects a fast deteriorating economic outlook during unconventional monetary policy period.

Chapter 3 of the dissertation is co-authored project. In this chapter, we consider the effect of investor sentiment from market microstructure perspective. We consider investor sentiment arises when noise traders actively trade on pseudo-signals (Shiller, 1984; Lee, 2001), and investigate the effect of investor sentiment on market reaction to macroeconomic news surprises. Noise traders are considered to respond to new information sub-optimally, and smart-money investors respond to news about fundamental value rapidly and optimally. We utilize both simultaneous news release analysis and normalized estimation proposed by Swanson and Williams (2014). When market sentiment is high, it indicates that noise traders are trading more actively, and we find market response to news surprises is weaker. On the other hand, when market sentiment is low, it indicates that noise traders are trading less actively, and it leads to a stronger market response to news surprises. 


\section{ACKNOWLEDGMENTS}

I would like to thank my advisor, Victor Chow, and my committee members Alex Kurov, Eric Olson, and Gulnara Zaynutdinova for their help and support. I also thank my colleagues for many helpful discussions and suggestions. 


\section{TABLE OF CONTENTS}

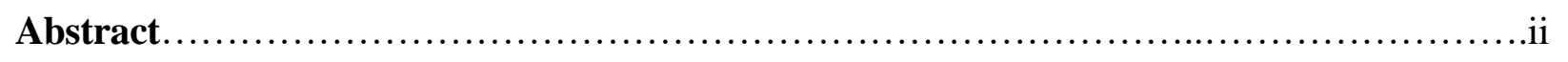

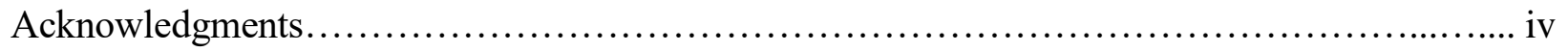

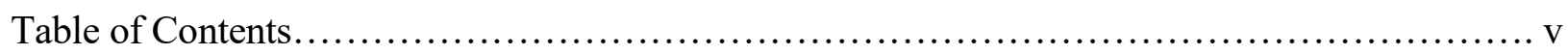

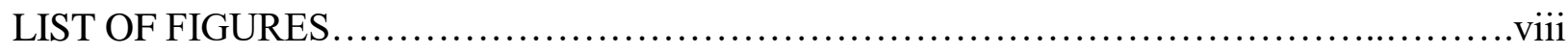

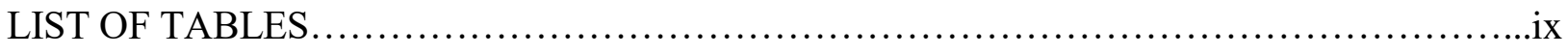

CHAPTER 1: Risk Premium, and Decomposition of Risk Aversion 1

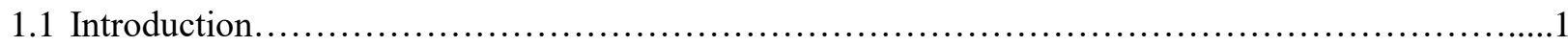

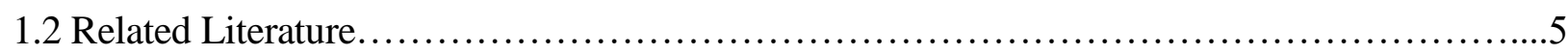

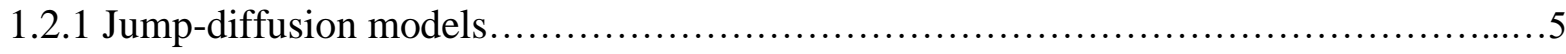

1.2.2 Disaster/Insurance Models with Rare Events............................................6

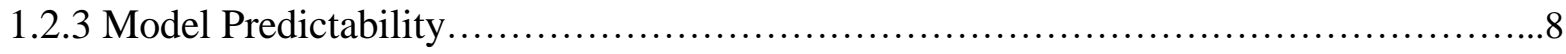

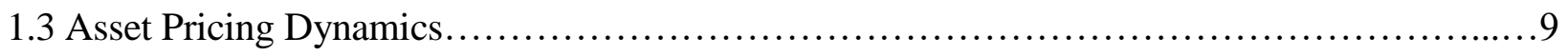

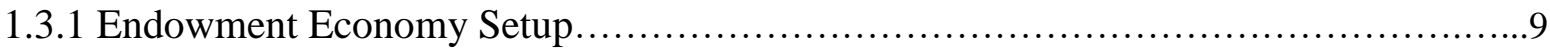

1.3.2 Jump-Diffusion Model in Value Function............................................12

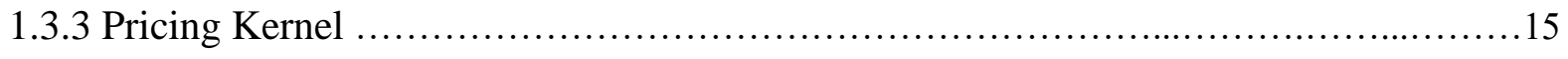

1.3.4 Equity Risk Premium and Separation of Risk Aversions...............................16

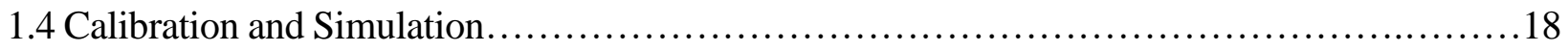

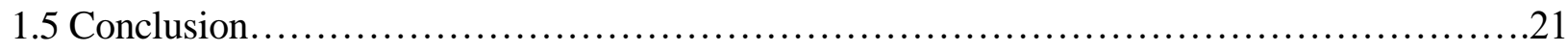

CHAPTER 2: The Impact of Monetary Policy Surprises on Aggregate Tail Risk Aversion 25

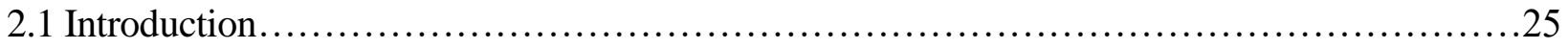

2.2 Decomposing the VIX Index \& Identification of VAR Model................................29 
2.2.1 Theoretical Motivation \& Risk Aversion Decomposition..........................29

2.2.2 Define Volatility Risk Aversion and Tail Risk Aversion............................32

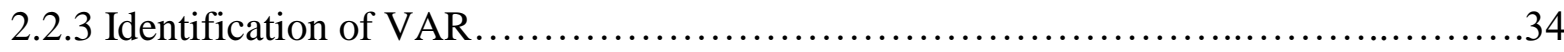

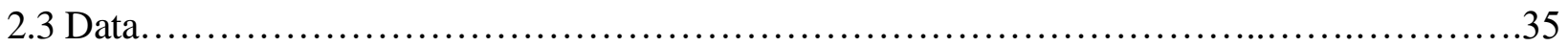

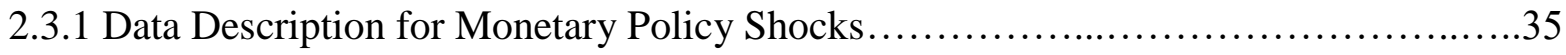

2.3.2 Data Description for Time-varying Risk Aversion...............................36

2.4 Estimation Results from the VAR Framework...................................... 37

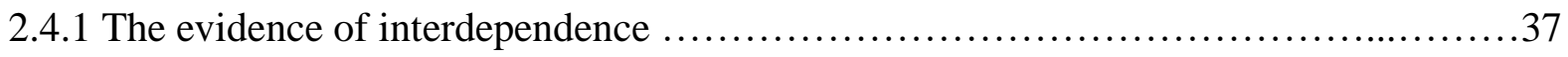

2.5 Estimation Results from Event Study Analysis.......................................40

2.5.1 Descriptive Statistics...............................................40

2.5.2 Effect of Monetary Surprise on Market Return and Risk Aversion ..................41

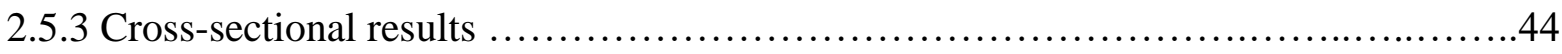

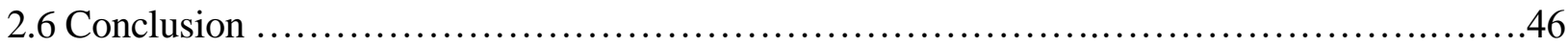

\section{CHAPTER 3: Does Investor Sentiment Affect the Market Reaction to Macroeconomic}

$\begin{array}{lr}\text { News? } & 59\end{array}$

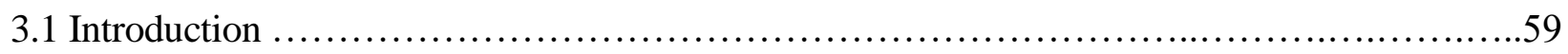

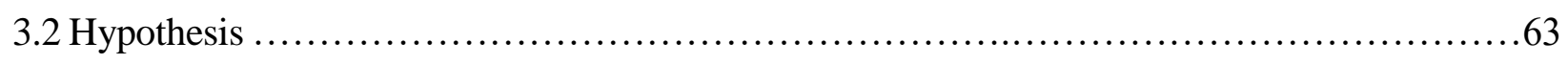

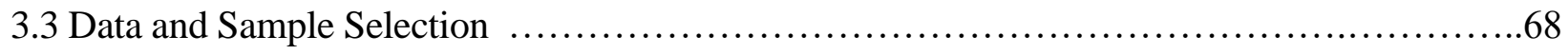

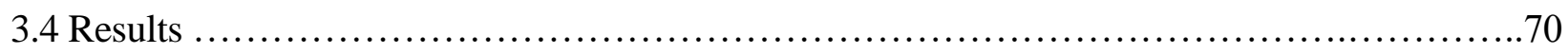

3.4.1 Effect of Macroeconomic news surprises on E-mini S\&P 500....................70

3.4.2 Descriptive Statistics of Market Moving News Announcements....................71 
3.4.3 Effect of Macroeconomic news surprises on E-mini S\&P 500 Conditional on Investor

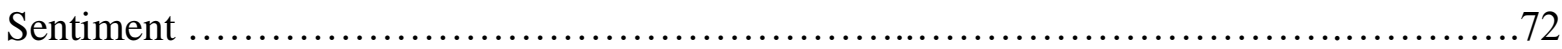

3.4.4 Effect of Positive and Negative Macroeconomic news surprises on E-mini S\&P 500

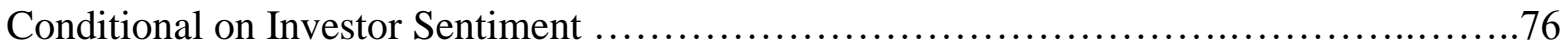

3.4.5 Robustness Checks......................................................... 79

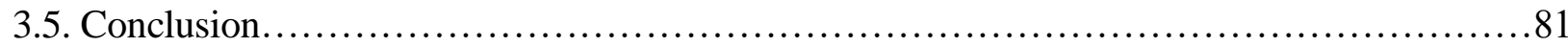

$\begin{array}{ll}\text { Bibliography } & 96\end{array}$

Appendix A Supplementary Appendix to "Risk Premium, and Decomposition of Risk Aversion" $\quad 104$

Appendix B Supplementary Appendix to "The Impact of Monetary Policy Surprises on $\begin{array}{ll}\text { Aggregate Tail Risk Aversion" } & 110\end{array}$

B.1 Define Risk Aversion Components............................................. 110

B.2 Impulse Responses under Structural VAR ..................................... 113

Appendix C Supplementary Appendix to "Does Investor Sentiment Affect the Market Reaction to Macroeconomic News?"

C.1 Derivation of Impact of Noise Trader on Stock Price Changes.......................... 121

C.2 Regression Analysis without independent sentiment dummy variables ....................123 


\section{LIST OF FIGURES}

Figure 1.1 Correlation of S\&P 500 Return and Per-capita Consumption Growth..................23

Figure 1.2 Equity Premium Isoquants and Confidence Regions...............................24

Figure 2.1 Monetary Policy Shocks, Volatility Risk Aversion, and Tail Risk Aversion............54

Figure 2.2 Impulse Responses to Stock Return Shock..................................55

Figure 2.3 Impulse Responses to Monetary Policy Shock $\ldots \ldots \ldots \ldots \ldots \ldots \ldots \ldots \ldots \ldots \ldots \ldots \ldots . . .56$

Figure 2.4 Impulse Responses to Tail Risk Aversion Shock.............................57

Figure 2.5 Impulse Responses to Volatility Risk Aversion Shock ...........................58

Figure 3.1 Time Variation in Investor Sentiment Index ............................. 94

Figure 3.2 Evidence of the Impact of Investor Sentiment on Market Return ..................95

Figure B.2.1 Impulse Responses to Stock with Long-run restriction on Fed Funds Rate............113

Figure B.2.2 Impulse Responses to Monetary Policy with Long-run restriction on Fed Funds Rate114

Figure B.2.3 Impulse Responses to Tail Risk Aversion with Long-run restriction on Fed Funds Rate .115

Figure B.2.4 Impulse Responses to Volatility Risk Aversion with Long-run restriction on Fed Funds

Rate .116

Figure B.2.5 Impulse Responses to Stock Price with Long-run restriction on Tail Risk Aversion 117

Figure B.2.6 Impulse Responses to Monetary Policy with Long-run restriction on Tail Risk Aversion .118

Figure B.2.7 Impulse Responses to Tail Risk Aversion with Long-run restriction on Tail Risk Aversion

Figure B.2.8 Impulse Responses to Volatility Risk Aversion with Long-run restriction on Tail Risk Aversion . . 120 


\section{LIST OF TABLES}

Table 1.1 Parameters for the disaster model simulation ...............................................................22

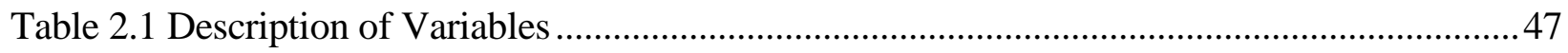

Table 2.2 ADF Unit Root Tests........................................................ 48

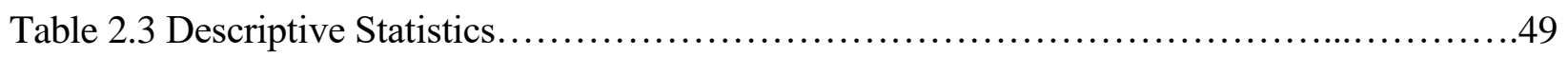

Table 2.4 Response of stock prices to target rate changes ...................................50

Table 2.5 Effect of target rate changes on investor risk aversion ..............................51

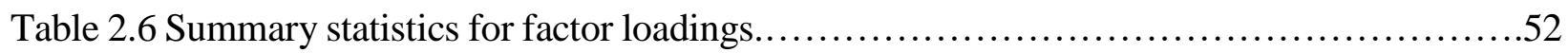

Table 2.7 Effect of the market risk, risk aversion on the response of daily stock..................53

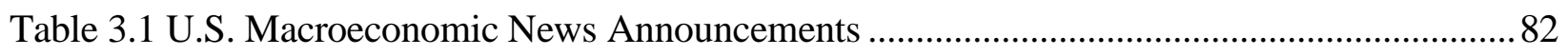

Table 3.2 Market Response to Macroeconomic News Surprises ........................................................ 83

Table 3.3 Summary Statistics of Market Moving News Surprises...................................................... 84

Table 3.4 Market Response to Macroeconomic News Surprises Conditional on Investor

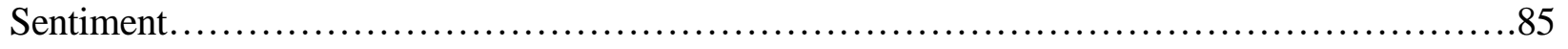

Table 3.5 Average Effect of Investor Sentiment on Market Response to Macroeconomic News....86

Table 3.6 Market Response to Positive Macroeconomic News Surprises Conditional on Investor

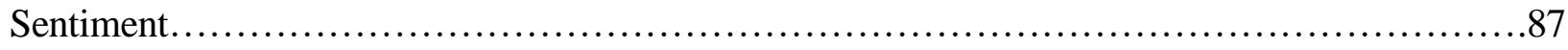

Table 3.7 Market Response to Negative Macroeconomic News Surprises Conditional on Investor

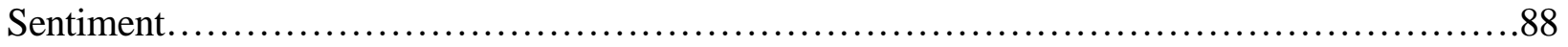

Table 3.8 Average Effect of Investor Sentiment on Market Response to Positive Macroeconomic

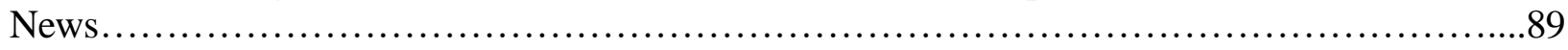

Table 3.9 Average Effect of Investor Sentiment on Market Response to Negative_Macroeconomic News. .90

Table 3.10 Average Effect of Investor Sentiment on Market Response to Macroeconomic News Controlling for State of Economy. .91 
Table 3.11 Average Effect of Investor Sentiment on Market Response to Positive Macroeconomic News Controlling for State of Economy............................................... 92

Table 3.12 Average Effect of Investor Sentiment on Market Response to Negative Macroeconomic News Controlling for State of Economy............................................93

Table C.2.1 Market Response to Macroeconomic News Surprises Conditional on Investor Sentiment......................................................................123

Table C.2.2 Average Effect of Investor Sentiment on Market Response to News Surprises.......124

Table C.2.3 Market Response to Positive Macroeconomic News Surprises Conditional on Investor Sentiment.

Table C.2.4 Market Response to Negative Macroeconomic News Surprises Conditional on Investor Sentiment. .126

Table C.2.5 Average Effect of Investor Sentiment on Market Response to Positive Macroeconomic News.

Table C.2.6 Average Effect of Investor Sentiment on Market Response to Negative_Macroeconomic News. 128

Table C.2.7 Average Effect of Investor Sentiment on Market Response to Macroeconomic News Controlling for State of Economy.

Table C.2.8 Average Effect of Investor Sentiment on Market Response to Positive Macroeconomic News Controlling for State of Economy 130

Table C.2.9 Average Effect of Investor Sentiment on the E-mini S\&P 500 to Negative Macroeconomic News Controlling for State of Economy. .131

Table C.2.10 Average Effect of Investor Sentiment on Market Response to Macroeconomic News Controlling for State of Economy.

Table C.2.11 Average Effect of Investor Sentiment on Market Response to Positive Macroeconomic News Controlling for State of Economy .133

Table C.2.12 Average Effect of Investor Sentiment on Market Response to Negative Macroeconomic News Controlling for State of Economy. 134 


\section{CHAPTER 1: Risk Premium, and Decomposition of Risk Aversion}

\subsection{Introduction}

Is there a spike in investor risk aversion when rare events happen? Do investors require higher risk premium to compensate for sudden large increase in risk? Do investors treat rare events (disasters) differently from frequent events? In one of the first studies related to rare events, Rietz (1988) proposed a hypothesis that the probability of rare disasters (such as economic depressions or wars) is a major determinant of asset risk premium. The Intertemporal Capital Asset Pricing Model (ICAPM) in Campbell $(1993,1996)$ shows that risk averse investors care about risks from both the market return and the changes in expected future market returns, and it induces a low risk tolerant investor to require a higher risk premium to hold risky assets. From a more behavioral perspective, if investors get utility by frequently evaluating their portfolios and are more sensitive to losses than to gains over these changes, meaning loss averse, their fear of a major drop in financial wealth will induce a higher demand in risk premium as compensation. The myopic loss aversion from Benartzi and Thaler (1995) shows that a rare event leads investor to reevaluate their portfolios and demand higher risk premium. A more recent study from Bollerslev and Todorov (2011) shows that the compensation for rare events accounts for a large fraction of the average equity and variance risk 
premia. From existing studies, rare events have a more drastic impact on risk averse investor than the impact from frequent events. However, there is no theoretical framework that has been developed to separate the risk aversion component towards rare events from daily volatility. This paper contributes to existing literature by developing a theoretical framework to decompose the risk aversion into tail component and volatility component.

The recent studies in tail risk premium prevail that rare events have important impact in financial markets. In general, stock prices are high when stocks bear little risk and no foreseeable disasters. Intuitively, a disaster reduces the fundamental value of a stock by a time-varying amount. A rise in disaster probability lowers the expected rate of return on equity, and motivates investors shift toward the risk-free asset or buy deep out-of-the-money puts. If investors are risk averse in the setup of Knight (1921) and Ellsberg (1961), then the uncertainty about rare events will be priced into financial prices in the form of a risk premium. Moreover, the international empirical evidence from Barro (2006) has shown that disasters have been sufficiently frequent, the probability of disasters affects the variance of the growth rate, and account for the high risk premium on equities. This paper incorporates and extends rare disaster models and jump-diffusion models, and provides a theoretical framework that presents how daily volatility and rare events can have varying impact on risk premium. The model decomposes the traditional risk aversion into two components: one risk aversion component associated with daily volatility, defined as volatility risk aversion, and the other risk aversion component related to rare events, defined as tail risk aversion.

The second contribution of this paper is to provide a tractable solution on how rare events affect risk premium that is channeled through investor risk aversion. The model tracts the changes of the time-varying risk aversion components under normal times and rare events, and proposes a solution on how time-varying risk aversion affect the equity risk premium. The decomposition of 
traditional risk aversion contributes to the explanations of myopic loss aversion and equity risk premium puzzle. Some decisions are made by investors just once or twice in a lifetime when facing rare events, such as the dot-com bubble of 2001, and the "Great Recession" of 2008, while some decisions are made daily. The two types of events should have different impact on investors when they reevaluate their portfolios in the presence of potential loss. The normal asset pricing models can be applicable in dealing with daily fluctuations but not with the risks associated with rare events. The coefficient of relative risk aversion is an important parameter for analyzing behavior toward risk, but good estimates of this parameter are difficult to obtain. A promising place for reliable estimation is a combination of rare macroeconomic disasters and tail risk premium from recent financial studies, which both have major influence on financial markets and equity risk premium.

Similar to existing disaster/insurance models, I model rare events as jumps in the aggregate endowment, and solve the equilibrium risk premium in an economy with a representative agent whose risk aversion varies towards frequent events and rare events. The equilibrium equity premium has two components: the diffusive part and jump part, both driven by risk aversions. I find that risk aversion toward rare events plays an important role in explaining the risk premium required by investors when there is a change in disaster probability and disaster size. To formally investigate this possibility of "rare-event premium," I adopt an equilibrium setting with one representative agent that places his/her consumption on the asset. The asset in this economy is a claim to the aggregate endowment, which is affected by two types of random shocks. One is a standard diffusive component, and the other is jump component which captures rare events that happen infrequently and suddenly by nature. In the "rare disaster" framework, the results are sensitive to the coefficient of rare risk aversion component, and also depend on the disaster probability. I calibrate the model in 
which the equity risk premium associated with varying disaster probability and risk aversions can be understood quantitatively.

Overall, the contribution of this paper is threefold. First, I utilize the (stochastic differential) power utility function to derive equilibrium solutions for the equity risk premium, that incorporates disaster probability and decomposed risk aversion components. I utilize a framework in which exogenous state variables follow jump diffusion processes, and equity risk premium is determined by representative agent's risk preference and model parameters. Second, I present a dynamic model for rare jumps which captures time-varying disaster probability/size and risk aversion components. Under the stochastic differential utility function, the jump component of the equity risk premium can be directly related to risk aversion and foreseeable disaster probability. An addition to existing models, I extend the general jump-diffusion model by decomposing risk aversion towards frequent and rare events separately, and solve trackable risk aversion parameters. Consistent with previous literature, this risk premium and risk aversion components can be expressed as the difference in exante expectation of jump tails. Third, I quantify the time-varying risk aversion to show the changes in risk aversion require different levels of risk premiums.

From the implications of theoretical model, it can be observed that both risk aversion components are positively related to equity risk premium. As the risk-adjusted return becomes higher, investors are likely to become more risk averse if they have potentially more to lose and require higher compensation for holding risky assets. Furthermore, the fear of disaster can be interpreted as a tractable way to model time-varying risk-aversion, and the rare risk aversion is an ex-ante measure of foreseeable disaster probability. In other words, the expected rare risk aversion can cause changes in equity risk premium and volatility.

The rest of the paper is organized as follows. Section 1.2 presents the literature review related 
to the jump-diffusion models and the disaster models, as well as the current literature on model predictability of tail risk premium. Section 1.3 develops a theoretical framework for understanding the decomposed components of investor risk aversion regarding to daily volatility and rare (tail) events. Section 1.4 describes the sample, defines variables used in calibration and simulation, and presents simple simulation results based on disaster probability and size. Section 1.5 presents some concluding remarks.

\subsection{Related Literature}

\subsubsection{Jump-diffusion models}

In one of the pioneer theoretical model in the intertemporal capital asset pricing model (ICAPM) setups, Cox, Ingersoll, and Ross (1985) use an intertemporal general equilibrium asset pricing model to study the term structure of interest rates. In this model, expectations, risk aversion, and preferences about consumption are incorporated in a way which is consistent with maximizing behavior and rational expectations. Other literature has decomposed the temporal variation in risk premium into two components: diffusive risk and jump risk. This decomposition allows investors to differ the likelihood of continuous diffusive movements and discrete jumps. Bates (1988) derives the characterization of asset market equilibrium when asset prices follow jump-diffusion processes, and develops the general methodology for pricing such assets. After imposing restrictions on distributions and preferences, this pricing model is tractable and valid even when jump risk is systematic and non-diversifiable. In more recent studies, Eraker and Shaliastovich (2008) examine equilibrium models in a framework that exogenous state variables follow jump diffusion processes. They find that large jumps (shocks) in consumption volatility translate into negative jumps in the assets' equilibrium prices due to a higher premium demanded by agents to compensate for higher 
risks. Bollerslev, Sizova and Tauchen (2012) show that stock market volatility clusters in time, carries a risk premium, and exhibits asymmetric leverage effects.

Other models related to jump-diffusion or volatility risk primium models have also been considered. In the setting of jump-diffusion state processes, Duffie, Pan, and Singleton (2000) provide an analytical treatment of a class of transforms and show the implications of stochastic volatility and jumps for option valuation. Their analytical results show that stochastic volatility and jump amplitude/timing have impact on option "smirks" of the joint distribution of jumps in both volatility and the underlying asset price. Bansal and Yaron (2004) construct consumption and dividend growth rates as containing a small long-run predictable component and fluctuating economic uncertainty. Wachter (2006) uses a jump process to model the large unexpected events for consumption, and shows that the equity risk premium depends on the time-varying jump risk. Bollerslev and Todorov (2014) estimate the time-varying risk-neutral jump tails in asset returns. Their empirical findings show that both of the tails exhibit highly statistically significant temporal variation, and this temporal variation in the shape and the magnitude of the jump tails can be related to the underlying asset return variation. Bekaert and Engstrom (2015) propose a simple extension to the model of Campbell and Cochrane by assuming a stochastic process for consumption growth that has a time-varying and non-Gaussian distribution. Consumption growth receives two types of shocks each period, both drawn from potentially fat-tailed, skewed distributions. While one shock has positive skewness, the other shock has negative skewness.

\subsubsection{Disaster/Insurance Models with Rare Events}

The strand of the literature that studies disaster has rekindled the idea in Rietz (1988) that 
fear of a large catastrophic event may induce a large equity premium. In insurance literature, the morality risk and catastrophes are considered discrete and only happen once or twice in a lifetime. Examples include death, airline disasters, hurricanes, and wars. Although insurance is used to cushion the impact of such rare events, it is impossible to perfectly insulate insurers from this type of claim. Cummins (1988) argues that many types of insurance subject the insurer to large jumps in liabilities (catastrophes). The guaranty fund insurance develops a pricing model that uses jumps to capture such catastrophes.

Dahl (2004) models the mortality intensity as a stochastic process. The advantage of introducing a stochastic mortality intensity is that it gives more realistic premiums and reserves, and it also quantifies the risk of the insurance companies associated with the underlying mortality intensity. Deng, Brockett, and MacMinn (2012) argue that catastrophic mortality and longevity jumps occur in historical data and have an important impact on security pricing, and introduce a stochastic diffusion model with a double-exponential jump diffusion process that captures both asymmetric rate jumps up and down and also cohort effect in mortality trends.

Cairns, Blake, and Dowd (2006a, 2006b) confirm that stochastic mortality is an important risk factor in both life insurance and pensions and affects how fair values, premium rates, and risk reserves are calculated, and they use a forward survival probability to capture the mortality risk and calculate the market risk-adjusted price of a longevity bond. Cox, Lin, and Pedersen (2010) propose a stochastic mortality model featuring both permanent longevity jump and temporary mortality jump processes, and captures the uneven effect of mortality events on different ages and the correlations among them.

Gabaix (2007, 2008) incorporates a time-varying intensity of disasters in the Rietz-Barro hypothesis that risk premia result from the possibility of rare, large disasters, and in turn generates 
time-varying risk premia and volatile asset prices and return predictability. Liu, Pan, and Wang (2005) study the asset pricing implication of imprecise knowledge about rare events by incorporating options in their analysis, and they find deep-out-of-the-money put options are extremely sensitive to market crashes. Options with varying degrees of moneyness therefore provide information for examining the importance of uncertainty aversion to rare events. Santa-Clara and Yan (2010) proposes a more flexible path-dependent jump intensity model to differentiate it from the volatility and show that jump risk is more important than diffusive risk. Barro and Jin (2011) and Barro and Ursua (2011) also argue that the premium depends on the probability and size distribution of disasters, gauged by proportionate declines in per capita consumption or gross domestic product, and they conclude a higher a signifies a thinner tail and, therefore, a lower equity premium, whereas a higher coefficient of relative risk aversion implies a higher premium. Wachter (2013) shows that there is time variation in risk premiums by assuming the probability of the crash to vary through time. This economic uncertainty can be contributed to temporal variations in our economy.

\subsubsection{Model Predictability}

One important aspect to study risk aversion and time varying risk premium is to test the predictability of disaster probability. Financial markets dislike economic uncertainty and better long-run growth perceptions raise equity prices. Bakshi and Kapadia (2003a) investigate whether the volatility risk premium is negative by examining the statistical properties of delta-hedged option portfolios. Their empirical results show that the underperformance is greater at times of higher volatility, and the volatility risk premium significantly affects delta-hedged portfolio gains, even after accounting for jump fears. Yan (2011) shows expected stock return is a function of the average jump size in the presence of jump risk, and the function can be proxied by the slope of option implied volatility smile 
which indicates a negative predictive relation between the slope of implied volatility smile and stock return.

Bollerslev, Sizova and Tauchen (2012) develop a consistent equilibrium-based model to explain the stock market volatility clusters in time and asymmetric leverage effects. Using highfrequency intraday data for the S\&P 500 and the VIX index, they show that the implications from the theoretical continuous-time model match well with the distinct shapes and patterns in the sample autocorrelations and dynamic cross-correlations actually observed in the data. In the most recent study, Bollerslev, Todorov, and $\mathrm{Xu}$ (2015) define the variance risk premium as the difference between the actual and risk-neutral expectations of the forward aggregate market variation. The authors show that variance risk premium helps predict future market returns, and much of this predictability may be attributed to the special compensation demanded by investors for bearing jump tail risk. Their findings demonstrate that market fears play an important role in understanding the return predictability. Intuitively, the compensation demanded by investors for bearing tail risk (jump fear) contributes to the expectation as well as the predictability of future market returns.

\subsection{Asset Pricing Dynamics}

\subsubsection{Endowment Economy Setup}

I assume an endowment economy with one representative agent. Similar to Duffie and Epstein (1992), the agent's utility function for a consumption process $C$ have the following recursion

$$
U=V_{0}
$$

and

$$
V_{t}=E_{t}\left[\int_{t}^{\infty} f\left(C_{s}, V_{s}\right) d s\right]
$$


where $U_{t}$ represents continuous utility of future consumption stream $C_{s}$, and $E_{t}$ denotes the expectation given information available at time t. The advantage of using a stochastic differential utility (SDU) is that Equation (1.1) exhibit intertemporal consistency, captures Bellman's characterization of optimality, and reserves much of the tractability. As Duffie and Epstein (1992) points out, another advantage of using SDU is that the jump-diffusion case of the utility defined above is a continuous-time analogue of the well-known recursive Epstein-Zin discrete-time utility. The recursive utility under SDU results in a more complex risk-free rate. The original recursive utility is designed to separate intertemporal substitution from risk aversion. If we focus on how the diffusive risk is priced relative to the rare events, then the special case of power utility is sufficient to capture the risk aversion component of the recursive utility.

To understand the role played by the recursive utility assumption, I consider a model with timevarying disaster risk and time-additive power utility

$$
f(C, V)=\frac{\delta C^{1-\gamma}}{1-\gamma}-\delta V
$$

where $\delta$ is the rate of time preference, and $\gamma$ is the relative risk aversion. I assume that $\delta>0$ and $\gamma>0$

For the purpose of modeling rare events, I assume the endowment or the aggregate consumption follows the stochastic process $\left\{C_{t}, 0 \leq t \leq T\right\}$. Specifically, let $C_{t}$ denote the aggregate consumption defined on the filtered probability space $(\Omega, F, P)$, where $\left(F_{t}\right)_{t \geq 0}$ refers to the information filtration. $C_{t}$ is the Markov process in $\mathbb{R}$ solving the stochastic differential equation (SDE) with jumps, and it can be expressed as follows,

$$
\frac{d C_{t}}{C_{t-}}=\left(\alpha-\frac{1}{2} \sigma^{2}-\lambda \mu_{t}\right) d t+\sigma d B_{t}+\left(e^{Z}-1\right) \mu[d x, d t]
$$


where $\alpha$ is the instantaneous changes, and $\sigma$ is the diffusive processes, respectively, $B_{t}$ is the standard Brownian motion and $\mu[d x, d t]$ is the Poisson random measure for the compound Poisson process with time-varying jump intensity $\lambda_{t}$, and $\mu[d x, d t]$ is the disaster probability measure according to with $x$ is distributed.

For simplicity and trackability, we denote $\mu \equiv \alpha-\frac{1}{2} \sigma^{2}-\lambda \mu_{t}$ and $d N_{t} \equiv \mu[d x, d t]$, and equation (1.3) can be rewritten as

$$
\frac{d C_{t}}{C_{t-}}=\mu d t+\sigma d B_{t}+\left(e^{Z}-1\right) d N_{t}
$$

where $\mu$ and $\sigma$ are the drift and diffusive processes, respectively. Given jump arrival at time t, the jump amplitude is controlled by a random variable $Z_{t}$. The jump intensity follows the process

$$
d \lambda_{t}=\varkappa\left(\mu_{\lambda}-\lambda_{t}\right) d t+\sigma_{\lambda} \sqrt{\lambda_{t}} d B_{\lambda, t}
$$

where $B_{\lambda, t}$ and $B_{p, t}$ are also standard Brownian motions, and $B_{t}, B_{\lambda, t}, B_{p, t}$ and $N_{t}$ are assumed to be independent. Equation $(1.3)^{\prime}$ and (1.4) show that $C_{t}$ is a mixed jump-diffusion process. The diffusion term $\mu d t+\sigma d B_{t}$ represents the representative agent's consumption behavior during normal times, and $\left(e^{Z}-1\right) d N_{t}$ captures the disasters, which allows for extreme instantaneous changes in $C_{t}$. In other words, $\lambda_{t}$ can be considered as a disaster intensity measure, and $\mu[d x, d t]$ the disaster probability over a time interval. The instantaneous change in log consumption is captured by $Z_{t}$, which is assumed to be normally distribute with mean $\mu_{J}$ and standard deviation $\sigma_{J}$.

\footnotetext{
* All processes are assumed to be right continuous with left limits. More precisely, the compensator for this compound Poisson process equal to $\frac{\lambda_{t} e^{-\frac{1}{2}(x-\alpha)^{2}}}{\sqrt{2 \pi \sigma_{J}^{2}}}$.
} 


\subsubsection{Jump-Diffusion Model in Value Function}

Following the standard setting, shares of the aggregate endowment are traded as stock in a market. Let $S_{t}$ denote the ex-dividend price of the stock, and assume the price-dividend ratio for the consumption claim is constant. Let $r_{f, t}$ denote the (instantaneous) risk-free rate. At any time $t$, the agent invests a fraction of $\theta_{t}$ of his wealth in the risky asset $S_{t}$, and $\left(1-\theta_{t}\right)$ in the risk-free asset, and consumes $C_{t}$. The agent starts with a positive initial wealth $W_{0}$, and trades competitively in the market. Let $W$ denote the wealth of the representative agent and $J(\lambda, W)$ the value function. Following Merton's (1976), we assume the stock price has the form $S_{t}=A(t) C_{t}$, where $C_{t}$ can be considered as the dividend payout rate and $A(t)$ is a deterministic function of $\mathrm{t}$ with $A(T)=0$, and the return of an investment opportunity available to the agent follows a jump-diffusion with random jumps. The stochastic differential equation for the underlying asset price with jumps can be expressed as follows,

$$
\frac{d S_{t}}{S_{t-}}=\left(\mu+\frac{A^{\prime}(t)}{A(t)}\right) d t+\sigma d B_{t}+\left(e^{\gamma_{J, t} Z_{t}}-1\right) d N_{t}
$$

Equation (1.5) gives the stochastic process of the asset price subject to jumps at random times. Intuitively, it can be explained as the arrival of random jumps from the stochastic differential equation for $S_{t}$. The last component of equation (1.5) represents the co-jumps of consumption stream $C_{t}$ with the market price $S_{t}$, which is expressed as the ratio of $\gamma_{J, t}$. Most existing studies assume that $\gamma_{J, t}=\gamma$, which means the jump size in the representative agent's total wealth return is the same as the jump size in the aggregate equity market return. Contrast to these studies, I assume that $\gamma_{J, t}$ is time-varying and different from $\gamma$, and the total wealth return and the aggregate equity market return can have jumps in different sizes. Then dynamics of wealth follows the process 


$$
\frac{d W_{t}}{W_{t-}}=\left[\theta_{t}\left(\mu-r_{f}+\frac{1+A^{\prime}(t)}{A(t)}\right)+r_{f}-\frac{C_{t-}}{W_{t-}}\right] d t+\theta_{t} \sigma d B_{t}+\theta_{t}\left(e^{\gamma_{J, t} Z_{t}}-1\right) d N_{t}
$$

In equilibrium, the representative agent's problem is to make optimal consumption and portfolio choice plans $\{c, \theta\}$ to optimize his utility, and the value function must satisfy the equation

$$
J(\lambda, W)=\sup _{\theta_{t}, C_{t}}\left\{U_{t}\right\}
$$

The above equation is equivalent to risk-sensitive portfolio optimization

$$
J(\lambda, W)=\inf _{\theta_{t}, C_{t}} \log \left\{U_{t}\right\}
$$

To solve the value function $J(\lambda, W)$, consider the Hamilton-Jacobi-Bellman equation for an investor who satisfies the above assumptions. The representative agent's value function, defined by Equation (1.7), has the terminal condition $J(\lambda, W)=0$, and the optimal consumption and portfolio choice must satisfy the following condition

$$
\begin{aligned}
\sup _{\theta_{t}, C_{t}}\left\{J _ { W } \left(W_{t} \theta_{t}(\right.\right. & \left.\left.\mu-r_{f}+C_{t} / S_{t}\right)+W_{t} r_{f}-C_{t}\right)+J_{\lambda} \mathcal{H}\left(\mu_{\lambda}-\lambda_{t}\right)+\frac{1}{2} J_{W W} W_{t}^{2} \theta_{t}^{2} \sigma^{2} \\
+ & \frac{1}{2} J_{\lambda \lambda} \sigma_{\lambda}^{2} \lambda_{t}+\inf _{\theta_{t}, C_{t}}\left\{\lambda_{t} E_{v}\left[J\left(\lambda_{t}, W_{t}\left(1+\theta_{t}\left(e^{\gamma_{J, t} z_{t}}-1\right)\right)\right)-J\left(\lambda_{t}, W_{t}\right)\right]\right\} \\
+ & \left.f\left(C_{t}, J\right)\right\}=0
\end{aligned}
$$

where $J_{W}, J_{\lambda}$ denote the first derivative of $J$ with respect to $W$ or $\lambda$, repectively, and $J_{W W}, J_{\lambda \lambda}$ are the second derivative of $J$ with respect to $W$ or $\lambda$. The instantaneous return from wealth invested in the risky asset is determined both by the dividend yield and the change in price. Moreover, the instantaneous expected change in the value function is determined by the continuous drift and jumps. One important implication of the HJB equation is that the risk associated with the jump component is evaluated at all possible alternative models under the $E_{v}(\cdot)$ distribution, and it reflects the agent's 
risk aversion against model uncertainty with respect to the jump component. Proposition 1 provides the solution to the HJB equation.

Proposition 1. Analysis of the HJB equation gives the following solution,

$$
J(W, \lambda)=f(\lambda) \frac{W^{1-\lambda}}{1-\gamma}
$$

where $f(\lambda)=e^{a+b \lambda}$ is a time-dependent coefficient, and $a, b$ satisfy

$$
\begin{gathered}
a=-\ln \left(\frac{(1-\gamma) A(t)^{1-\lambda}}{\delta}\left(\mu-\frac{1}{2} \gamma \sigma^{2}\right)+\frac{A(t)^{1-\lambda}}{\delta} b \varkappa \mu_{\lambda}-A(t)^{1-\lambda}\right)-b \lambda \\
b=\frac{\varkappa \pm \sqrt{\varkappa^{2}+\sigma_{\lambda}^{2} \lambda_{t} E_{v}\left[e^{\left(1-\gamma_{J} t\right) Z}-1\right]}}{\sigma_{\lambda}^{2}}
\end{gathered}
$$

It follows from Equation (1.12) that $\gamma>0, b>0$. Therefore, by (1.10), an increase in disaster probability reduces utility for the representative agent. The agent requires compensation for this risk, and thus time-varying disaster risk increases the equity premium.

Moreover, taking the derivative of Equation (1.9) with respect to portfolio choice $\theta_{t}$, evaluating at $\theta_{t}=1$ and setting to zero implies

$$
\mu_{\pi, t}=-\delta-\gamma \mu+\frac{1}{2} \gamma(\gamma+1) \sigma^{2}
$$

Furthermore, following the argument from Wachter (2013), the absence of arbitrage implies

$$
\mu_{\pi, t}=-r_{f}-\lambda_{t} E_{v}\left[\left(e^{-\gamma_{J, t} Z}-1\right)\right]
$$

Combing and rearranging Equation (1.13) and (1.14), and the risk-free rate under power utility is given by 


$$
r_{f}=\delta+\gamma \mu-\frac{1}{2} \gamma(\gamma+1) \sigma^{2}-\lambda_{t} E_{v}\left[\left(e^{-\gamma_{J, t} Z}-1\right)\right]
$$

The risk-free rate has two components. $\delta+\gamma \mu-\frac{1}{2} \gamma(\gamma+1) \sigma^{2}$ is the same as in the standard model without disaster risk, where $\delta$ represents the discounting rate, $\mu$ is the intertemporal smoothing, and $\gamma$ is the risk aversion associated with precautionary savings. $\lambda_{t} E_{v}\left[e^{-\gamma_{J}, t}-1\right]$ represents the disaster risk from both quadratic and tail variations. Intuitively, an increase in the probability of a rare disaster increases the agent's desire to save, and thus lowers the risk-free rate.

\subsubsection{Pricing Kernel}

Following Duffie and Epstein (1992) and Duffie and Skiadas (1994), the pricing kernel of a representative agent economy with stochastic differential utility takes the following form

$$
\pi_{t}=\exp \left\{\int_{0}^{t} f_{V}\left(C_{s}, V_{s}\right) d s\right\} f_{C}\left(C_{t}, V_{t}\right)
$$

where $f_{C}$ and $f_{V}$ are the first-order derivatives of $f$ with respect to the consumption and value function respectively. Setting the optimal consumption to the endowment $Y$, the equilibrium pricing kernel follows

$$
\left.\pi_{t}=\exp \left\{\int_{0}^{t} \delta \frac{1-\gamma}{1-\phi}\left[\left(1-\frac{1-\phi}{1-\gamma}\right) \frac{C_{s}^{1-\phi}}{(1-\gamma) V_{s}^{\frac{1-\phi}{1-\gamma}}}-1\right] d s\right)\right\} \delta C_{t}^{-\phi}\left((1-\gamma) V_{t}\right)^{\frac{\phi-\gamma}{1-\gamma}}
$$

In the case of power utility, we have $\phi=\gamma$, and the above equation becomes

$$
\pi_{t}=e^{-\delta t} C_{t}^{-\gamma}
$$


Investors require equity premium when there is comovement of the agent's marginal utility and the price process for stocks. We define there are two sources comovement: comovement during normal times, and comovement during time of disaster. Ito's Lemma implies that $\pi_{t}$ satisfies

$$
\frac{d \pi_{t}}{\pi_{t-}}=\mu_{\pi, t} d t+\gamma \sigma_{\pi, t} d B_{t}+\left(e^{-\gamma_{J, t} Z}-1\right) d N_{t}
$$

where $\sigma_{\pi, t}, \mu_{\pi, t}, \lambda_{t}$ are the diffusion and jump parameters affecting the endowment process, $B_{t}$ is the standard Brownian motion and $N_{t}$ is a Poisson process with time-varying intensity $\lambda_{t}$. And $B_{t}, B_{\lambda, t}$ and $N_{t}$ are assumed to be independent. $Z_{t}$ is a random variable that has time-invariant distribution v. Moreover,

$$
\mu_{\pi, t}=-\delta-\gamma \mu+\frac{1}{2} \gamma(\gamma+1) \sigma^{2}
$$

Assumptions (1.19) and (1.20) imply that the diffusion term $\mu_{\pi, t} d t+\gamma \sigma_{\pi, t} d B_{t}$ represents price movements during normal times. Furthermore, $\left(e^{-\gamma_{J, t} Z}-1\right) d N_{t}$ captures disasters that allows for large instantaneous changes in prices. In this model, a disaster is defined as a large shock to asset prices, and these shocks can come through a financial crisis, a natural disaster, and a surprise change in fiscal/monetary policy.

\subsubsection{Equity Risk Premium and Separation of Risk Aversions}

Define $\pi_{t}=\exp \left\{\int_{0}^{t} f_{V}\left(C_{s}, V_{s}\right) d s\right\} f_{C}\left(C_{t}, V_{t}\right)$ as the state-price density (Duffie and Skiadas, 1994). Let $F_{t}=F\left(D_{t}, \lambda_{t}\right)$ be the stock price of the claim to future dividends. Following Wachter (2013) argument, absence of arbitrage implies that $F_{t}$ is the integral of future dividend flows discounted using the state-price density (pricing kernel). It can be expressed as

$$
F\left(D_{t}, \lambda_{t}\right)=E_{t}\left[\int_{t}^{\infty} \frac{\pi_{s}}{\pi_{t}} D_{s} d_{s}\right]
$$


The equity premium arises from the co-movement of the agent's marginal utility with the price process for stocks. There are two sources of the co-movement: Co-movement during normal times (diffusion risk), and co-movement in times of disaster (jump risk). Applying Ito's Lemma to $F\left(D_{t}, \lambda_{t}\right)$ implies

$$
\frac{d F_{t}}{F_{t-}}=\mu_{F, t} d t+\sigma_{F, t} d\left[d B_{t} d B_{\lambda, t}\right]^{T}+\left(e^{\phi Z}-1\right) d N_{t}
$$

for processes $\mu_{F, t}$ and $\sigma_{F, t}$. Ito's Lemma also implies

$$
\frac{d \pi_{t}}{\pi_{t-}}=\mu_{\pi, t} d t+\sigma_{\pi, t} d\left[d B_{t} d B_{\lambda, t}\right]^{T}+\left(e^{-\gamma_{J, t} Z}-1\right) d N_{t}
$$

Follows from Equation (1.22) that the risk-free rate under power utility is given by

$$
r_{f}=\delta+\gamma \mu-\frac{1}{2} \gamma(\gamma+1) \sigma^{2}-\lambda_{t} E_{v}\left[\left(e^{-\gamma_{J, t} Z}-1\right)\right]
$$

Proposition 2. Assuming that stock price is the claim to future dividends, then the equity premium for power utility can be computed as

$$
\begin{aligned}
r_{t}-r_{f}=\phi \gamma \sigma^{2} & +\lambda_{t} E_{v}\left[2\left(\phi-\gamma_{J, t}\right) Z+(\phi Z)^{2}-\phi \gamma_{J, t} Z^{2}+\left(\gamma_{J, t} Z\right)^{2}\right] \\
& +\lambda_{t} E_{v}\left\{\sum_{n=3}^{\infty} \frac{1}{n !} Z^{n}\left[\phi^{n}+\left(\phi-\gamma_{T, t}\right)^{n}-\left(-\gamma_{T, t}\right)^{n}\right]\right\}
\end{aligned}
$$

where $\phi$ is a parameter, and as $\phi>0$ indicates that dividends decrease more than consumption in the event of a disaster. To distinct the difference of separated risk aversion components, we definie $\gamma, \gamma_{J, t}$, and $\gamma_{T, t}$ are the risk aversion related to standard model, quadratic and tail variations, respectively. $\phi \lambda \sigma^{2}$ is the equity premium in the standard model with normally distributed consumption growth, and the second and third term on the right hand side are the impact factors that arises from the risk of a disaster.

The equity premium puzzle is arguably one of the most studied topics in academia. The idea that rare disasters, or tail events, may help explain the equity premium puzzle can be traced back to 
the original work by Rietz (1988). Compared to the standard consumption-based asset pricing models, the decomposed risk aversion model in this paper can plausibly help explain the equity premium puzzle. Generally, utility functions do not incorporate volatility risk and in turn imply that variance risk premium equals to 0 (Bollerslev and Todorov, 2011). The model in this paper incorporates jump-diffusion and disaster models, and can provide the risk aversion component associated with quadratic variation and tail variation separately. More specifically, $\lambda_{t} E_{v}[2(\phi-$ $\left.\left.\gamma_{J, t}\right) Z+(\phi Z)^{2}-\phi \gamma_{J, t} Z^{2}+\left(\gamma_{J, t} Z\right)^{2}\right]$ is the impact factor of the disaster risk from quadratic variation (or the variation generated from the first two moments). Moreover, $\lambda_{t} E_{v}\left\{\sum_{n=3}^{\infty} \frac{Z^{n}}{n !}\left[\left(-\gamma_{T, t}\right)^{n}-\phi^{n}-\left(\phi-\gamma_{T, t}\right)^{n}\right\}\right.$ is the impact factor of the disaster risk from tail variation (or the variation generated from higher moments), and it represents the risk premium required by risk averse investors facing rare events. The tail risk premium, as seen in seen in Chow, et. al. (2016) paper, is close to zero when there is no events cause jumps in financial market, however, it spikes in large magnitude when rare events happen. Government bond, on the other hand, is considered risk free, and risk averse investors do not require an increase in yield to hold them when tail events happen. Consequently, the stock returns need to be higher than the returns on government bonds for investors to hold these risky assets. Thus, the large increase in required tail risk premium in the present of rare events can plausibly explain the equity premium puzzle.

\subsection{Calibration and Simulation}

In this section, I implement the maximum likelihood method from Chen, Dou, and Kogan (2015) to simulate the asset pricing models with rare disasters. The likelihood of rare events is difficult to evaluate statistically, however, investors' risk aversion to large disasters can have economically large 
impact on asset prices. Following Barro (2006), I assume the log growth rate of consumption and the log return of S\&P 500 jointly follow the process

$$
\left(\begin{array}{l}
g_{t} \\
r_{t}
\end{array}\right)=\left(1-b_{t}\right) u_{t}-b_{t}\left(\begin{array}{c}
v_{t} \\
\beta v_{t}+\varepsilon_{t}
\end{array}\right)
$$

where $b_{t}$ takes the value of 1 or 0 with associated disaster probability $p$ or $1-p$, respectively, and $b_{t}$ has an IID Bernoulli distribution. $v_{t}$ is the $\log$ of consumption decline. ${ }^{\dagger}$ Moreover, $\varepsilon_{t}$ is an independent shock to $r_{t}$ with $\varepsilon_{t} \sim N\left(0, \sigma^{2}\right)$ so that $r_{t}$ and $g_{t}$ are not perfectly correlated in a disaster state. In the non-disaster state, $g_{t}$ and $r_{t}$ are jointly normal with mean $\left(\mu_{t}, \alpha_{t}\right)$, and the covariance of $g_{t}$ and $r_{t}$ is

$$
\operatorname{cov}\left(g_{t}, r_{t}\right)=\left(\begin{array}{cc}
\sigma_{1}^{2} & \rho \sigma_{1} \sigma_{2} \\
\rho \sigma_{1} \sigma_{2} & \sigma_{2}^{2}
\end{array}\right)
$$

where $\sigma_{1}$ and $\sigma_{2}$ are volatility of consumption growth and stock return, respectively. $\rho$ is the correlation of $g_{t}$ and $r_{t}$.

In the quantitative analysis, I use annual real per-capita consumption growth (only includes nondurables and services) from the U.S. and the CRSP value-weighted S\&P 500 returns for the period of 1929 to 2015 .

\section{[Insert Figure 1.1 about here]}

In Figure 1.1, the annual historical data of consumption growth and market returns are plotted. From the graph, they tend to move in the same direction, and the correlation between them is 0.63 . The parameters $\mu, \sigma_{1}, \sigma_{2}, v$, and $\rho$ are fixed based on historical data. Following Chen, et al. (2015), the lower bound for disaster size is set at 7\%, and the leverage parameter $\phi$ is 3 . The values of these parameters are presented in Table 1.1.

\footnotetext{
${ }^{+}$In Chen, Dou, and Kogan (2015), $v_{t}$ follows a truncated exponential distribution, $v_{t} \sim 1_{\{v \geq \underline{v}\}} \lambda e^{-\lambda(v-\underline{v})}$, with the lower bound for disaster size equal to $\underline{v}$.
} 


\section{[Insert Table 1.1 about here]}

In Figure 1.2, I plot the 90\%, 95\% and 99\% confidence regions for disaster size $(\lambda)$ and disaster probability $(p)$ based on the unconstrained likelihood function ${ }^{\ddagger}$. The equity premium isoquants for different levels of relative risk aversion $(\lambda=3,15,30)$ are plotted. From Equation (1.25), we know that the representative agent's risk aversion can be additive. Thus, we consider $\lambda=$ 3 as the case for static relative risk aversion, $\lambda=15$ as the case for static risk aversion plus volatility risk aversion, and $\lambda=30$ as the case for the agent's risk aversion in the events of disaster. They are the lines with the combinations of $\lambda$ and $p$ required to match the average equity premium $6.31 \%$ for a given value of $\gamma$. The $95 \%$ confidence region for $(\lambda, p)$ is quite wide. All three lines cross the $95 \%$ confidence region shows that given different levels of risk aversions, there exist many combinations of $\lambda$ and $p$ that match both the observed equity premium and are considered consistent with historical macroeconomic data. Based on the points in Figure 1.2, there are six points of $(\lambda, p)$ that are located at the intersections of the equity premium isoquants and the boundary of $95 \%$ confidence region. For $\gamma=3$, the two points are $(p=0.27 \% ; \lambda=3.147)$ and $(p=4.22 \% ; \lambda=7.55)$. For $\gamma=15$, the two points are $(p=0.11 \% ; \lambda=16)$ and $(p=6.3 \% ; \lambda=53.49)$. For $\gamma=30$, the two points are $(p=0.08 \% ; \lambda=35)$ and $(p=1.56 \% ; \lambda=448)$.

[Insert Figure 1.2 about here]

For $\gamma=3$, the foreseeable disaster probability is increases with disaster size. When different levels of risk aversion are compared, as the representative agent gets more risk averse, the perceived disaster size can be large even when the associated foreseeable disaster probability is small. It is consistent with the model implication.

\footnotetext{
${ }^{\ddagger}$ For detailed specification, please see Equation (48) in Chen, Dou, Kogan (2015)
} 


\subsection{Conclusion}

This paper theoretically investigates the equilibrium risk premium in an economy with a representative agent whose risk aversion varies towards frequent events and rare events. I find that risk aversion toward rare events plays an important role in explaining the risk premium required by investors when there is a change in disaster probability and disaster size. To formally investigate this possibility of "rare-event premium," I adopt an equilibrium setting with one representative agent that places his/her consumption on the asset. The asset in this economy is a claim to the aggregate endowment, which is affected by frequent volatility and rare disasters. In the "rare disasters" framework, the results are sensitive to the coefficient of relative risk aversion, and also depend on the disaster probability. I also calibrate the model in which the equity risk premium associated with varying risk aversions can be understood quantitatively.

The dynamic model for rare jumps captures time-varying disaster probability/size and risk aversions. Under the stochastic differential utility function, the jump component of the equity risk premium involves a multi-factor structure that can be directly related to representative agent's risk aversions and foreseeable disaster probability. Comparing to previous models, I extend the general jump-diffusion model by decomposing investors' risk aversion towards frequent and rare events separately, and focus on solving trackable risk aversion parameters. Consistent with previous literature, this risk premium and risk aversions can be expressed as the difference in ex-ante expectation of jump tails. I quantify the time-varying risk aversions to show the changes in risk aversion require different levels of risk premiums. Furthermore, the fear of disaster can be interpreted as a tractable way to model time-varying risk-aversions, and the rare risk aversion is an ex-ante measure of foreseeable disaster probability. In other words, the expected rare risk aversion can cause changes in equity risk premium and volatility. 
Table 1.1. Parameters for the disaster model simulation

Average growth in consumption $\mu$

0.0188

Volatility of consumption growth $\sigma_{1}$

0.0192

Average market return $r_{t}$

0.0631

Volatility of market return $\sigma_{2}$

0.1884

Correlation $\rho$

0.56

Leverage $\phi$ 
Figure 1.1. Correlation of S\&P 500 Return and Per-capita Consumption Growth

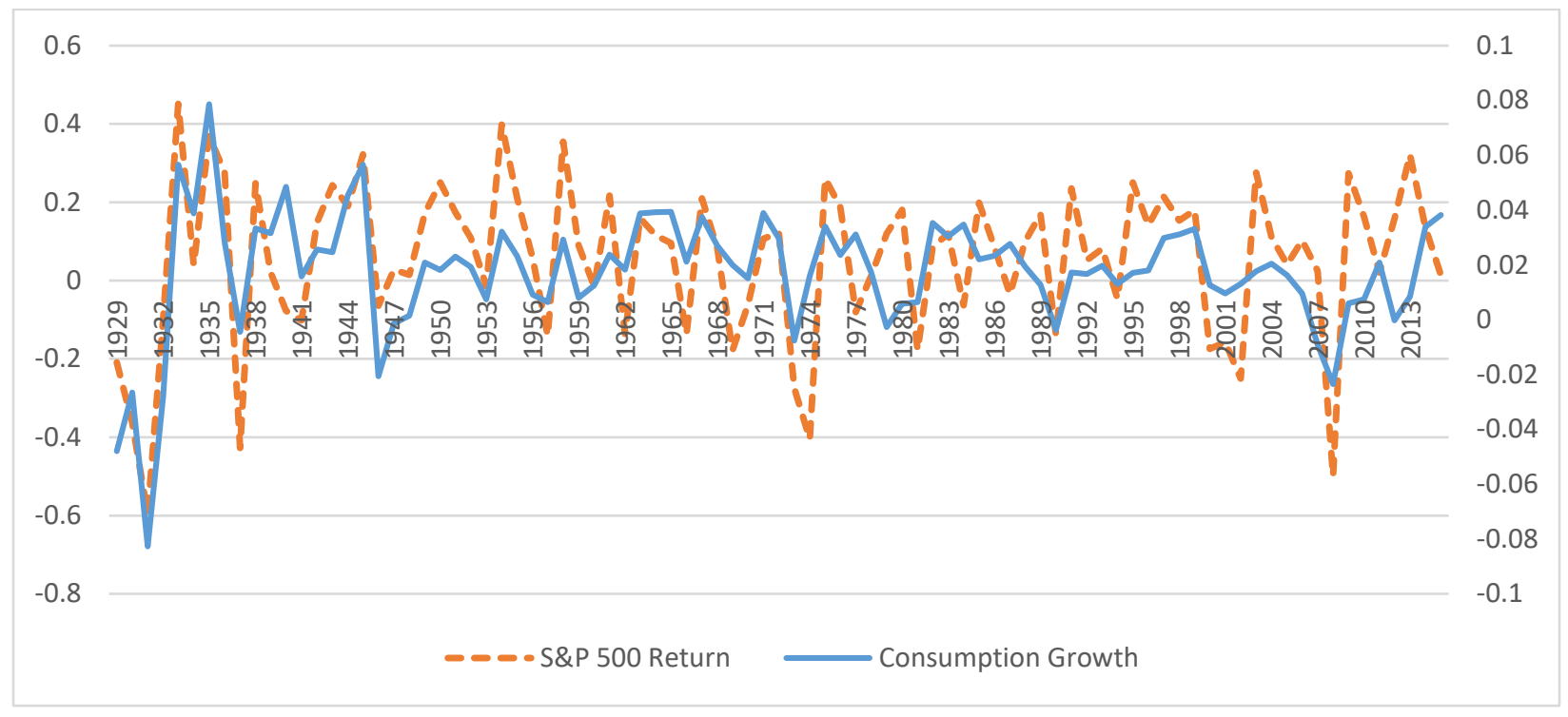

Figure 1.1. plots the annual historical data of consumption growth and market returns. Consumption growth is annual real per-capita consumption growth (only includes nondurables and services) from the U.S., and the CRSP value-weighted S\&P 500 returns for the period of 1929 to 2015. 
Figure. 1.2 Equity Premium Isoquants and Confidence Regions

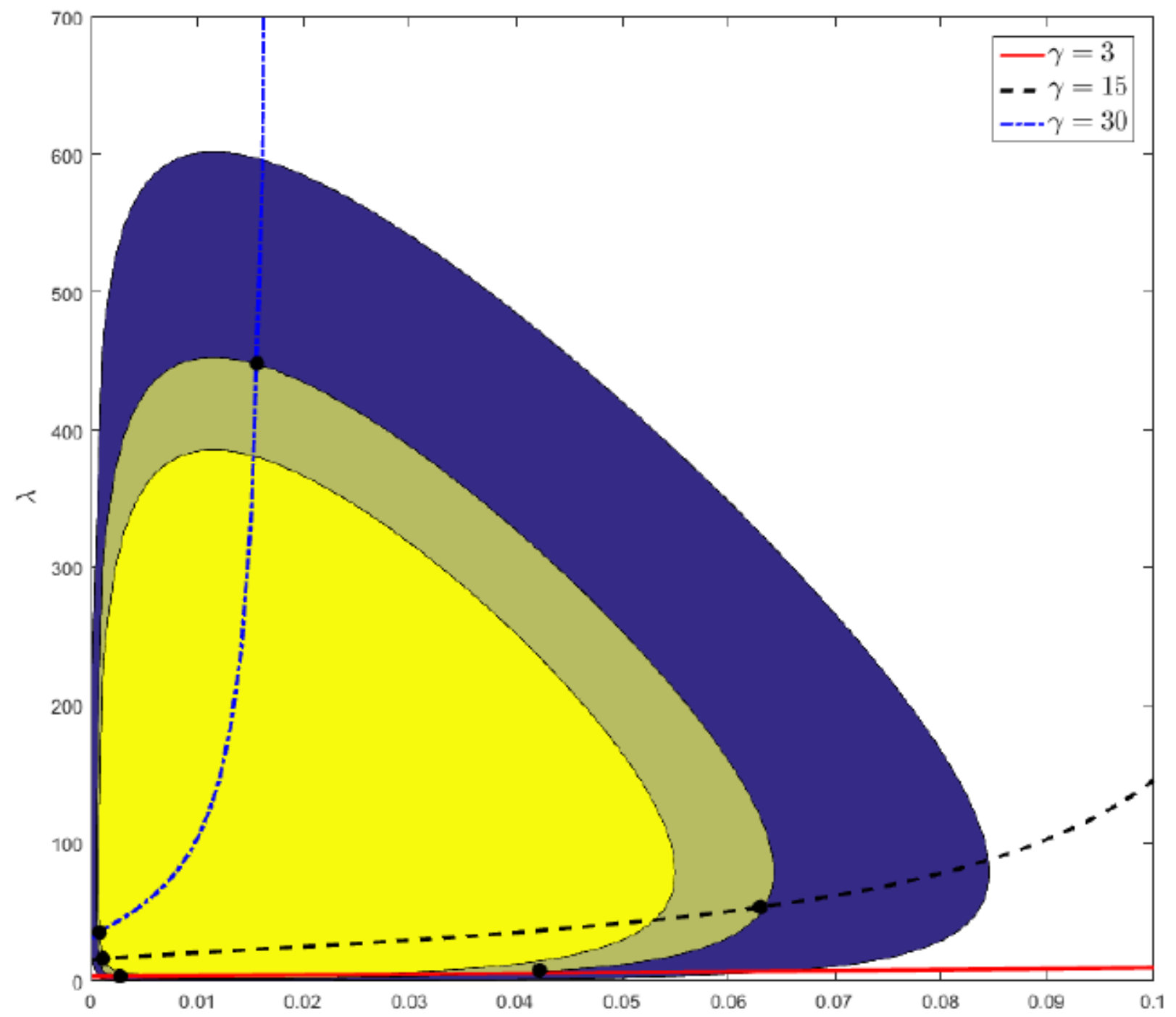

Figure 1.2 plots the $90 \%, 95 \%$ and $99 \%$ confidence regions for disaster size $(\lambda)$ and disaster probability $(p)$. The figure is based on the maximum likelihood method from Chen, Dou, and Kogan (2015) to simulate the asset pricing models with rare disasters. The equity premium isoquants for different levels of relative risk aversion $(\lambda=3,15,30)$ are plotted. The representative agent's risk aversion can be additive. Thus, we consider $\lambda=3$ as the case for static relative risk aversion, $\lambda=15$ as the case for static risk aversion plus volatility risk aversion, and $\lambda=30$ as the case for the agent's risk aversion in the events of disaster. They are the lines with the combinations of $\lambda$ and $p$ required to match the average equity premium $6.31 \%$ for a given value of $\gamma$. 


\section{CHAPTER 2: The Impact of Monetary Policy Surprises on Aggregate Tail Risk Aversion}

\subsection{Introduction}

The last financial crisis has rekindled the idea that monetary policy can induce financial instability. The Federal Reserve's role in setting loose monetary policy has been cited as one of the factors to the 2008 financial crisis. Besides the impact of monetary policy in causing financial markets instability, some literature has considered the role of monetary policy in investor's risk-taking decisions in financial markets (e.g. Rajan, 2006; Adrian and Shin, 2008; Borio and Zhu, 2008). Changes in monetary policy, especially surprise policy changes, is not only likely to influence stock prices through the fed funds rate, but also impact the degree of uncertainty and risk aversion faced by investors. A rise in the probability of such surprises influences the expected rate of return on equity, and motivates investors shift toward risk-free assets or buy deep out-of-the-money puts. We first show that an investor's risk aversion towards frequent volatility (quadratic variations) and rare events (tail variations) is different, and utilize a theoretical model to decompose the risk aversion components into volatility risk aversion and tail risk aversion. The model implicates that both risk aversion components can be determinants of equity risk premium. We then empirically investigate the channels of how monetary policy shocks affect market return and both components of investor risk aversion and how these factors are interlinked. 
The first goal of this paper is to provide a theoretical framework on the decomposition of investor risk aversion towards daily volatility and large tail jumps, and provide resolution on the determinant roles of varying risk aversion on equity risk premium. Volatilities exist in financial market constantly, and there are also rare events such as the 1987 Black Monday, the Great Recession, and the 2016 Brexit Referendum. A rational investor should react differently in the presence of rare events from daily volatilities. In this paper we first present a dynamic model that decomposes time-varying risk aversion into volatility risk aversion and tail risk aversion. Under the stochastic differential utility function, the jump component of the equity risk premium can be directly related to separated investor risk aversion components and foreseeable probability of rare events. Moreover, we quantify the time-varying risk aversion to show the changes in risk aversion require different levels of risk premiums.

In the empirical study the main goal is to provide a systematic investigation of the interdependence of stock market returns, decomposed investor risk aversion, and monetary surprises. We examine whether there is contemporaneous response among these factors. The VIX index is widely considered as a gauge for market fears. Bollerslev and Todorov (2011) points out that the VIX contains compensation for time-varying volatilities and jump intensities, and fears for rare events. They also show that a nontrivial portion of the index may be attributed to rare events. Two potential problems emerge before we can test the interdependence of stock market, risk aversion, and monetary policy. One is that the VIX index is the implied volatility from the Black-Scholes (1973) model, and it reflects total variations in both diffusion and jump components (Bates, 2000). As Ang, et. al. (2006) point out, a more serious problem is that VIX combines both stochastic volatility and stochastic volatility risk premium, and decomposing VIX into the true innovation in volatility and the volatility risk premium requires a formal model. To address this problem, we use 
the decomposed VIX index from Chow, Jiang, and Li (2016) that decompose volatilities and their associated risk premiums into quadratic variation (frequent volatilities) and tail variations (rare events) from the CBOE VIX index. The decomposed variance and tail risk premium developed in Chow, et. al. (2016) are used as proxies for the volatility risk aversion and tail risk aversion.

The third goal of the paper is to establish a solid empirical link among stock market return, volatility/tail risk aversion, and monetary surprises. Chen (2002) extends Campbell's model and shows that risk-averse investors want to directly hedge against changes in future market volatility. This effect emerges because risk-averse investors reduce current consumption to increase precautionary savings when there is increased uncertainty about expected market returns. Moreover, the expected market returns and volatility can be deeply related to changes in monetary policy. Bernanke and Kuttner (2005) show that the effect of monetary surprises on expected excess returns can be related to the impact of monetary policy on investor risk aversion or the riskiness of stocks. One important contribution of this paper is to establish how each factor drives the co-movements among stock market returns, risk aversion, and monetary shocks. By using the risk aversion proxies derived from VIX, we test the effect of monetary policy on stock market, and also provide more precise information on how the effect of risk aversion is channeled through.

More specifically, we investigate the empirical link among stock prices, time-varying risk aversion, and monetary policy within a VAR framework and event study analysis. Our sample period ranges from January 1994 to October 2014. We first use a VAR framework with a combination of short-run and long-run restrictions to study the empirical link among these factors. The VAR approach has been influential in the analysis of monetary policy effects in both traditional macroeconomic analysis and stock market reactions (eg, Sims, 1980, Patelis, 1997, Thorbecke, 1997, and Neri, 2004). The sample period is from January 1994 to December 2008. After December 2008, 
the fed funds rate has remained around zero. We find that there is contemporaneous response among stock market, time-varying risk aversion, and monetary policy surprises. The findings show that a positive shock to stock prices generally decreases both volatility and tail risk aversion and increases fed funds rate. A bullish stock market can reflect an improving economy, then the Federal Reserve is likely to consider increasing the fed fund rate to tame the inflation. A positive shock to monetary policy means that an unexpected increase in fed funds rate, which normally indicate an improving economy. It decreases both volatility risk aversion and tail risk aversion but decreases stock prices.

When the fed funds rate was set at its zero-lower bound at the end of 2008, the Federal Reserve employed unconventional tools to achieve its policy effects on the economy, and carried out some unprecedented procedures to influence longer-term interest rates. These unconventional tools were dramatically different from those used during conventional times. Due to the unconventional tools used in the recent periods, further analysis is needed to assess the impact of unconventional monetary policy shocks on risk aversion and stock market. We follow Lutz (2015) and Kurov and Gu (2016) and use an event study approach to assess the impact of unconventional monetary policy shocks on stock market and risk aversion. The advantage of the event study methodology allows us to measure changes in policy and account for the effects related to FOMC policy decisions. Event study methodologies have been used to study the interaction between the stock market and monetary policy. In similar event study analysis, Bernanke and Kuttner (2005) and Ehrmann and Fratzcher (2004) estimate the effect of an unanticipated rate cut to increase the returns of stock prices. We find that a surprise decline in the expected short-term rate leads to an increase in stock prices and tail risk aversion. The effect on tail risk aversion seems to contradict with the results from the VAR analysis. A possible explanation is that a surprise decline in short-term rate can lead investors to believe that a surprise drop in expected short-term rate actually reflects a fast deteriorating economic 
environment, and thus explains the increase in tail risk aversion.

The rest of the paper is organized as follows. Section 2.2 develops a theoretical framework for understanding the decomposed components of investor risk aversion regarding to daily volatility and rare (tail) events, and introduces the risk aversion proxies derived from VIX index. Section 2.3 describes the sample, defines monetary surprise and time-varying risk aversion variables, and explains how these variables are calculated. Section 2.4 describes the study's findings from the VAR analysis, and section 2.5 describes the results from event study analysis. Section 2.6 presents some concluding remarks.

\subsection{Decomposing the VIX Index \& Identification of VAR Model}

\subsubsection{Theoretical Motivation \& Risk Aversion Decomposition}

This section presents a model that tracts and decomposes the time-varying risk aversion towards frequent volatility and rare events, and proposes a solution on how investor time-varying risk aversion affects the equity risk premium. ${ }^{1}$

In equilibrium, the representative agent's problem is to make optimal consumption and portfolio choice plans $\{c, \theta\}$ to optimize his utility, and the value function must satisfy the equation

$$
J(\lambda, W)=\sup _{\theta_{t}, C_{t}}\left\{U_{t}\right\}
$$

where $\theta_{t}$ is the fraction of the investor's wealth that been invested in the risky asset at any time $t$, and $\left(1-\theta_{t}\right)$ in the risk-free asset, and consumes $C_{t}$. To solve the value function $J(\lambda, W)$, consider the Hamilton-Jacobi-Bellman (HJB) equation for an investor who satisfies the above assumptions, and taking the derivative of HJB equation with respect to portfolio choice $\theta_{t}$, evaluating at $\theta_{t}=1$

\footnotetext{
${ }^{1}$ For a more detailed derivation, please see Chapter 1 of the dissertation.
} 
and setting the HJB equation to zero. The representative agent's value function, defined by Equation (2.1), has the terminal condition $J(\lambda, W)=0$, and the optimal consumption and portfolio choice must satisfy the following condition

$$
\mu_{\pi, t}=-\delta-\gamma \mu+\frac{1}{2} \gamma(\gamma+1) \sigma^{2}
$$

where $\pi_{t}$ is the state-price density, $\mu_{\pi, t}$ and $\sigma$ are the drift and diffusive processes, respectively. $\gamma$ is the relative risk aversion, and $\delta$ is the rate of time preference. Furthermore, following the argument from Wachter (2013), the absence of arbitrage implies

$$
\mu_{\pi, t}=-r_{f}-\lambda_{t} E_{v}\left[\left(e^{-\gamma_{J, t} Z}-1\right)\right]
$$

Combing and rearranging Equation (2.2) and (2.3), and the risk-free rate under power utility is given by

$$
r_{f}=\delta+\gamma \mu-\frac{1}{2} \gamma(\gamma+1) \sigma^{2}-\lambda_{t} E_{v}\left[\left(e^{-\gamma_{J, t} z}-1\right)\right]
$$

The risk-free rate has two components. $\delta+\gamma \mu-\frac{1}{2} \gamma(\gamma+1) \sigma^{2}$ is the same as in the standard model without disaster risk, where $\delta$ represents the discounting rate, $\mu$ is the intertemporal smoothing, and $\gamma$ is the risk aversion associated with precautionary savings. $\lambda_{t} E_{v}\left[e^{-\gamma_{J}, t^{Z}}-1\right]$ represents the disaster risk from both quadratic and tail variations. Intuitively, an increase in the probability of a rare disaster increases the agent's desire to save, and thus lowers the risk-free rate.

The equity risk premium arises when there is co-movement between investor's marginal utility and the price process for stocks. The sources of this co-movement emerge during both normal volatility times and tail jump times. Following Wachter (2013), the co-movement can be expressed in the following form,

$$
\mu_{F, t}+\mu_{\pi, t}+\frac{D_{t}}{F_{t}}+\sigma_{\pi, t} \sigma_{F, t}^{T}+\lambda_{t} E_{v}\left[e^{(\phi-\gamma) Z}-1\right]=0
$$


where $F_{t}$ is the stock price of future dividend claims, $D_{t}$ is the dividend claim at time $\mathrm{t}, \phi$ is the leverage. To further decompose the disasters into quadratic variation and tail variation, we apply Taylor expansion to $e^{(\phi-\gamma) Z}-1$, and substituting $\mu_{\pi, t}=-r_{f}-\lambda_{t} E_{v}\left[\left(e^{-\gamma_{J} Z}-1\right)\right]$ into Equation (2.5) and rearrange gives

$$
\begin{aligned}
r_{t}-r_{f}=\phi \gamma \sigma^{2} & +\lambda_{t} E_{v}\left[2\left(\phi-\gamma_{J, t}\right) Z+(\phi Z)^{2}-\phi \gamma_{J, t} Z^{2}+\left(\gamma_{J, t} Z\right)^{2}\right] \\
& +\lambda_{t} E_{v}\left\{\sum_{n=3}^{\infty} \frac{1}{n !} Z^{n}\left[\phi^{n}+\left(\phi-\gamma_{T, t}\right)^{n}-\left(-\gamma_{T, t}\right)^{n}\right]\right\}
\end{aligned}
$$

where $\phi$ is a parameter, and as $\phi>0$ indicates that dividends decrease more than consumption in the event of a disaster. To distinct the difference of separated risk aversion components, we define $\gamma, \gamma_{J, t}$, and $\gamma_{T, t}$ are the risk aversion related to standard model, quadratic and tail variations, respectively. $\phi \lambda \sigma^{2}$ is the equity premium in the standard model with normally distributed consumption growth, and the second and third term on the right hand side are the impact factors that arises from the risk of a disaster. More specifically, $\lambda_{t} E_{v}\left[2\left(\phi-\gamma_{J, t}\right) Z+(\phi Z)^{2}-\phi \gamma_{J, t} Z^{2}+\right.$ $\left.\left(\gamma_{J, t} Z\right)^{2}\right]$ is the impact factor of the disaster risk from quadratic variation (or the variation generated from the first two moments), and $\lambda_{t} E_{v}\left\{\sum_{n=3}^{\infty} \frac{Z^{n}}{n !}\left[\left(-\gamma_{T, t}\right)^{n}-\phi^{n}-\left(\phi-\gamma_{T, t}\right)^{n}\right\}\right.$ is the impact factor of the disaster risk from tail variation (or the variation generated from higher moments). In this paper, we focus on the time-varying risk aversion components in the second and third terms on the righthand side of Equation (2.5). From the theoretical model, volatility and tail risk aversion are found to be factors in equity risk premium.

From the implications of theoretical model, it can be observed that volatility risk aversion is positively related to equity risk premium. As risk premium increases, investors are likely to become more risk averse since they have potentially more to lose. Furthermore, the fear of rare events can 
be interpreted as a tractable way to model time-varying tail risk-aversion, and both risk aversion components are an ex-ante measure of foreseeable probability of rare events.

\subsubsection{Define Volatility Risk Aversion and Tail Risk Aversion}

The VIX index has been previously decomposed into an uncertainty and a risk aversion component: one component that reflects actual expected stock market volatility (uncertainty) and a residual that reflects risk aversion (Bekaert, Hoerova, Duca, 2013). In this paper, we further decompose the VIX index into four components: uncertainty during rare events and daily volatility, risk aversion during rare events and daily volatility. Intuitively, a more risk averse investor requires higher risk premium to hold risky assets. Thus, we define the risk premiums (not uncertainty) of VIX as the proxies of time-varying risk aversion. In the formal model from Chow, Jiang, and Li (2016), volatilities and their associated risk premiums are decomposed into quadratic variation (frequent volatilities) and tail variations (rare events) from the CBOE VIX index. The decomposed VIX gives us two different risk aversion measures. One is volatility risk aversion that represents risk premium required by investors for quadratic variations. The other is tail risk aversion which represents risk premium required by investor for rare events (tail variations). We find that the interdependence exists among stock market, investor risk aversion, and monetary policy.

I follow the decomposition approach in Chow, Jiang, and Li (2016) to define volatility/tail uncertainty and volatility/tail risk aversion. ${ }^{2}$ The realized variance is defined as volatility uncertainty (VU hereafter), and the risk premium proxy with jumps from quadratic variations as volatility risk aversion (VRA hereafter).

\footnotetext{
${ }^{2}$ For a simplified derivation, please refer to Appendix B. For detailed decomposition derivation, please refer to Chow, Jiang, and Li (2016) working paper.
} 


$$
\begin{aligned}
V U_{t+1}=R V_{t+1} & =\mathbb{Q} \mathbb{V}_{[t, t+1]}=\int_{t}^{t+1} \sigma^{2} d t+\int_{t}^{t+1} x^{2} \mu(d x, d t) \\
& =\mathbb{C} \mathbb{V}_{[t, t+1]}+\mathbb{D} \mathbb{Q} \mathbb{V}_{[t, t+1]}
\end{aligned}
$$

where $R V$ is realized variance, $\mathbb{Q V}$ is quadratic variation, $\mathbb{C V}$ is continuously instant variance, and $\mathbb{D Q V}$ is jump quadratic variability.

$$
V R A_{t+1}=E_{t}^{\mathbb{Q}}\left(\mathbb{Q} \mathbb{V}_{[t, t+1]}\right)-E_{t}^{\mathbb{P}}\left(\mathbb{Q} \mathbb{V}_{[t, t+1]}\right)=V_{t}^{B K M}-E_{t}^{\mathbb{P}}\left(R V_{t+1}\right)
$$

where $\mathbb{Q}, \mathbb{P}$ are (options based) risk-neutral space and physical probability space, respectively, and $V_{t}^{B K M}$ is an unbiased ex-ante estimate of quadratic variation. VRA serves as a risk premium proxy for ordinary price fluctuation with volatility jumps, and can be considered as rational risk-averse investors' compensation for holding risky assets.

Moreover, the VIX can be further decomposed into tail uncertainty (TU hereafter) as a polynomial combination of all possible higher orders of logarithm returns and tail risk aversion (TRA hereafter) as the tail risk premium proxy with tail jumps from tail variations. ${ }^{3}$

$$
\begin{gathered}
T U_{t+1}=\mathbb{P V}_{[t, t+1]}-\mathbb{Q V}_{[t, t+1]}=R V I X_{t+1}^{2}-R V_{t+1}=\sum_{n=2}^{\infty} \frac{2}{n !} \int_{t}^{t+1} \int_{R^{0}} x^{n} \mu[d x, d t] \\
=\sum_{n=3}^{\infty} \frac{2}{n !} r_{t+1}^{n}
\end{gathered}
$$

where $\mathbb{P V}$ is polynomial variation, and RVIX is the realized VIX. It can be considered as a combination of third moment and above log-returns computed by the difference between the squared realized VIX and the realized variance.

$$
T R A_{t+1}=E_{t}^{\mathbb{Q}}\left(T U_{t+1}\right)-E_{t}^{\mathbb{P}}\left(T U_{t+1}\right)=\left(V I X_{t}^{2}-V_{t}^{B K M}\right)-E_{t}^{\mathbb{P}}\left(T U_{t+1}\right)
$$

where $E_{t}^{\mathbb{P}}\left(T U_{t+1}\right)=E_{t}^{\mathbb{P}}\left(\mathbb{P} V_{[t, t+1]}\right)-E_{t}^{\mathbb{P}}\left(R V_{t+1}\right)=\sum_{n=3}^{\infty} \frac{2}{n !} E_{t}^{\mathbb{P}}\left(r_{t+1}^{n}\right)$.

\footnotetext{
${ }^{3}$ For detailed proof, please refer to Corollary 1 in Chow, Jiang, and Li (2016).
} 
TRA serves as a compensation for expected tail jumps, and can be considered as rational risk-averse investor's required compensation (risk premium) for holding risky assets during rare events. The description of these variables are in Table 2.1.

[Insert table 2.1 about here]

\subsubsection{Identification of VAR}

We begin our analysis with a standard VAR on measures of stock market reactions, monetary policy shocks and time-varying risk aversion. Many empirical studies have used this VAR approach, since it involves the joint estimation of all variables in one system. In this paper, we follow a standard practice in VAR analysis to identify the different shocks through a series of contemporaneous restrictions on the effects of the shocks on all the variables (see Sims, 1980, 1992, and Christiano et al, 1999). Similar to Bjornland and Leitemo (2009), we assume $Z_{t}$ to be the $(4 \times 1)$ vector of variables: $Z_{t}=\left(\Delta T R A_{t}, \Delta V R A_{t}, i_{t}, \Delta S_{t}\right)^{\prime}$, where we assume that tail risk aversion $\left(T R A_{t}\right)$, volatility risk aversion $\left(V R A_{t}\right)$, and monthly interest rate are first differenced to obtain stationary, and the results from the augmented Dickie-Fuller test confirm that these variables are stationary. The reduced-form VAR can be written by its moving average

$$
Z_{t}=B(L) v_{t}
$$

where $B(L)=\sum_{j=0}^{\infty} B_{j} L^{j}$ is the matrix lag operator and $v_{t}$ is a vector of reduced-form residuals with the covariance matrix $\Omega$. Following the literature, we assume that the orthogonal disturbances $\left(\varepsilon_{t}\right)$ can be written as linear combinations of the innovations $\left(v_{t}\right)$,

$$
v_{t}=S \varepsilon_{t}
$$

With a four-variable VAR, we can identify four shocks. Ordering the vector of uncorrelated shocks as $\varepsilon_{t}=\left(\varepsilon_{t}^{T R A}, \varepsilon_{t}^{V R A}, \varepsilon_{t}^{S P}, \varepsilon_{t}^{M P}\right)$, and the recursive order among tail/volatility risk aversion, monetary and stock price shocks imply the following restriction on the $\mathrm{S}$ matrix 


$$
\left[\begin{array}{c}
\Delta T R A \\
\Delta V R A \\
\Delta S \\
\Delta i
\end{array}\right]=\left[\begin{array}{cccc}
S_{11} & 0 & 0 & 0 \\
S_{21} & S_{22} & 0 & 0 \\
S_{31} & S_{32} & S_{33} & 0 \\
S_{41} & S_{42} & S_{43} & S_{44}
\end{array}\right]\left[\begin{array}{c}
\varepsilon^{T R A} \\
\varepsilon^{V R A} \\
\varepsilon^{S P} \\
\varepsilon^{M P}
\end{array}\right]
$$

where $B(L) S=C(L)$. To identify $S$, we first assume that the vector $\varepsilon_{t}$ is normalized so that they all have unit variance. The normalization of $\operatorname{cov}\left(\varepsilon_{t}\right)$ implies that $S S^{\prime}=\Omega$. As shown in standard VAR literature on monetary policy shocks, the S matrix with a four-variable system contains sixteen elements.

The impulse response functions are calculated for 24 periods corresponding to 2 years. Further, similar to existing VAR literature (e.g. Stock and Watson, 2001, Bloom, 2009, and Bekaert, Hoerova, Duca, 2013), we compute $68 \%$ bootstrapped confidence intervals around the IRF point estimates, which correspond to about 1 standard deviations. These confidence intervals allow us to assess the accuracy of the IRF estimates over the sample periods. Moreover, a lag of four is determined by the Schwarz and Hannan-Quinn information criteria in the VAR-model.

\subsection{Data}

\subsubsection{Data Description for Monetary Policy Shocks}

To assess the impact of monetary policy actions on time-varying risk aversion, our sample period is from 1994 to 2014. The sample starts in 1994 because it is when the Federal Open Market Committee (FOMC) started to announce its decisions immediately after the meetings. The change in 1994 has allowed for better prediction of the future target rate and more precise estimation of monetary policy shocks (Gürkaynak, Sack and Swanson, 2007). Similar to Lutz (2015) and Kurov and Chen (2016), we divide the sample into two subperiods. The conventional monetary policy period is from January 1994 to December 2008 since the fed funds rate has remained around zero after December 2008. For 
the conventional period, we use the daily effective fed funds rate under the VAR framework to obtain monetary policy shocks.

After the FOMC meeting of December 16, 2008 the fed funds target rate has been at the zero-lower bound, thus, we consider the unconventional policy period from December 2008 to October 2014. The unconventional monetary policy shocks are computed using 8-9 quarters ahead Eurodollar futures rate. The unexpected changes in the federal funds target rate is computed using price changes in the fed funds futures on FOMC meeting days:

$$
\Delta i_{t}^{u}=\frac{D}{D-d}\left(f_{t}^{0}-f_{t-1}^{0}\right)
$$

where $\Delta i_{t}^{u}$ is the unexpected target rate change, $f_{t}^{0}$ is the current month implied futures rates, $D$ is the number of days in the month and $d$ is the day of the current FOMC meeting. $\frac{D}{D-d}$ is a scaling factor that is needed because the fed funds futures prices are based on the average monthly fed funds rate. To mitigate event study biases, the policy surprises and realized variance are calculated using intraday data.

\subsubsection{Data Description for Time-varying Risk Aversion}

We utilize the aggregate S\&P 500 index as a proxy for the market portfolio. The S\&P 500 index is from January1994 to October 2014, and the returns are calculated at daily levels. The daily VIX index is obtained from the Chicago Board Options Exchange (CBOE). ${ }^{4}$ In addition, the volatility and tail risk aversion are obtained from Chow, et al. (2016) paper. $^{5}$

[Insert Figure 2.1 about here]

\footnotetext{
${ }^{4}$ The intraday data is obtained from Genesis Financial Technologies.

${ }^{5}$ For detailed estimation methodology, please refer to Chow, Jiang, and Li (2016) working paper.
} 
Figure 2.1 shows the graphs for measures of monetary policy surprises, volatility risk aversion, and tail risk aversion, respectively. Monetary policy surprises are calculated as the unexpected component of the change in the fed funds target rate from January 1994 to November 2008 and the change in the 8-9 quarters ahead Eurodollar futures rate from December 2008 to October 2014. The volatility risk aversion is a proxy of required compensation by rational risk-averse investor for holding risky assets during volatility jumps. Tail risk aversion is a proxy of required compensation by rational risk-averse investor for holding risk assets during rare jumps. The graphs show similar patterns. Risk aversion move in a similar direction and magnitude.

\subsection{Estimation Results from the VAR Framework}

\subsubsection{The evidence of interdependence under Generalized VAR Analysis}

We begin our analysis with generalized VAR analysis on market response, fed funds rate, and risk aversion proxies, using daily data from January 1994 to December 2008. We follow the standard practice in many VAR models on monetary policy and set all variables in first difference and checked for unit root by using augmented Dickey-Fuller test. The ADF unit root tests are shown in Table 2.2, and all data series can clearly be rejected as unit roots. This implies that any potential cointegrating relationship between the variables will be implicitly determined in the model (Blanchard and Quah, 1989; Hamilton, 1994).

[Insert Table 2.2 about here]

[Insert Figure 2.2 about here]

Figure 2.2 graphs the results for estimated impulse responses to a stock market shock using generalized VAR. It shows how a shock to the stock market affect other variables. A positive shock from stock returns leads a marginally significant positive respond in fed funds rate. The findings 
indicate that stock price shocks can be important indicators for the interest rate setting. A well performing stock market can indicate a booming economy. The response might be motivated by the Federal Reserve's confidence in economy and concern about reducing the impact on inflation. Following Bjornland and Leitemo (2009), the stock price shock has persistent effects on itself, and allows for long-lasting booms in the stock market to be explained by non-fundamental factors. A one standard deviation positive shock to the stock price decreases both tail risk aversion and volatility risk aversion. Both the response of tail and volatility risk aversion remain significantly lower. Explanations consistent with this observation are that investors have less fear about the market, and a decrease in investor's overall risk aversion when there is a sudden positive jump in the stock market, thus increases consumption and investment through a wealth and Tobin $\mathrm{Q}$ effect, and affecting both volatility and tail risk aversion.

[Insert Figure 2.3 about here]

Since our main goal is to understand the interaction between monetary policy and investor risk aversion, we focus on illustrating how monetary shocks affect stock market and volatility and tail risk aversion. Figure 2.3 show the results for the impulse responses to the interest rate shock. The monetary policy shock has an initial negative impact on stock returns. The result of initial decreasing stock returns can be explained by the increase in the discount rate of dividends caused by an increase in the federal funds rate. A potential explanation of the stock returns revert back might be that as the shock is been digested by investors as possibly positive signals of expanding economy condition. A one standard deviation positive shock to the fed funds rate decreases both tail risk aversion and volatility risk aversion. Similar to figure 2.2 , the response of both tail and volatility risk aversion remain significantly lower. The decrease in risk aversion shows that investor's expectation on the occurring probability of rare event decreases and require lower risk premium. Moreover, the 
overall risk aversion drops since a tightening monetary policy normally indicates a non-recession scenario, and the Federal Reserve does not foresee any incoming black swan events that impose systematic risk to the economy. Overall, volatility risk aversion and tail risk aversion respond to stock market shock and monetary policy shock in a similar manner under the VAR framework. The findings show a positive monetary policy shock, which indicates no foreseeable economic contraction decreases both tail risk aversion and volatility risk aversion, and decreases stock prices initially. The recent example would be that stock market keeps hitting new highs although federal reserve has confirmed a path to increase short term funds target rate.

[Insert Figure 2.4 about here]

From the theoretical model, we observe that both volatility and tail risk aversion affect equity risk premium, we now utilize how risk aversion shocks affect stock market and Federal funds rate. Figure 2.4 shows the impulse responses to the tail risk aversion. Federal funds rate responds to the tail risk aversion shock negatively. Since tail risk aversion correspond with rare events, the result of decreasing interest rate can be explained by expected expansionary monetary policy to mitigate the effect of rare events. A shock to tail risk aversion has positive effect on volatility risk aversion. A one standard deviation positive shock to the TRA decreases stock prices. The response of stock prices remains negative. This can be explained by selling off risky assets and shifting to risk-free assets.

\section{[Insert Figure 2.5 about here]}

Figure 2.5 shows the results for the impulse responses to the volatility risk aversion. The volatility risk aversion shock has significant impact on tail risk aversion. Tail risk aversion increases temporarily, then starts to decrease. The result can be explained that a sudden increase in volatility risk aversion can induce an immediate increase in the tail risk aversion component, but the response 
of tail risk aversion starts to decrease after one month. Similar to the impact of tail risk aversion, a volatility risk aversion shock has significant negative impact on interest rate. Since volatility risk aversion corresponds with daily volatility events, it is expected that interest rate should respond to daily events. A one standard deviation positive shock to the volatility risk aversion lowers stock returns, but the response of stock returns reverts after two months. This response of stock prices is

plausibly caused by sudden increase in volatility that leads to a temporary decrease in stock prices. Overall, one standard deviation positive shock to volatility risk aversion and tail risk aversion have similar impact on stock price and interest rate. The findings indicate that both tail and volatility risk aversion have prominent effect on both stock price and interest rate. With the decomposed risk aversion, we can now distinguish the part of risk aversion of rational investor that drives the changes in stock price and interest rate.

\subsection{Estimation Results from Event Study Analysis}

\subsubsection{Descriptive Statistics}

This section examines the response of stock market, risk aversion to monetary policy surprises under event study analysis framework.

\section{[Insert Table 2.3 here]}

Our sample includes 168 FOMC monetary surprises from January 1994 to October 2014. Summary statistics for daily S\&P 500 returns and proxies for investors' risk aversion are shown in Table 2.3. The summary statistics for the overall sample period are shown in Column (2) through (5).

The daily returns of S\&P 500 have a mean of $0.41 \%$, which represent the index average return during the entire sample period. The range of these returns is from $-2.94 \%$ to $+5.14 \%$. The mean of the changes in volatility risk aversion $\left(V R A_{t}\right)$ and tail risk aversion $\left(T R A_{t}\right)$ is $-0.038 \%$ and $-0.002 \%$, 
respectively. We also divide our overall sample into two sub-groups (Columns (6) through (9)) based on two monetary policy periods. Conventional period is from January 1994 to December 2008, and the unconventional period is from January 2009 to October 2014. The daily returns are slightly higher during conventional periods, it can be contributed to the recovery from the recession, and stock markets keep hitting new highs. Moreover, the measure of tail risk aversion is higher during unconventional, and it can be potentially due to fears in the financial markets in this period.

Intuitively, when risk aversion increase, a rational investor believes there is higher risk exposure for owning underlying asset, and they may require a higher risk premium to hold risky assets or shift to less risky assets. This can lead to negative correlations between stock returns and the risk aversion measures. The correlations shown in Panel B support this observation. The daily stock market returns are negatively correlated with both volatility risk aversion and tail risk aversion. Moreover, stock market return and tail risk aversion become positively correlated during unconventional monetary policy periods. The correlation coefficients between stock market return and volatility risk aversion increase to -0.71 in unconventional period. The correlation coefficients between stock market return and tail risk aversion show similar results, and it increases to 0.46 in this period.

\subsubsection{Effect of Monetary Surprise on Market Return and Risk Aversion}

Since the fed funds rate was set at its zero-lower bound during unconventional period, an event study analysis should provide more information on how monetary policy surprises effect market return, volatility and tail risk aversion. After December 16, 2008, the fed funds rate remained near zero, and the Fed carried out some unprecedented procedures to influence longer-term interest rates. The FOMC also provided information about expected path of monetary policy to guide the market 
expectations of future rates. Following Kurov and Gu (2016), the changes in expectations about the future path of monetary policy is measured by implied rates of Eurodollar futures contracts with 89 quarters to expiration. As they point out that changes in this rate around monetary announcements can be regarded as a measure of new information contained in policy guidance. In this section, we examine the effect of monetary policy surprises on the stock market and the risk aversion during different sample periods. To ensure our results are not driven by a small number of outliers, we estimate the regression using both OLS and the MM robust regression procedure.

We first use event-study analysis to test the hypothesis that monetary surprises impact stock returns and time-varying risk aversion. If risk aversion measure investors' behavior when exposed to uncertainty, then monetary surprises should have impact on risk aversion. To measure the sensitivity of market returns and risk aversion to surprise changes in monetary policy, we estimate the following equations,

$$
R_{m, t}=\alpha+\beta_{m} \Delta i_{t}+\varepsilon_{t}
$$

where $R_{m, t}$ are the S\&P 500 daily returns, and investor volatility and tail risk aversion respectively, $\Delta i_{t}$ is unexpected changes in fed funds rate or 8-9 quarters Eurodollar futures contracts, and $\beta_{m}$ measures the average response to monetary policy surprises.

[Insert Table 2.4 about here]

Table 2.4 shows the response of stock returns to target rate changes. Overall, the results presented in this table are generally consistent with previous studies. A surprising decrease in shortterm rate have positive impact on stock returns. The coefficient estimate of the monetary surprise to stock market is negative and statistically significant. Based on the OLS estimates, a 25-basis-point decline in the expected short-term rate leads to an approximately 0.92 percent increase in stock prices for the full sample period. Outside of the recession period, the stock market respond to surprise 
increase in fed funds rate is negative. However, during recession period, the surprise change in fed funds rate have insignificant effect on stock returns based on OLS estimates. Kontonikas et al. (2013) argue that investors interpret unexpected rate cuts during recession period as a signal of deteriorating economic condition. Moreover, unexpected rate changes have strongest effect on market returns during unconventional period. A 25-basis-point decline in the expected short-term rate leads to about 1.15 percent increase in market returns for the unconventional period.

We also estimate a simple event study regression for both volatility and tail risk aversion using intraday measure of monetary policy surprises.

[Insert Table 2.5 about here]

Table 2.5 presents the estimation results of volatility and tail risk aversion response to monetary surprises. The coefficient estimates of the monetary surprise to time-varying risk aversion is overall negative that indicates a surprise rate hike increases investor's risk aversion. Based on the OLS estimates, panel A shows a 25-basis-point decline in the target rate and expected short-term rate leads to an approximately $0.69 \%$ and $0.18 \%$ decrease in volatility and tail risk aversion, respectively. A positive monetary surprise increase volatility risk aversion during non-recession period, and a positive surprise has a significant positive effect on tail risk aversion during recession period. The results are generally consistent with the results from the VAR analysis. Panel C shows the coefficient estimate of the monetary surprise to volatility risk aversion is positive, but the impact on tail risk aversion is negative from OLS estimates. Based on the OLS estimates, a 25-basis-point decline in the expected short-term rate leads to an approximately $0.45 \%$ increase in tail risk aversion. The lack of statistical significance could be caused by limited number of observations. From the VAR analysis, we know that a surprise drop in short-term rate should increase stock prices but decrease risk aversion. However, based on the OLS estimate in Table 2.5, an increase in tail risk 
aversion is associated with a surprise decline in short-term rate during unconventional period. Tail risk aversion is a proxy measure of investor's expectation on the occurrence of rare events. Similar to the argument in Kontonikas et al. (2013), the negative coefficient sign could be interpreted as investor believes that a surprise drop in short-term rate reflects a deteriorating economic environment in unconventional monetary policy period.

\subsubsection{Cross-sectional results}

In this section, we use cross-sectional analysis to test the hypothesis that monetary surprises impact stock returns partially through its effect on investors' time-varying risk aversion. If the effect of monetary surprises on stock returns is, in part, channeled through risk-aversion, stocks that are more sensitive to the changes of investors risk perceptions should react more strongly to such surprises. To measure the sensitivity of individual stock returns to changes in risk aversion, we follow Kurov (2010) and first estimate the effect of monetary surprises on individual stocks,

$$
R_{i t}=\alpha_{i}+\delta_{i} \Delta i_{t}+\varepsilon_{i}
$$

where $R_{i t}$ is the return of S\&P 500 individual stocks, $\Delta i_{t}$ is unexpected changes in fed funds rate, and $\delta_{i}$ measures the average individual stock response to monetary surprises. Secondly, to measure the sensitivity of firm-level stock returns to changes in investor risk aversion, we estimate the following model for daily returns on stock $i$,

$$
R_{i t}=\alpha_{i}+\beta_{i}^{m k t} R_{m, t}+\beta_{i}^{V R A} \Delta V R A_{t}+\beta_{i}^{T R A} \Delta T R A_{t}+\varepsilon_{i}
$$

where $R_{m, t}$ is the S\&P 500 index daily returns from CRSP, $\triangle V R A_{t}$ and $\Delta T R A_{t}$ are changes in volatility and tail risk aversion. The coefficients $\beta_{i}^{V R A}$ and $\beta_{i}^{T R A}$ measure sensitivities of individual stock returns to changes in investor risk aversion. The model is estimated over the sample periods for stocks included in the S\&P 500 index as in January 2014. Stocks with fewer than 1260 daily 
return observations are removed, leaving a sample of 202 firms. The summary statistics for the estimated beta coefficients are presented in Table 2.6. The volatility risk aversion betas are positively correlated with tail risk aversion betas, showing that stocks sensitive to changes in volatility risk aversion are also more affected by changes in tail risk aversion.

[Insert Table 2.6 about here]

To explain the heterogeneity in cross-sectional responses, we regress the following model to test whether stocks most sensitive to changes in volatility and tail risk aversion react more strongly to monetary surprises,

$$
\delta_{i}=\alpha_{0}+\alpha_{1} \beta_{i}^{m k t}+\alpha_{2} \beta_{i}^{V R A}+\alpha_{3} \beta_{i}^{T R A}+\varepsilon_{i}
$$

[Insert Table 2.7 about here]

The regression results are reported in Table 2.7. $\beta_{i}^{m k t}, \beta_{i}^{V R A}$ and $\beta_{i}^{T R A}$ are normalized using their sample means and standard deviations. The regression in (2.18) estimates the effect of sensitivities to market betas and changes in investor volatility/tail risk aversion on the impact of target rate changes on stock returns. In the full sample period, stocks that are more sensitive to market betas are impacted more negatively by monetary surprises, and stocks most sensitive to changes in risk aversion are also more affected by monetary surprises but in a different direction. It can be explained that an increase in investor risk aversion generally decreases stock returns, thus, we observe positive slope coefficients in Panel A. The results from conventional monetary policy period are similar to the ones from full sample period. The results in Panel B are consistent with the results from the VAR analysis. However, during the unconventional policy period, the sign of the coefficient of tail risk aversion beta changes from positive to negative. These findings suggest the effect of monetary surprises on stock returns are at least partially through its effects on changes in volatility and tail risk aversion changes. 


\subsection{Conclusion}

This paper examines the interdependence of stock market, risk aversion, and monetary policy surprises. From implications of the theoretical model, both volatility and tail risk aversion are important components of equity risk premium and play important roles in explaining the risk premium. In the empirical investigation, we first use a VAR framework to study the empirical link among these factors. The VAR analysis is from January 1994 to December 2008 since the fed funds rate has remained around zero after December 2008. We find that a positive shock to stock prices generally decreases both volatility and tail risk aversion and increases fed funds rate, and a positive shock to monetary policy decreases both volatility risk aversion and tail risk aversion since an increase in interest rate normally indicates an improving economy.

After December 16, 2008, the fed funds rate remained near zero, and the Fed carried out some unprecedented procedures to influence longer-term interest rates. We utilize event study analysis to address the effect of expected short-term rate surprises, and find that a surprise decline in the expected short-term rate has a positive impact on stock prices, which is consistent with the effect during conventional monetary policy period. However, a surprise decline in the expected short-term rate has a mixed effect on tail risk aversion during unconventional monetary policy periods. It seems to contradict with the results from the VAR analysis. However, tail risk aversion is a proxy measure of investor's expectation on the occurrence of rare events, a plausible explanation is that investor believes a surprise drop in short-term rate reflects a fast worsening economic outlook in unconventional monetary policy period. 
Table 2.1. Description of Variables

\begin{tabular}{lll}
\hline Name & Label & Description \\
\hline Volatility Uncertainty & VUC & (conditional realized variance) \\
Tail Uncertainty & TUC & (conditional RVIX - conditional RV) \\
Volatility Risk Aversion & VRA & $\left(V^{B K M}\right.$ - conditional RV) \\
Tail Risk aversion & TRA & (VIX squared - $\left.V^{B K M}-\mathrm{TUC}\right)$ \\
Realized variance & RVAR & $\begin{array}{l}\text { Realized variance computed using squared 5-minute } \\
\text { returns of E-mini S\&P 500 }\end{array}$ \\
Monetary Surpriese & $\Delta i_{t}$ & Unexpected change in Fed funds futures prices \\
Fed Funds Rate & FED & Effective FED funds rate \\
\hline
\end{tabular}


Table 2.2 ADF Unit Root Tests

\begin{tabular}{lcccc}
\hline Variable & MONETARY & STOCK & VOLATILITY & TAIL \\
& $-3.42 * *$ & $-10.53 * * *$ & $-11.74 * * *$ & $-6.62 * * *$ \\
& $(-2.88)$ & $(-2.88)$ & $(-2.88)$ & $(-2.88)$ \\
\hline
\end{tabular}

Table 2.2 report the augmented Dickey-Fuller tests (ADF-tests) for the null hypothesis of unit roots in the first differenced data of interest rate, inflation adjusted stock market returns, volatility and tail risk aversion. All first difference series of the data can clearly be rejected as unit roots. EngelGranger Cointegration test is used to test for cointegration. The null hypothesis of no cointegration can clearly be rejected with a t-statistic of -12.32 . $t$-values with $5 \%$ critical values in parentheses. 
Table 2.3. Descriptive Statistics

Panel A. Summary Statistics

\begin{tabular}{|c|c|c|c|c|c|c|c|c|}
\hline \multirow[b]{2}{*}{$\underline{\text { Variable }}$} & \multicolumn{4}{|c|}{ Overall Sample } & \multicolumn{2}{|c|}{ Conventional } & \multicolumn{2}{|c|}{ Unconventional } \\
\hline & Mean & S.D. & $\underline{\text { Min }}$ & $\underline{\operatorname{Max}}$ & $\underline{\text { Mean }}$ & $\underline{\text { S.D. }}$ & Mean & S.D. \\
\hline$\underline{(1)}$ & (2) & (3) & (4) & $\underline{(5)}$ & $\underline{(6)}$ & (7) & (8) & (9) \\
\hline$R_{t}$ & 0.413 & 1.328 & -2.939 & 5.136 & 0.431 & 1.342 & 0.364 & 1.301 \\
\hline$\Delta V R A_{t}$ & -0.380 & 1.501 & -14.259 & 4.162 & -0.318 & 1.112 & -0.552 & 2.253 \\
\hline$\Delta T R A_{t}$ & -0.002 & 0.374 & -1.952 & 2.117 & -0.022 & 0.403 & 0.050 & 0.275 \\
\hline$\Delta i_{t}$ & -0.014 & 0.093 & -0.482 & 0.240 & -0.017 & 0.092 & -0.007 & 0.095 \\
\hline Events & 168 & & & & 123 & & 45 & \\
\hline
\end{tabular}

\begin{tabular}{cccc|ccc|ccc}
\hline \multicolumn{3}{c}{ Panel B. Correlations of stock returns, risk aversion, and monetary surprises } \\
\hline \multicolumn{3}{c}{ All Sample } & \multicolumn{3}{c}{ Conventional } & \multicolumn{5}{c}{ Unconventional } \\
\hline$R_{t}$ & $-0.65^{* * *}$ & -0.07 & $-0.33_{t} * * *$ & $-0.68^{* * *}$ & $-0.19^{* *}$ & $-0.29^{* * *}$ & $-0.71^{* * *}$ & $0.46^{* * *}$ & -0.45 \\
$\Delta V R A_{t}$ & 1 & $-0.38^{* * *}$ & $0.26^{* * *}$ & 1.00 & $-0.19^{* *}$ & $0.17^{*}$ & 1.00 & $-0.90^{* * *}$ & $0.41^{* * *}$ \\
$\Delta T R A_{t}$ & $-0.38^{* * *}$ & 1.00 & 0.07 & $-0.19^{* *}$ & 1.00 & 0.14 & $-0.90^{* * *}$ & 1.00 & -0.24 \\
$\Delta i_{t}$ & $0.26^{* * *}$ & 0.07 & 1.00 & $0.17^{*}$ & 0.14 & 1.00 & $0.41^{* * *}$ & -0.24 & 1.00 \\
\hline
\end{tabular}

The table shows summary statistics. Panel A reports the summary statistics for the various variables in our sample. The summary statistics for the overall sample period are reported in Column (2) through (5). We also divide our overall sample into two sub-groups (Columns (6) through (9)) based on the conventional and unconventional periods. All variables are expressed in percentage. Panel B. reports Pearson correlation coefficients. The sample period is from January 1994 to October 2014. The conventional period is from January 1994 to December 2008, and the unconventional period is from January 2009 to October 2014. 
Table 2.4. Response of stock prices to target rate changes

\begin{tabular}{|c|c|c|c|c|}
\hline & \multicolumn{2}{|l|}{ OLS } & \multicolumn{2}{|c|}{ Robust regression } \\
\hline \multicolumn{5}{|l|}{ Panel A. Full Sample } \\
\hline Intercept & -0.05 & $(0.07)$ & $-0.14 * *$ & $(0.06)$ \\
\hline$\Delta i_{t}$ & $-3.61 * * *$ & $(1.36)$ & $-3.69 * * *$ & $(0.82)$ \\
\hline$R^{2}$ & \multicolumn{2}{|l|}{0.112} & \multicolumn{2}{|l|}{0.02} \\
\hline $\mathrm{N}$ & \multicolumn{4}{|l|}{168} \\
\hline \multicolumn{5}{|c|}{ Panel B. Conventional period } \\
\hline Intercept & -0.04 & $(0.08)$ & $-0.13^{*}$ & $(0.07)$ \\
\hline $\begin{array}{l}\Delta i_{t} \\
\text { recession })\end{array}$ & -0.88 & $(2.71)$ & $-2.67 * *$ & $(1.22)$ \\
\hline$\Delta i_{t}($ Out-of- recession $)$ & $-4.42 * *$ & $(1.74)$ & 2.25 & $(1.41)$ \\
\hline$R^{2}$ & \multicolumn{2}{|l|}{0.09} & \multicolumn{2}{|l|}{0.039} \\
\hline $\mathrm{N}$ & \multicolumn{4}{|l|}{123} \\
\hline \multicolumn{5}{|c|}{ Panel C. Unconventional period } \\
\hline Intercept & -0.07 & $(0.13)$ & -0.12 & $(0.12)$ \\
\hline$\Delta i_{t}$ & $-4.63 * * *$ & $(1.54)$ & $-2.98 * *$ & $(1.42)$ \\
\hline$R^{2}$ & \multicolumn{2}{|l|}{0.202} & \multicolumn{2}{|l|}{0.094} \\
\hline $\mathrm{N}$ & \multicolumn{4}{|l|}{45} \\
\hline
\end{tabular}

The table reports estimates for the following model: $R_{m, t}=\alpha+\beta_{m} \Delta i_{t}+\varepsilon_{t}$, where $\Delta i_{t}$ is the change in the 8-9 quarters ahead Eurodollar futures rate and $R_{m, t}$ is the S\&P 500 daily returns. The sample period is from January 1994 through October 2014 and contains 168 FOMC meetings. The regressions are estimated using OLS with the White (1980) heteroskedasticity consistent covariance matrix and robust M-estimator of Huber (1973). Standard errors are shown in parentheses. *,**, *** indicate statistical significance at $10 \%, 5 \%$, and $1 \%$ levels, respectively. 
Table 2.5. Effect of target rate changes on investor risk aversion

\begin{tabular}{|c|c|c|c|c|c|c|c|c|}
\hline & \multicolumn{4}{|c|}{$\triangle V R A$} & \multicolumn{4}{|c|}{$\triangle T R A$} \\
\hline & \multicolumn{2}{|l|}{ OLS } & \multicolumn{2}{|c|}{ Robust regression } & \multicolumn{2}{|l|}{ OLS } & \multicolumn{2}{|c|}{ Robust regression } \\
\hline \multicolumn{9}{|c|}{ Panel A. Full Sample } \\
\hline Intercept & 0.04 & $(0.06)$ & $0.12 * * *$ & $(0.03)$ & 0.01 & $(0.06)$ & $0.06 * * *$ & $(0.02)$ \\
\hline$\Delta i_{t}$ & $2.77 *$ & $(1.68)$ & 0.34 & $(0.30)$ & $0.72 * *$ & (1.55) & $0.75^{* * *}$ & $(0.27)$ \\
\hline$R^{2}$ & 0.066 & & 0.004 & & 0.005 & & 0.016 & \\
\hline $\mathrm{N}$ & 168 & & & & & & & \\
\hline \multicolumn{9}{|c|}{ Panel B. Conventional period } \\
\hline Intercept & 0.06 & $(0.06)$ & $0.12^{* * *}$ & $(0.03)$ & 0.01 & $(0.08)$ & $0.07^{*}$ & $\overline{(0.03)}$ \\
\hline $\begin{array}{c}\Delta i_{t} \\
\text { (Recession) }\end{array}$ & -1.37 & $(1.28)$ & 0.79 & $(0.62)$ & $3.29^{*}$ & (1.96) & -0.24 & $(0.52)$ \\
\hline $\begin{array}{l}\Delta i_{t} \text { (Out-of- } \\
\text { recession) }\end{array}$ & $3.33^{* * *}$ & $(1.06)$ & 0.12 & $(0.53)$ & -1.99 & (1.86) & 0.73 & $(0.67)$ \\
\hline$R^{2}$ & 0.104 & & 0.005 & & 0.063 & & 0.001 & \\
\hline $\mathrm{N}$ & 123 & & & & & & & \\
\hline \multicolumn{9}{|c|}{ Panel C. Unconventional period } \\
\hline Intercept & -0.07 & $(0.17)$ & 0.07 & $(0.05)$ & 0.13 & $(0.09)$ & $0.05^{* * *}$ & $(0.02)$ \\
\hline$\Delta i_{t}$ & 6.52 & $(5.10)$ & 0.47 & $(0.58)$ & -1.81 & (2.77) & 0.15 & $(0.25)$ \\
\hline$R^{2}$ & 0.171 & & 0.012 & & 0.055 & & 0.003 & \\
\hline $\mathrm{N}$ & 45 & & & & & & & \\
\hline
\end{tabular}

The table reports estimates for the following model: $R_{m, t}=\alpha+\beta_{m} \Delta i_{t}+\varepsilon_{t}$, where $\Delta i_{t}$ is the change in the 8-9 quarters ahead Eurodollar futures rate, $V R A_{t}$ is the proxy for normal risk aversion that investor face from quadratic variation, and $R A_{t}$ is the proxy for rare risk aversion that investor fact from tail variation. During conventional period, the sample period is divided into recession and outof-recession period. The recession date is set from September 2007 to December 2008 as in Kontonikas, MacDonald and Saggu (2013). The overall sample period is from January 1994 through October 2014 and contains 168 FOMC meetings. The regressions are estimated using OLS with the White (1980) heteroskedasticity consistent covariance matrix and robust M-estimator of Huber (1973). Standard errors are shown in parentheses. *, **, *** indicate statistical significance at $10 \%$, $5 \%$, and $1 \%$ levels, respectively. 
Table 2.6. Summary statistics for factor loadings.

\begin{tabular}{|c|c|c|c|}
\hline \multicolumn{4}{|c|}{ Panel A. Summary statistics } \\
\hline & $\beta_{i}^{m k t}$ & $\beta_{i}^{V R A}$ & $\beta_{i}^{T R A}$ \\
\hline \multicolumn{4}{|c|}{ Panel A. Descriptive statistics } \\
\hline Mean & 0.786 & -0.068 & 0.021 \\
\hline Standard deviation & 0.426 & 0.386 & 0.799 \\
\hline Minimum & -0.575 & -2.909 & -3.484 \\
\hline Maximum & 2.047 & 0.945 & 4.012 \\
\hline \multicolumn{4}{|c|}{ Panel B. Correlations for full sample period } \\
\hline$\beta_{i}^{m k t}$ & 1 & $0.26 * * *$ & 0.11 \\
\hline$\beta_{i}^{V R A}$ & & & $0.55 * * *$ \\
\hline$\beta_{i}^{T R A}$ & & & 1 \\
\hline \multicolumn{4}{|c|}{ Panel C. Correlations for Conventional monetary period } \\
\hline$\beta_{i}^{m k t}$ & 1 & $0.35 * * *$ & $0.23 * * *$ \\
\hline$\beta_{i}^{V R A}$ & & & $0.55 * * *$ \\
\hline$\beta_{i}^{T R A}$ & & & 1 \\
\hline \multicolumn{4}{|c|}{ Panel D. Correlations for Unconventional monetary period } \\
\hline$\beta_{i}^{m k t}$ & 1 & $0.783 * * *$ & $0.37 * * *$ \\
\hline$\beta_{i}^{V R A}$ & & & $0.82 * * *$ \\
\hline$\beta_{i}^{T R A}$ & & & 1 \\
\hline
\end{tabular}

The table shows the summary statistics and Pearson correlations of the factor loadings (betas). The sample contains 202 firms from January 1994 to December 2014. ***Correlation is statistically significant at $1 \%$ level. 
Table 2.7. Effect of the market risk, risk aversion on the response of daily stock returns

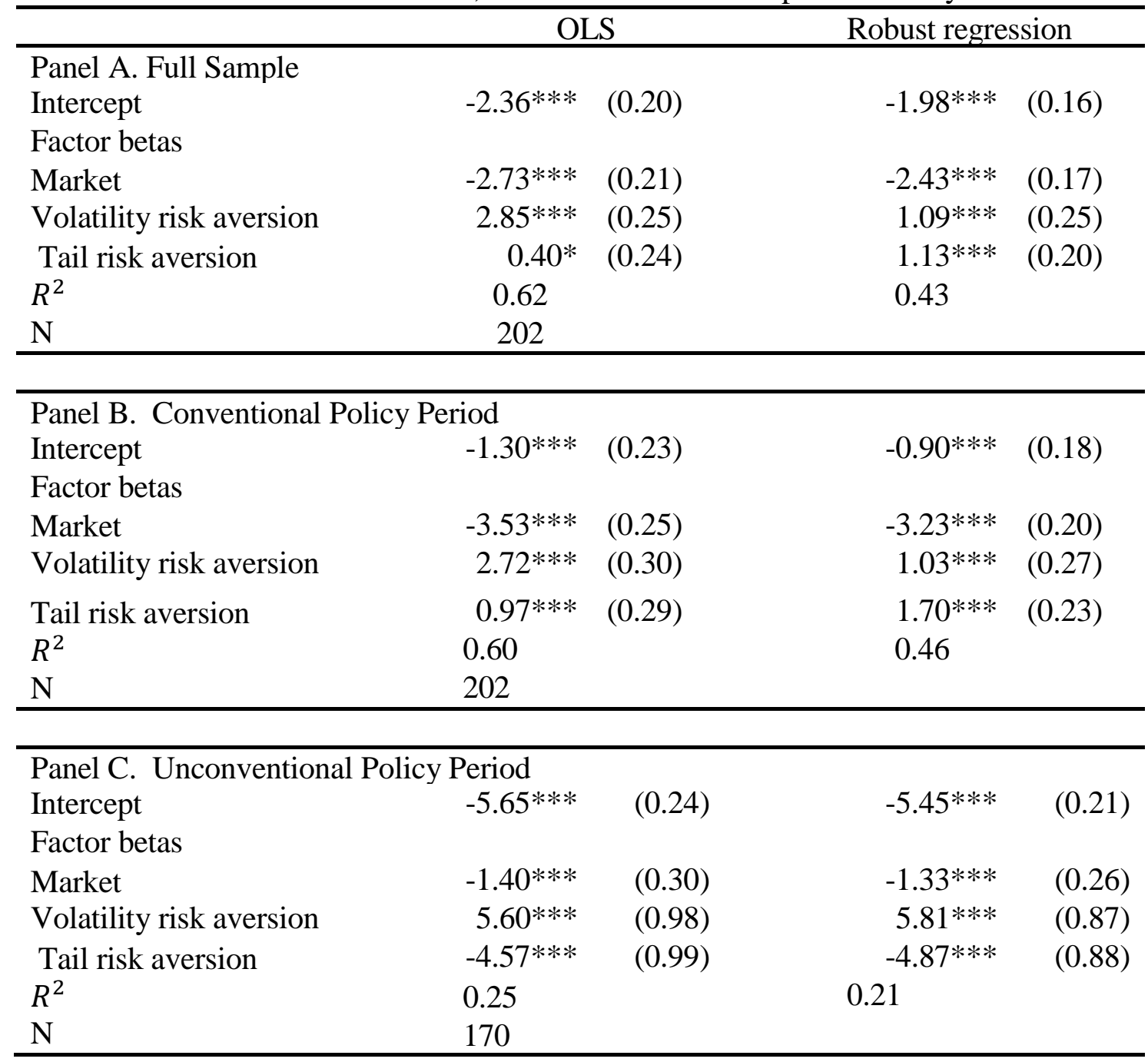

The reported coefficients are for the following cross-sectional regression: $\delta_{i}=\alpha_{0}+\alpha_{1} \beta_{i}^{\text {mkt }}+$ $\alpha_{2} \beta_{i}^{V R A}+\alpha_{3} \beta_{i}^{T R A}+\varepsilon_{i}$, where $\gamma_{i}$ is the average individual stock response to monetary news, and $\beta_{i}^{m k t}, \beta_{i}^{V R A}$, and $\beta_{i}^{T R A}$ are the factor loadings (betas) for market, volatility risk aversion, and tail risk aversion, respectively. The factor loadings (betas) are normalized using their sample means and standard deviations. The sample contains 202 firms that have more than 5 years return observations. $*, * *, * * *$ indicate statistical significance at $10 \%, 5 \%$, and $1 \%$ levels, respectively. 
Figure 2.1. Monetary Policy Shocks, Volatility Risk Aversion, and Tail Risk Aversion Panel A. Monetary Policy Shocks

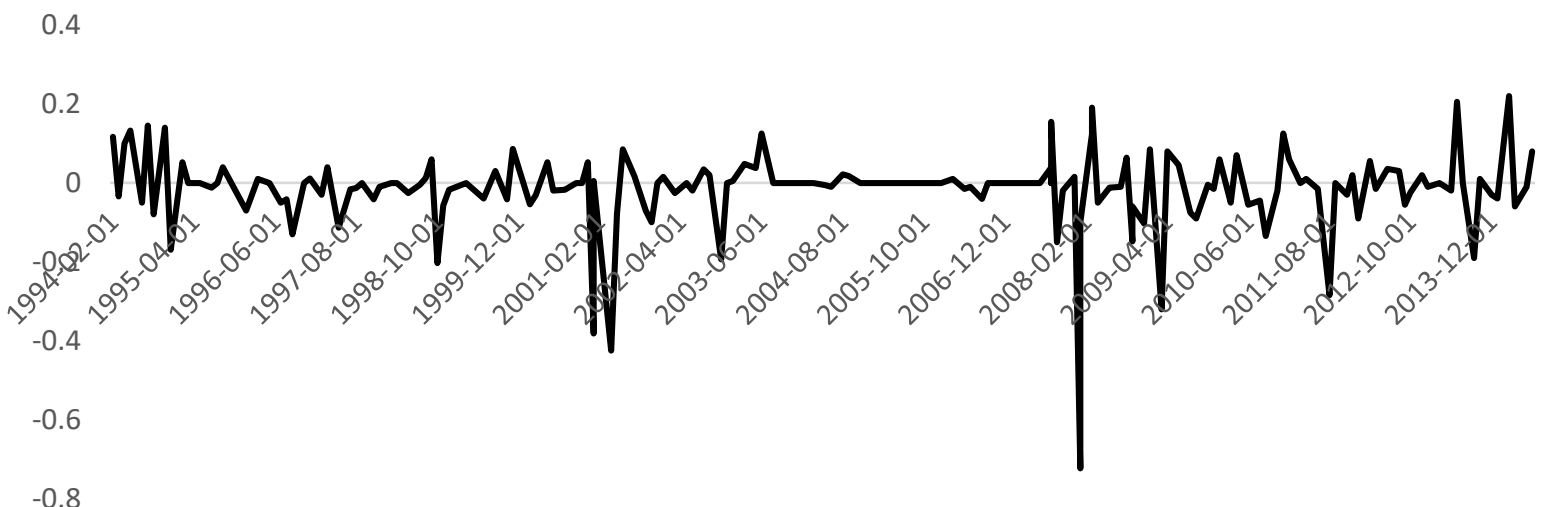

Panel B. Volatility Risk Aversion

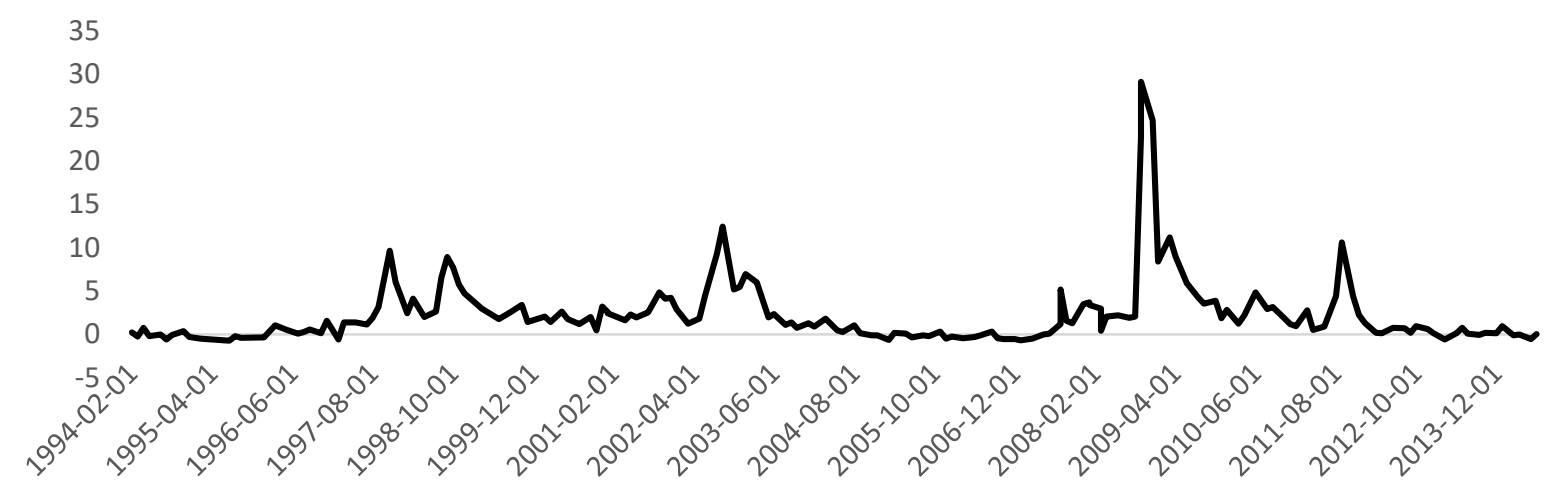

Panel C. Tail Risk Aversion

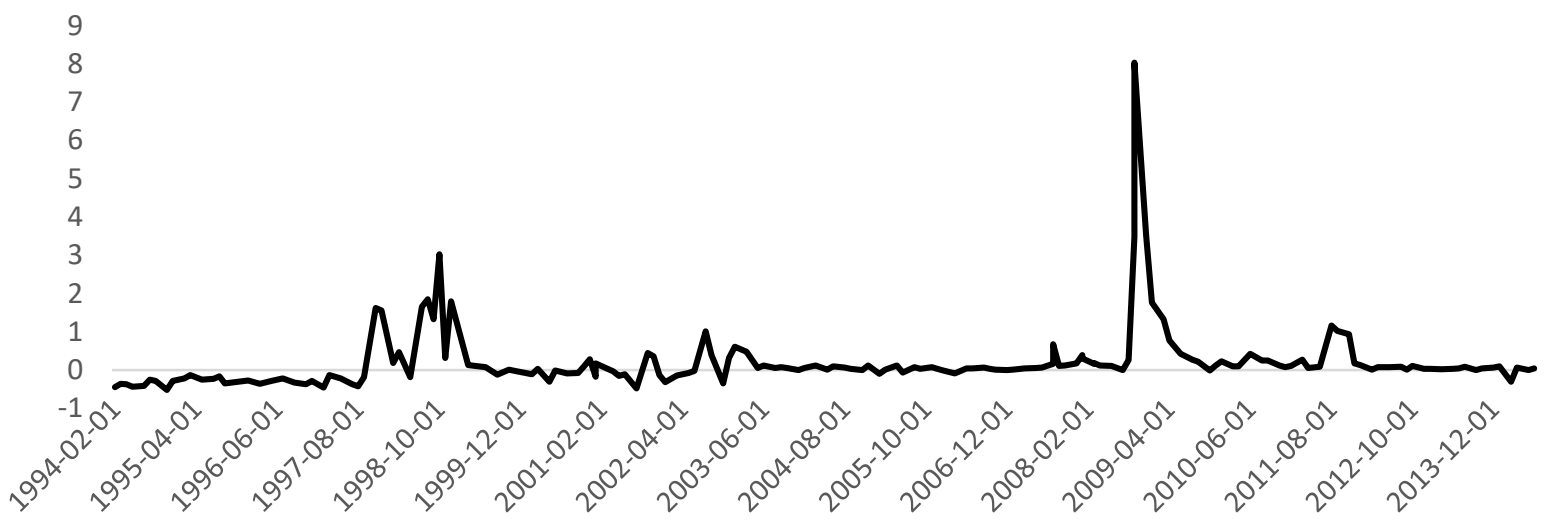

Note: Monetary policy shocks are calculated as the unexpected component of the change in the fed funds target rate from January 1994 to November 2008 and the change in the 8-9 quarters ahead Eurodollar futures rate from December 2008 to October 2014. The volatility risk aversion is a proxy of rational risk-averse investor's required compensation for holding risky assets during volatility jumps. Tail risk aversion is a proxy of rational risk-averse investor's required compensation for holding risk assets during rare jumps. 
Figure 2.2. Impulse Responses to Stock Price Shock
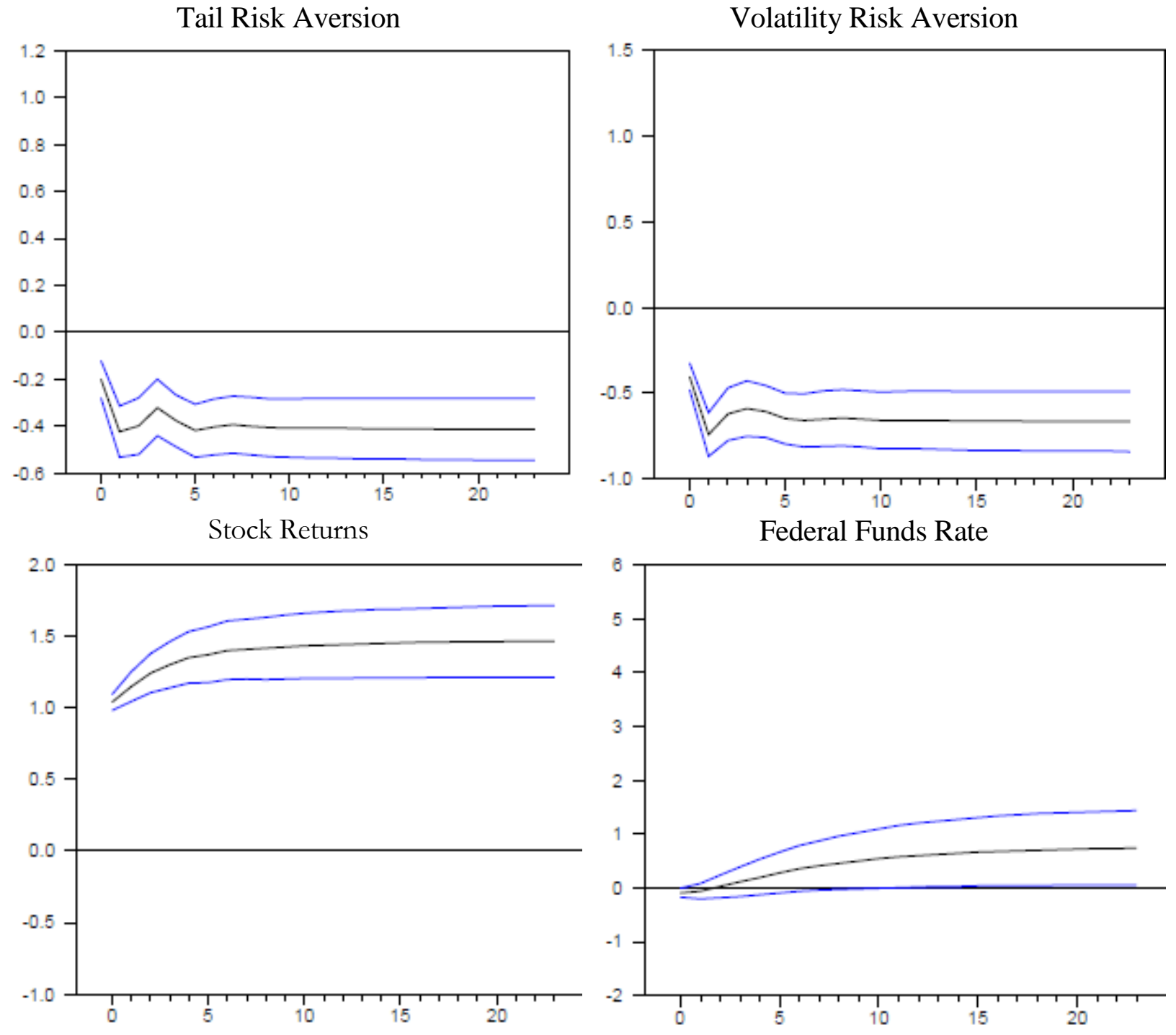

Figure 2.2. Impulse responses for the federal funds rate, the stock prices, volatility risk aversion and tail risk aversion from a stock price shock. 
Figure 2.3. Impulse Responses to Monetary Policy Shock
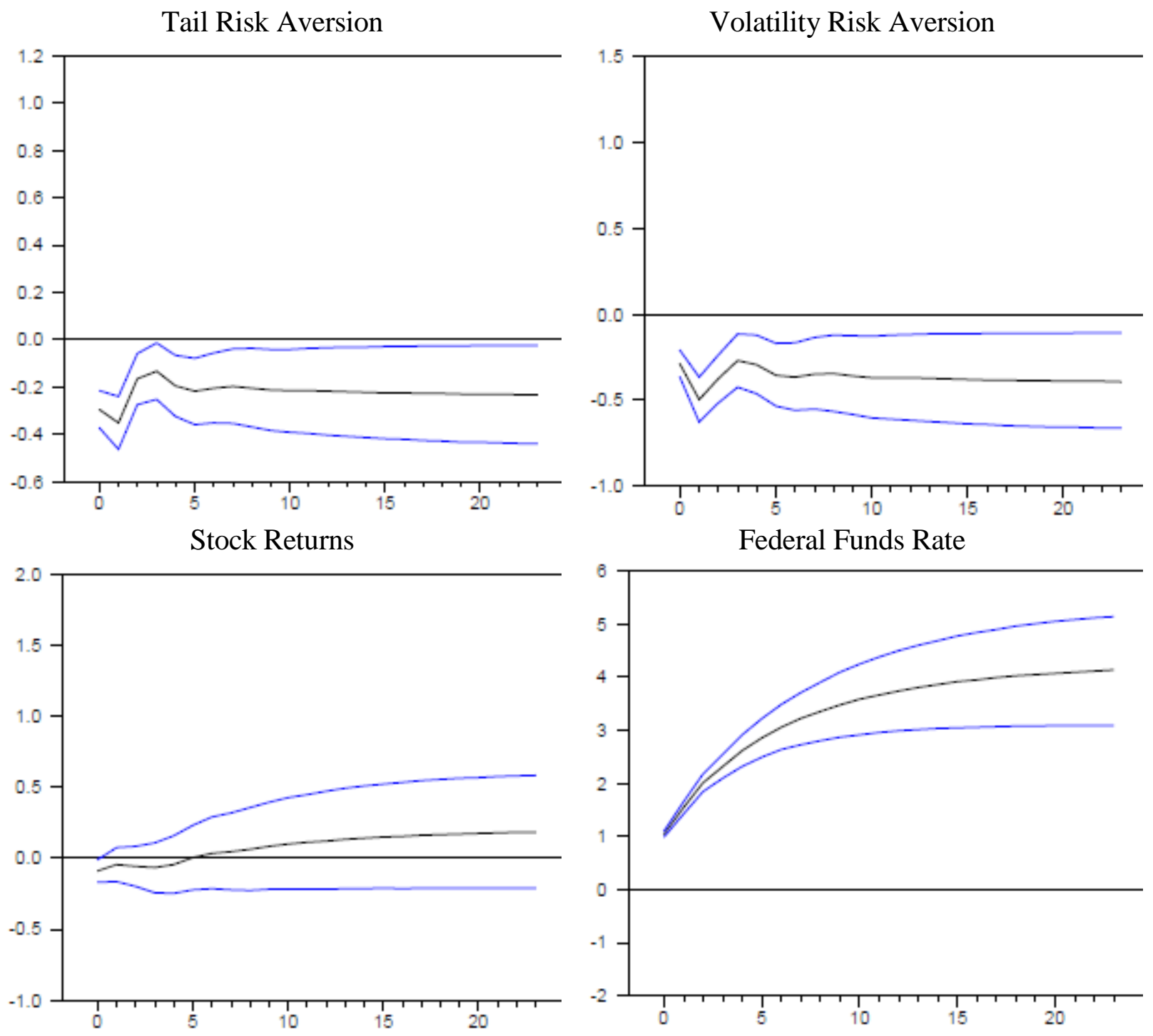

Figure 2.3. Impulse responses for the federal funds rate, the stock prices, volatility risk aversion and tail risk aversion from a monetary policy shock. 
Figure 2.4. Impulse Responses to Tail Risk Aversion Shock
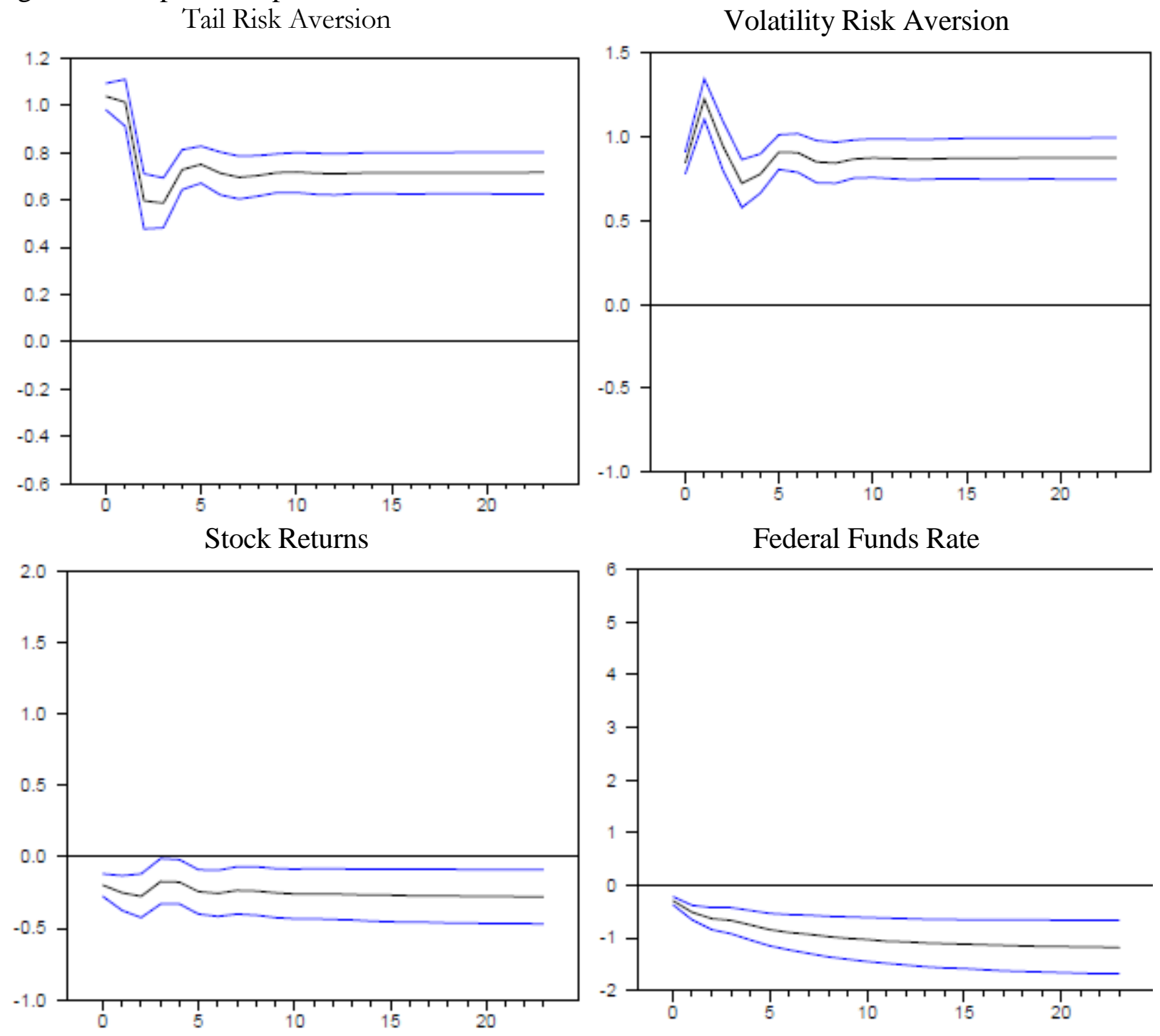

Figure 2.4. Impulse responses for the federal funds rate, volatility risk aversion, the stock prices, and inflation from the tail risk aversion shock. 
Figure 2.5. Impulse Responses to Volatility Risk Aversion with Long-run restriction on Monetary Tail Risk Aversion
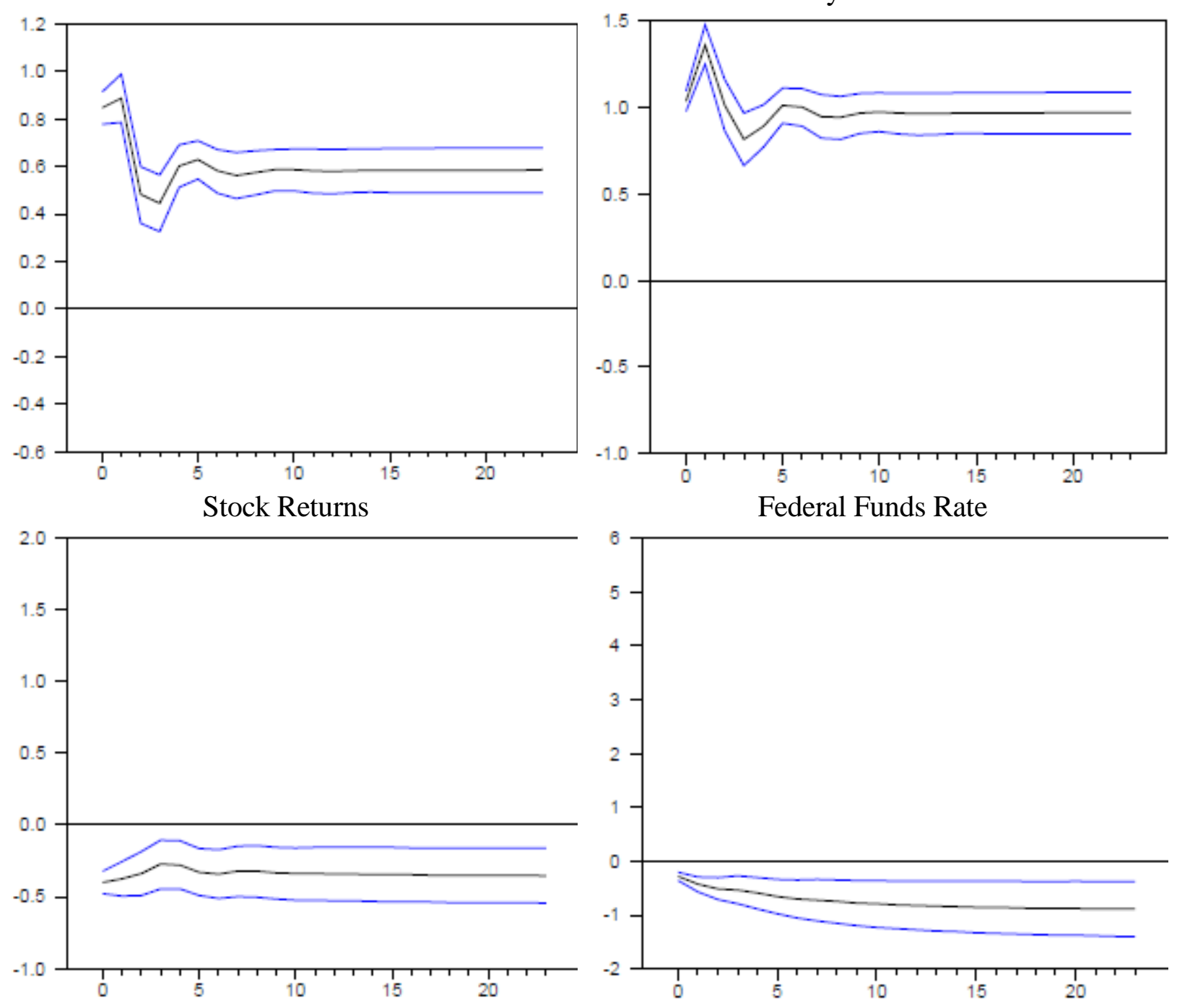

Figure 2.5. Impulse responses for tail risk aversion, federal funds rate, stock prices, and inflation from the volatility risk aversion shock. 


\section{CHAPTER 3: Does Investor Sentiment Affect the Market Reaction to Macroeconomic}

\section{News?}

\subsection{Introduction}

There is a long-standing academic research interest in the relationship between investor sentiment and financial market. Prior literature has shown that investor sentiment has significant impact on financial markets (e.g., Brown and Cliff, 2005; Baker and Wurgler, 2006, 2007; Kaplanski and Levy, 2010). From the perspective of market microstructure, smart-money investors or informed traders take advantage of their private information and compete aggressively to exploit profit opportunities, while noise traders are more likely to commit cognitive errors and potentially impact price efficiency and return anomalies. However, as Black (1986) points out, noise traders are an important component and make trading in financial markets possible. This paper uses survey based investor sentiment proxies to examine for trading activities of ordinary investors, and investigates how market responds to macroeconomic news surprises during high and low states of investor sentiment.

Investor sentiment measures the overall attitude or feelings of investors toward a financial market or a specific financial product, and is not always based on fundamentals. Investor sentiment can impact on the trading activity and price movement of the underlying assets. Two investor sentiment measures are used in this paper. One is American Association of Individual Investors 
(AAII) Sentiment Index, and the other is Investor Intelligence sentiment index. As described on AAII website, AAII members are asked the question each week: "Do they feel the direction of the stock market over the next six months will be up (bullish), no change (neutral) or down (bearish)?"’ The survey is open to all AAII members. The Investors Intelligence sentiment index, on the other hand, is derived from a compilation of the forecasts of the newsletter writers. As described on Investor Intelligence website, this sentiment survey has been widely adopted as a contrarian indicator. It assumes that a consensus trend is about to reverse, traders will have the opportunity to profit on a reversal in price movement. ${ }^{10}$ Following Fisher and Statman (2006) and Kurov (2008), we compute an investor sentiment index as a ratio of the percentage of bullish investors to the total of the percentage of bullish and bearish investors.

We investigate the effects of investor sentiment on the short-run response of the E-mini S\&P 500 futures to macroeconomic news surprises, and we use the news surprises as new information arriving in markets that triggers trading activities from both informed and noise traders. When Lee (2001) summarizes Shiller (1984) paper, he points out sentiments arise when investors trade on pseudo-signals, such as price and volume patterns, or the forecasts of Wall Street gurus. Pseudosignals refer to noise traders sub-optimal use of available information, over- and underreactions to legitimate information signals. Pseudo-signals are used in this paper to differentiate the optimal and sub-optimal use of information between informed traders and noise traders. Following their arguments, sentiment measures noise traders' willingness to participate in buying and selling activities. Sentiment effects are likely to be more influential when noise traders actively place orders in financial markets. For high investor sentiment, which generally signifies more active trading by noise traders, the proportion of orders placed by noise traders increase relative to informed traders,

\footnotetext{
${ }^{9}$ http://www.aaii.com/sentimentsurvey

${ }^{10}$ https://www.investorsintelligence.com/x/us_advisors_sentiment.html
} 
and it can lead to price deviating from fundamental value and inefficient market adjustment dynamics due to likely cognitive errors. For low investor sentiment, on the other hand, which generally signifies less active trading activities from noise traders, the proportion of orders placed by noise traders decrease relative to informed traders, and it can lead to a more efficient market adjustment process due to a more dominant force from informed traders. When there are macroeconomic news surprises, computed as the difference between the actual and expected value of economic data, forward-looking smart-money investors not only process news surprises accurately and optimally, but also adjust their expectations on future economic condition, whereas noise traders likely commit cognitive errors and not be able to response to new information optimally.

Previous literature has focused on the effects of macroeconomic news announcements and investor sentiment separately. Andersen, Bollerslev, Diebold and Vega (2003) examine 23 major macroeconomic news announcements and find that exchange rates adjust to announcement surprises very rapidly. Boyd and Jagannathan (2005) find that the response of stock market unemployment news varies conditional on the state of economy. Through studying major macroeconomic series with revisions, Gilbert (2011) shows that S\&P 500 stock returns are affected by both initial macroeconomic announcements and their revisions. There is also a strand of literature studies how investor sentiment impacts financial markets. Shefrin and Statman (1994) consider that sentimentdriven trading could introduce noise into the prices and drive prices away from fundamental values, and they show that sentiment is an important factor of stock prices in their behavioral capital asset pricing theory. Moreover, Mian and Sankaraguruswamy (2016) use firms' earnings news and find stock price sensitivity to good (bad) earnings news is higher during high (low) sentiment periods than during low (high) sentiment periods. We combine and interact the effect of investor sentiment 
on market reaction around macroeconomic announcements. To account for the effect, we use the weekly reports of American Association of Individual Investors (AAII) and Investor Intelligence as investor sentiment proxies in our paper, and we examine 33 scheduled U.S. macroeconomic news announcements that are frequently covered in the financial media. We also compute the ten-minute returns around the macroeconomic announcement as our measure of E-mini S\&P 500 futures price response to news surprises. ${ }^{11}$

We first examine whether the E-mini S\&P 500 market reacts to the 33 influential macroeconomic news surprises. Consistent with existing findings, the results show that majority of the macroeconomic news surprises have significant effects on futures market returns. In line with the methodologies in Kurov and Stan (2016), we then use the market-moving news surprises to construct interactive variables and examine whether stock index futures returns are affected by news surprises conditional on different levels of investor sentiment and control for the state of economic conditions. Overall, market reacts to news surprises stronger during low sentiment periods and weaker during high sentiment, however, the statistical significance of individual news surprises drops. These results potentially surfer from small-sample issues due to the limited observations from news surprises.

To avoid the small-sample problems from simultaneous news release analysis, we follow the procedure proposed by Swanson and Williams (2014) and estimate the surprises for all announcements in a single estimation. After computing the surprise component of the news announcements, we normalize the coefficient of news surprises during normal sentiment periods and compare it to the coefficients of news surprises during high/low sentiment periods from January 1998 to September 2016.

\footnotetext{
11 The ten-minute returns is calculated as five minutes before to five minutes after macroeconomic news announcements.
} 
In general, we find that investor sentiment has significant impact on the market reaction to macroeconomic news surprises. Furthermore, it is consistent with our hypothesis that the response of E-mini S\&P 500 to macroeconomic news surprises become weaker during high sentiment and become stronger during low sentiment in the presence of varying investor sentiment related to total shares demanded by noise traders. The results still hold when we separate positive news surprises from negative news surprise and control for state of economy. Our results provide evidence that market reacts to news surprises stronger when sentiment is low. On the other hand, more active noise trading activities on pseudo-signals during high sentiment impede price adjustment dynamics and cause price deviation from fundamental value.

\subsection{Hypothesis}

Noise traders are considered to act on signals that are value-irrelevant, and smart-money investors respond to news about fundamental value rapidly and optimally. Black (1986) points out that noise trading is a necessary part of the price discovery process and the "missing ingredient" in traditional asset pricing model. Noise trading helps to explain the large trading volume and volatility, and it also helps to explain price deviation from fundamental value and the continued existence of arbitrage. While determining the optimal strategy and making security selections, smart-money investors consider both fundamental valuation and behavior of noise traders. More generally, when public information is released to markets, smart-money investors respond to such information optimally, and they can choose to either based on the fundamental values of the underlying assets or make profitable trade with noise traders.

In the classical framework, financial markets should only react to the "surprise" component of new information. Under the efficient market hypothesis $(\mathrm{EMH})$, asset prices fully reflect all 
available information. In this case, smart-money investors dominate the market and determine the price, and current stock price represents the present value of expected future dividends, as formulated as follows:

$$
P_{t}=\sum_{i=1}^{\infty} \frac{E_{t} D_{t+i}}{(1+r+\pi)^{i}},
$$

where $P_{t}$ is considered as the stock's intrinsic value at time t, $E_{t} D_{t+i}$ is the expected future dividend at time $t+i$, and $r$ is the interest rate on long-term risk-free claims, and $\pi$ is the risk premium investors require to invest in risky assets. Together, $(r+\pi)$ is considered the discount rate for the expected dividend stream.

If we assume dividends grow at a constant rate $g$, then Gordon constant growth model defines stock value as the discounted value of future expected dividends.

$$
P=\frac{D(1+g)}{r+\pi-g},
$$

where $P$ is the current stock price, $\mathrm{D}$ is the current dividend, $\mathrm{g}$ is the expected (constant) rate of growth in D.

Shiller (1984) develops an alternative model that includes two types of investors: smartmoney investors who trade on the basis of fundamental information, and noise traders who do not trade on the basis of an optimal response to news about fundamentals. The model is expressed as follows:

$$
P_{t}=\sum_{k=0}^{\infty} \frac{E_{t} D_{t+k}+\phi E_{t} Y_{t+k}}{(1+\rho+\phi)^{k+1}},
$$

where $P_{t}$ is the present value of fair stock price, $Y_{t}$ is the total value of stock demanded per share by noise traders and $Y_{t}$ is assumed to be time-varying and not based on expected returns optimally forecasted; $\rho$ is the expected real return such that there is no demand for shares by smart-money investors; $\phi$ is the risk premium that induces smart-money investors to hold all shares, and it can 
also be viewed as the cost of arbitrage. The demand for shares by smart-money investors is expressed as a portion of total shares outstanding: $Q_{t}=\frac{E_{t}\left(R_{t}\right)-\rho}{\phi}$. As $\phi$ approaches to zero, $P_{t}$ becomes the discounted value of future dividends, and Equation (1) emerges as a special case of the efficient market model.

We assume that dividend grows at the constant rate of $g$, and the growth rate of total value of stock demanded by noise traders is at a constant rate of $\hat{g}$. Using geometric series to equation (3), it can be simplified as follows:

$$
P=\frac{D(1+g)}{\rho+\phi-g}+\frac{\phi Y(1+\hat{g})}{\rho+\phi-\hat{g}}
$$

Under efficient market model, $\phi$ equals to zero, and Equation (2) and (4) are equivalent to each other. We define $\rho \equiv(r+\pi)$, and it follows that

$$
P=\frac{D(1+g)}{r+\pi+\phi-g}+\frac{\phi Y(1+\hat{g})}{r+\pi+\phi-\hat{g}}
$$

The usual findings in the event-studies literature show that financial markets are forwardlooking, and that the unexpected (or surprise) component of macroeconomic data releases should have significant effect on financial markets. In the alternative model proposed by Shiller (1984) the jumps in price around announcements represents what the smart money traders think the announcement means for both future dividends and the demand for shares by noise traders. In our case, when macroeconomic news announcements are released, forward-looking smart-money investors adjust their expectations of future economic condition, and also consider the demand for shares by noise traders.

Since we know that smart-money investors have optimal response to news about fundamental value, then what is the cause that gives rise to the common investor sentiment? Prior literature on investor sentiment has shown that sentiment has significant impact on financial markets 
(e.g. Brown and Cliff, 2005; Baker and Wurgler, 2006; Kaplanski and Levy, 2010). Lee (2001) suggest sentiments arise when investors trade on pseudo-signals, such as price and volume patterns, or the economic and earnings forecasts. The total number of shares demanded by noise traders captures any price effect that is due to sub-optimal use of available information. In this sense, high market sentiment indicates that noise traders trade on pseudo-signals more actively, and it likely leads to an increase of the total shares demanded by noise traders. Such action can cause price deviations from present value of expected dividends and then provide arbitrage opportunities for smart-money investors. On the other hand, low market sentiment indicates that noise traders trade less actively on these pseudo-signals, and prices respond to new information more efficiently and adjust to the fundamental value rapidly.

Similar to Boyd, Hu, and Jagannathan (2005), we denote $u$ as the macroeconomic news surprises, so that $\frac{d P / P}{d u}$ represents the percentage change in the stock prices in response to news surprises. When news surprises become public information, forward looking rational investors adjust their expectations on future economic conditions, and on potential change in future monetary policy. We define the component of stock price response that is strictly due to a change in the risk-free rate $r$ and the growth rate of shares demanded by noise traders $\hat{g}$, separately. Then from Equation (5) it follows:

$$
\left.\frac{d P / P}{d u}\right|_{d \pi=d \phi=d g=0}=-\left[\frac{D(1+g)}{P(r+\pi+\phi-g)^{2}}+\frac{\phi\left(1-Q_{t}\right)(1+\hat{g})}{(r+\pi+\phi-\hat{g})^{2}}\right] \frac{d r}{d u}+\left[\frac{\phi\left(1-Q_{t}\right)(1+r+\pi+\phi)}{(r+\pi+\phi-\hat{g})^{2}}\right] \frac{d \hat{g}}{d u}
$$

In general, good economic news indicates improving future economic conditions. Rational investors would expect Federal Reserve to raise short-term interest rates, which leads to an increase

\footnotetext{
${ }^{12}$ For detailed derivation, please refer to the appendix.
} 
in risk-free rate, and it implies that $d r / d u>0$. Therefore, when news surprises are released into the markets, we can expect that the percentage change in the stock prices will be smaller when the portion of shares demanded by smart money decreases. Shiller (1984) shows that the market clears when total shares demanded equals to supplied, such that $Q_{t}+Y_{t} / P_{t}=1$, where $Q_{t}$ is the demand for shares by smart-money investors as a portion of total shares outstanding, and $Y_{t} / P_{t}$ is the total shares demanded by noise traders. When the market clears, a decrease in the total shares demanded by smart money implies an increase in the total shares of noise traders. The percentage change in the stock prices in response to news surprises should be smaller when the total shares demanded by noise traders increase due to a decrease in the shares demanded by smart-money investors.

When market sentiment is high, it indicates that noise traders are trading more actively on pseudo-signals, and they have a higher demand for shares. An increased demand by noise traders can cause a weaker response of the E-mini S\&P 500 to news surprises, and a weak adjustment of price dynamics to such new information. On the other hand, when market sentiment is low, it indicates that noise traders are trading less actively on such pseudo-signals, and it leads to a stronger response of E-mini S\&P 500 to news surprises, and a strong adjustment of price dynamics to such new information around news announcements.

We test the following hypothesis:

Hypothesis I: In the presence of varying investor sentiment related to total shares demanded by noise traders, stock prices response to macroeconomic news surprises become weaker during periods of high sentiment and become stronger during periods of low sentiment.

We then further divide news surprises into positive and negative surprises and test whether we observe same market responses. 


\subsection{Data and Sample Selection}

We use five-minute returns of the E-mini S\&P 500 five minutes before and five minutes after the news announcements. The E-mini S\&P 500 futures trade on GLOBEX electronic trading system. The E-mini futures are very actively traded and considered highly liquid. We examine trades from January 1998 to September 2016, which includes multiple business cycles and investor sentiment shifts. One advantage of using futures data is that some influential macroeconomic news announcements are released around 8:30 am which is before regular stock markets open, and the trading hours of the E-mini S\&P 500 is almost 24 hours, except been closed from 3:15 PM to 3:30 PM and 4:30 PM to 5:00 PM CT, which can well capture market response to news surprises.

To test the impact of overall news surprises on E-mini S\&P 500, we examine 33 scheduled U.S. macroeconomic news announcements. In addition to the macroeconomic announcements examined in Andersen, Bollerslev, Diebold and Vega (2003), we also include ten other announcements that are frequently covered in financial media: ADP employment, building permits, existing home sales, the ISM non-manufacturing index, pending home sales, preliminary and final University of Michigan consumer sentiment index, Chicago Purchasing Manager Index, Empire State Manufacturing Survey, and Philadelphia Fed Business Outlook. Following Andersen, Bollerslev, Diebold and Vega (2003) and Kurov and Stan (2016), the news announcements are categorized as follows: real activity, consumption, investment, government purchases, net exports, prices, and forward looking. Table 1 reports the basic description of the macroeconomic announcements.

\section{[Insert Table 3.1 about here]}

Following Balduzzi, Elton, and Green (2001) and Kurov and Stan (2016), we focus on the news surprises. The news surprises are computed and standardized as the difference between the 
actual and the expected values. Standardized news surprises are used to examine how stock index futures markets are affected from five minutes before to five minutes after macroeconomic news announcements. The standardized announcement surprises are calculated as follows:

$$
S_{i t}=\frac{A_{i t}-F_{i t}}{\sigma_{i}}
$$

where $A_{i t}$ is the announced value for announcement $\mathrm{i}, F_{i t}$ is the expected median value of the Bloomberg forecast for announcement $\mathrm{i}$, and $\sigma_{i}$ is the sample standard deviation of $\left(A_{i t}-F_{i t}\right)$.

A challenge to testing the influence of investor sentiment is that it cannot be directly observed. The proxies for investor sentiment used in this paper are the weekly survey conducted by the American Association of Individual Investors (AAII) and Investor Intelligence. AAII sentiment measure is from a weekly survey of individual investors wherethe responses are classified as bullish, bearish or neutral. The Investor Intelligence sentiment measure represents the outlook of about 150 independent market newsletters where the newsletters are classified as bullish, bearish or correction. Following Fisher and Statman (2006) and Kurov (2008), we compute sentiment index as a ratio of the percentage of bullish investors to the sum of the percentage of bullish and bearish investors. We then define low investor sentiment when it is below its $25^{\text {th }}$ percentile, define high investor sentiment if it is above its $75^{\text {th }}$ percentile, and normal investor sentiment if it is between $25^{\text {th }}$ percentile and $75^{\text {th }}$ percentile.

[Insert Figure 3.1 about here]

Figure 1 plots both sentiment measures for our sample period. The sentiment measures tend to move together. Over the sample period, the correlation between the AAII index and the Investor Intelligence index is 0.443 suggesting that both sentiment indices tend to move in the same direction. 


\subsection{Results}

\subsubsection{Effect of Macroeconomic news surprises on E-mini $S \& P 500$}

We first examine the effect of macroeconomic announcements on the returns of E-mini S\&P 500.

The baseline regression tests how the futures market is affected from 5 minutes before to 5 minutes after macroeconomic announcements. The regression is estimated using ordinary least squares with White (1980) heteroskedasticity consistent covariance matrix. The regression equation is,

$$
R_{t}=a_{1}+\sum_{i=1}^{I} \beta_{i} S_{i t}+\varepsilon_{t}
$$

where $R_{t}$ is the continuously compounded E-mini S\&P 500 return from five minutes before to five minutes after a macroeconomic news release, and $S_{i t}$ is the standardized surprise corresponding to announcement $i$ at time t. $S_{i t}$ equals to 0 if the actual released data of announcement $i$ equals to previously forecasted. The estimation only includes time intervals containing at least one of the news surprises. This model specification also accounts for multiple news announcements that are released at the same time. We estimate regression equation (3.7) for the time period from January 1998 to September 2016 for all 33 announcements. The results are presented in Table 3.2.

[Insert Table 3.2 about here]

The results from Table 3.2 show that news surprises generally have statistically significant effects on stock returns. For example, the stock market responds to GDP news surprises positively i.e. when actual GDP announcement is greater than expected returns on ES grow. Results also show that returns respond to unemployment rate surprises negatively when there is a positive surprise, greater than expected unemployment, returns decline. Higher than expected GDP growth indicates that the overall economy is performing well, which is good news for stocks. On the other hand, a higher than expected unemployment rate sends a signal that economic activity is slowing down, 
which is bad news for stocks. All announcements in the "real activity" category, except the unemployment rate, have positive effects on stock returns.

Moreover, higher than expected increase in new home sales, and factory orders are good news for the overall economy and stocks. Consumer price index (CPI) is an indicator of inflation, is considered bad news if the inflation has increased more than expected and has a negative effect on stock returns. Finally, all of the forward looking macroeconomic indicators have positive and significant effects. For example, the Institute for Supply Management (ISM) manufacturing and nonmanufacturing surveys, closely watched economic indicators, have positive surprise on stock returns. Overall, 20 out of the 33 announcements have statistically significant effects on stock returns. Based on the baseline regression results, we select 20 macroeconomic news announcements that have statistically significant effects on index futures for further investigation.

\subsection{Descriptive Statistics of Market Moving News Announcements}

In the following analysis, we focus on the macroeconomic news surprises that have significant effects on E-mini S\&P 500 returns identified in Section 3.4.1. Our sample includes 2,901 releases of macroeconomic news announcements that have statistically significant effect on index futures returns. In the remaining sections, we have reversed the signs of news surprises for initial unemployment claims and unemployment rate since a higher than expected unemployment figure is actually bad news to financial markets. In Table 3.3, we report the descriptive statistics of the key variables for the full sample period.

\section{[Insert Table 3.3 about here]}

Panel A shows the summary statistics. The continuously compounded returns, $R_{(-5,+5)}$, have a mean of $0.002 \%$, which represent the index futures average response to positive, negative 
surprises and no surprises. The range of these returns is from $-1.617 \%$ to $+2.083 \%$. The mean of news surprises $\left(S_{t}\right)$ is 0.021 , which indicates that news surprises have been positive on average. Moreover, the mean for AAII sentiment index and Investor Intelligence sentiment index are about 0.64 and 0.558 , respectively, which indicates that the average of both sentiment proxies are considered as normal sentiment. The range of the sentiment indices are from 0.218 to 0.809 and from 0.212 to 0.893 , respectively. It suggests that these two measures of investor sentiment are similar in our sample. Panel B shows the Pearson Correlation of the key variables. The correlation between macroeconomic news surprises and market return is 0.3 . However, market return has no contemporaneous correlations with either investor sentiment measures. Furthermore, news surprises are positively correlated with Investor Intelligence and AAII sentiment at 0.054 and 0.065 , respectively.

3.4.3 Effect of Macroeconomic news surprises on E-mini S\&P 500 Conditional on Investor Sentiment

We now examine whether investor sentiment affects the market reaction to macroeconomic news. To look for such evidence, we first graph the cumulative average returns (CARs) in an intraday event window surrounding the news announcements. Following Bernile, Hu, and Tang (2016), we invert the sign of returns for negative news surprises. This allows aggregating CARs for both positive and negative news surprises. Figure 3.2 shows the CARs in the interval from 90 minutes before to 30 minutes after the announcements based on different sentiment levels. Panel A shows the CARs around news announcements based on AAII sentiment index levels, and panel B shows the CARs based on Investor Intelligence sentiment index levels.

[Insert Figure 3.2 about here] 
Both panels of figure 3.2 shows that the cumulative average return around announcements is higher during low sentiment than during high sentiment. As shown above, the difference in CARs coincides with our hypothesis that the response of E-mini S\&P 500 to macroeconomic news surprises becomes weaker during high sentiment and becomes stronger during low sentiment. It provides evidence that noise traders can impact price adjustment process and cause a weak adjustment of price dynamics to such new information. On the other hand, a higher CAR during low sentiment indicates that noise traders are trading less actively on such pseudo-signals, and it leads to a stronger adjustment of price dynamics to such new information around news announcements.

In this section, we form interactive variables and estimate the time-varying response of stock market to macroeconomic news. We begin by running the regression in Equation (3.8) that accounts for simultaneous market-moving news announcements during different sentiment periods.

$$
R_{t}=\alpha_{t}+b_{t} I N V_{t}^{\text {low }}+c_{t} I N V_{t}^{\text {high }}+\sum_{i=1}^{I}\left(d_{i}+e_{i} I N V_{t}^{\text {low }}+f_{i} I N V_{t}^{\text {high }}\right) S_{i t}+\varepsilon_{t}
$$

where $I N V_{t}^{\text {low }}$ is a dummy variable equal to 1 on days when the investor sentiment measure is below the 25 th percentile, $I N V_{t}^{\text {high }}$ equals to one on days when the investor sentiment measure is above the 75 th percentile.

\section{[Insert Table 3.4 about here]}

The results in Table 3.4 show that investor sentiment generally has no significant impact on 10-minutes market returns and the market-moving news surprises are mostly significant during normal sentiment periods. However, the statistical significance of the news surprises drops out largely during low and high sentiment periods. For AAII sentiment index, the impact of

\footnotetext{
13 The regression analysis without independent dummy variables, $R_{t}=\alpha_{t}+\sum_{i=1}^{I}\left(b_{i}+c_{i} I N V_{t}^{\text {low }}+\right.$ $\left.d_{i} I N V_{t}^{\text {high }}\right) S_{i t}+\varepsilon_{t}$, is reported in Appendix C.
} 
unemployment rate and ISM manufacturing and Philadelphia Fed Business Outlook remain significant and positive during low sentiment periods, and the effect of ADP employment, advance retail sales, existing home sales, consumer credit, and ISM manufacturing are significant and negative during high sentiment periods. For Investor Intelligence sentiment index, unemployment news surprises, advance retail sales, factory orders, and few other news surprises have statistically significant and positive effect on futures market returns during low sentiment, and ADP employment and Chicago PMI has significant and negative effect on market returns during high sentiment. Nevertheless, majority of news surprises have positive (negative) impact on market return during low (high) sentiment, although they are not statistically significant. The decrease of statistical significance of these market-moving news announcements can be contributed to small-sample issues. As Table 1 shows that there are only about 200 observations for each individual news announcements from January 1998 to September 2016. To avoid the small-sample problems from simultaneous news release analysis, we follow the procedure proposed by Swanson and Williams (2014). Their procedure assumes the relative magnitudes of the response coefficients $d_{i}$ in Equation (3.8) are constant over time and allows us to estimate the surprises for all announcements in a single estimation.

We begin by running the regression in Equation (3.8) simultaneously for different sentiment periods and saving the estimated coefficients $\widehat{d_{0}}$ of normal sentiment periods. We then use these estimates to compute normalized announcement surprises as $\widehat{d S}_{t}$ for the 20 market-moving macroeconomic announcements. We sum up the normalized surprises for announcements that are released at the same time. The generalized Equation (3.8) becomes the following specification:

$$
\begin{gathered}
R_{t}=\alpha_{t}+b_{t} I N V_{t}^{\text {low }}+c_{t} I N V_{t}^{\text {high }}+d_{t} \widehat{d_{0} S_{t}}+e_{t} \widehat{d_{0} S_{t}} I N V_{t}^{\text {low }}+f_{t} \widehat{d_{0} S_{t}} I N V_{t}^{\text {high }} \\
+u_{t}
\end{gathered}
$$


where $\widehat{b_{0} S_{t}}$ is the normalized news surprises during normal sentiment periods, $\widehat{b_{0} S_{t}} I N V_{t}^{\text {low }}$ is the normalized news surprises during low sentiment periods, and $\widehat{b_{0} S_{t}} I N V_{t}^{\text {high }}$ is the normalized news surprises during high sentiment periods.

\section{[Insert Table 3.5 about here]}

Table 3.5 presents the average responses of E-mini S\&P 500 to normalized macroeconomic news surprises during different investor sentiment periods. The second column shows the results based on AAII sentiment index, and the third column shows that results based on Investor Intelligence sentiment index. The intercept, which captures the E-mini S\&P 500 returns to the incidence of normalized macro news that meet the previous expectations, is statistically insignificant. Moreover, low and high sentiment have insignificant effect on 10 minutes market returns. The coefficient of $S_{t}$, which depicts the average value of E-mini returns to the normalized news surprises when sentiment is normal, is 1 and is statistically significant with a t-statistics of 10.67 and 9.01, respectively. Using the normalization procedure, we can test and make a comparison if market respond to high/low sentiment is lower/higher. The coefficient of the interaction variable, $S_{t} * I N V_{t}^{\text {low }}$, is 0.39 with a tstatistic 2.57 , which shows that the response of the E-mini S\&P 500 to surprises strengthen by about $39 \%$ during low investor sentiment periods measured by AAII sentiment index. Under the Investor Intelligence sentiment measure, the response of the E-mini S\&P 500 to surprises is stronger and strengthen by about $81 \%$ during low investor sentiment periods. The reported coefficient estimate for $S_{t} * I N V_{t}^{\text {high }}$ is -0.547 with a t-statistic of -3.44 when using AAII sentiment index, and it is -0.29 with a t-statistic of -1.86 when using Investor Intelligence sentiment index. The results suggest that the response of E-mini returns to news surprises decrease by about $54.6 \%$ and $29 \%$ during high sentiment periods. 
In general, we can conclude that investor sentiment affect the market reaction to normalized macroeconomic news. Furthermore, it is consistent with our hypothesis that the response of E-mini S\&P 500 to macroeconomic news surprises become weaker during high sentiment and become stronger during low sentiment in the presence of varying investor sentiment related to total shares demanded by noise traders.

3.4.4 Effect of Positive and Negative Macroeconomic news surprises on E-mini S\&P 500 Conditional on Investor Sentiment

In this section, we primarily test and document whether we observe the same market response after dividing the news surprises into positive and native ones. We differentiate the positive news surprises from negative ones and examine them separately. Before proceeding further, we need to address the positive news surprises that actually have negative impact on the market. A negative news surprise from "Initial unemployment claims" and "Unemployment Rate" have actually positive effect on market, thus, we revert the signs of news surprise for these two news announcements.

[Insert Table 3.6 about here]

The results of our positive macroeconomic news surprises are reported in Table 3.6. Consistent with our hypothesis, market responds stronger to positive macroeconomic news surprise during low sentiment period, whereas it responds relatively weaker during high sentiment period. Using AAII sentiment, the prevalent GDP news surprise has a statistically significant coefficient of 0.088 in low sentiment period compared to an insignificant coefficient of -0.01in high sentiment period. Market response to nonfarm employment is about 0.378 during low sentiment period compared to 0.063 during high sentiment period. Similar results are observed for ADP employment, 
existing home sales, ISM manufacturing and non-manufacturing, and various other news surprises. With the separation of positive news surprise from negative news surprise, the findings still hold.

[Insert Table 3.7 about here]

The results of response of E-mini S\&P 500 to negative news surprises are reported in Table 3.7. Similar to the results from Table 3.6, market responds stronger to negative macroeconomic news surprise during low sentiment period, whereas it responds relatively weaker during high sentiment period. For both AAII and Investor Intelligence sentiment measures, majority of the market moving news surprises remain statistically significant after separating the negative news surprises from positive ones. For example, using Investor Intelligence sentiment measure, the initial unemployment claims have a statistically significant coefficient of 0.07 in low sentiment period compared to an insignificant coefficient of 0.035 in high sentiment period. Market response to unemployment rate is about 0.0 .037 during low sentiment period compared to -0.217 during high sentiment period. Market response to news surprise is generally stronger at low sentiment levels compared to the response at high sentiment levels.

\section{[Insert Table 3.8 about here]}

Following the same methodology used in Table 3.5, we present the average responses of E-mini S\&P 500 to positive normalized macroeconomic news surprises conditional on different sentiment levels. Low investor sentiment has significant positive effect on market response. The coefficient of the interaction variable, $S_{t} * I N V_{t}^{\text {low }}$, is -0.238 but insignificant. The response is stronger, about $53.9 \%$, during low investor sentiment periods using Investor Intelligence sentiment measure. The reported coefficient estimate for $S_{t} * I N V_{t}^{\text {high }}$ is -0.56 with a t-statistic of -2.09 when using AAII sentiment index, and it is -0.633 with a t-statistic of -2.22 using Investor Intelligence sentiment index. The average effect of market response to positive normalized news surprise at different sentiment 
levels show that market responds stronger when sentiment is low compared to its response to news surprise when sentiment is high.

[Insert Table 3.9 about here]

Table 3.9 presents the average responses of E-mini S\&P 500 to negative macroeconomic news surprises at different sentiment levels. We observe similar results as in Table 3.8. The coefficient of the interaction variable, $S_{t} * I N V_{t}^{\text {low }}$, is 0.035 with a t-statistic 0.2 , which shows that the response of the E-mini S\&P 500 to surprises is about 3.5\% stronger during low investor sentiment periods measured by AAII sentiment index. The response difference is about $-6.3 \%$, during low investor sentiment periods using Investor Intelligence sentiment measure. The reported coefficient estimate for $S_{t} * I N V_{t}^{\text {high }}$ is $-52.8 \%$ with a t-statistic of -2.23 when using AAII sentiment index, and it is 0.4 with a t-statistic of -2.08 using Investor Intelligence sentiment. The results suggest that market response to news surprises is $52.8 \%$ and $40 \%$ lower during high sentiment periods. Consistent with the results in Table 3.5 and Table 3.8, the average effect of market response to negative news surprise is stronger when sentiment is low, and it is weaker when sentiment is high.

Overall, when separating news surprises into positive and negative surprises, the results support our second hypothesis. We still observe a stronger response of E-mini S\&P 500 during low sentiment periods compared to high sentiment periods. Market responds to new information more efficiently when noise traders place order less actively, which is a proxy by low investor sentiment.

\subsubsection{Robustness Checks}

It is possible that the state of economy may have an impact on the prevailing investor sentiment and affect the results of the regressions. We now add the state of the economy as a control variable in the following model. When the economy is in the state of recession, investor sentiment is likely 
to be low, and when the economy is expanding, investor sentiment is likely to be high. Adding this control variable can provide us the response of E-mini S\&P 500 to news surprises under the prevailing sentiment in a specific state of economy. We use two different measures of the state of the economy: the monthly smoothed U.S. recession probability and the monthly Chicago Fed National Activity Index (CFNAI). The smoothed U.S. recession probability was originally developed in Chauvet (1998) using dynamic-factor Markow-switching (DFMS) model. If the smoothed U.S. recession probability is above $80 \%$, it indicates the start of an economy recession, and if it is below $20 \%$, it is considered a signal of the start of an economy expansion. A zero value of CFNAI indicates that the economy is expanding; positive values indicate above-average growth; and negative values indicate below-average growth. We also consider the possible influence of uncertainty on the market reaction to the news surprises, thus we include daily VIX changes as a control variable. The regression equation is shown as follows:

$$
\begin{gathered}
R_{t}=\alpha_{t}+b_{t} I N V_{t}^{\text {low }}+c_{t} I N V_{t}^{\text {high }}+d_{t} \widehat{b_{0} S_{t}}+e_{t} \widehat{b_{0} S_{t}} I N V_{t}^{\text {low }}+f_{t} \widehat{b_{0} S_{t}} I N V_{t}^{\text {high }}+g_{t} \widehat{b_{0} S_{t}} \text { econ } \\
+u_{t}
\end{gathered}
$$

where econ denotes the control variables for robustness check. The results are shown in Table 3.10.

\section{[Insert Table 3.10 about here]}

When the control variables are added, the results are similar to the ones reported in Table 3.5, and the effects of normalized news surprises under different sentiment levels remain statistically significant. Furthermore, for the AAII sentiment index, the coefficients on the interaction between the CFNAI and news surprises is -0.171 with a t-statistic of -2.12 , and it suggests that the response of E-mini returns to news surprises decrease by about $17.1 \%$ when the National Activity Index shows above-average growth. However, the other coefficients on the interaction between the smoothed U.S. recession probability and news surprises is statistically insignificant, which indicates it has no impact on E-mini S\&P 500 returns. Moreover, a positive change in VIX has significant negative impact on 
market returns, however, the coefficient of the interactive variable of VIX and news surprise has insignificant impact on market response, which indicates it has no impact on market returns around news surprises.

\section{[Insert Table 3.11 about here]}

Table 3.11 presents the results of average effect of investor sentiment on market response to positive normalized news surprises. Low investor sentiment has significant effect on market response. The effects of normalized news surprises under different sentiment levels remain largely significant. Furthermore, for both AAII and Investor Intelligence sentiment measures, the coefficients of interactive variables of the smoothed U.S. recession probability and CFNAI with news surprises are statistically significant, and it suggests that the state of economy has significant effect on the response of E-mini returns to positive news surprises. It may suggest that investors in general discount positive news surprises when economy is in contraction. Moreover, the VIX has no significant effect on market response. Nevertheless, the response is stronger during low sentiment compared to the response during high sentiment, which is consistent with our hypothesis after controlling for the state of economy.

\section{[Insert Table 3.12 about here]}

Table 3.12 presents the results of average effect of investor sentiment on market response to negative normalized news surprises. When the control variables are added, the results are similar to the ones reported in Table 3.10, and the effects of normalized news surprises under different sentiment levels remain statistically significant. Furthermore, for both sentiment measures, the interactive variables of state of economy and news surprises generally have insignificant effect on market response. Moreover, compared to the effect during normal and high sentiment periods, we 
can observe that the average effect of market response to news surprises is weaker during high investor sentiment periods compared to the response during high sentiment periods.

Overall, our results are consistent with the view that investor sentiment affect how E-mini S\&P 500 respond to influential macroeconomic news surprises, and the state of economy has little effect on market returns to news surprises.

\subsection{Conclusion}

Our paper investigates the effect of investor sentiment on market reaction to news announcements. We extend the investor sentiment argument to the setting of macroeconomic news surprises from January 1998 to September 2016, and examine 33 scheduled U.S. macroeconomic news announcements that are frequently covered in the financial media. We document that varying investor sentiment levels have different impact on the market reaction to macroeconomic news surprises. Consistent with our hypothesis, the response of E-mini S\&P 500 to macroeconomic news surprises is stronger during low sentiment than during high sentiment in the presence of varying investor sentiment. When we examine positive news surprises and negative news surprises separately and control for state of economy, the results still hold. Our results provide evidence that market reacts to news surprises stronger, as noise traders place trade less actively on pseudo-signals when sentiment is low. On the other hand, more active noise trading activities during high sentiment impede price adjustment dynamics and cause weaker market responses to news surprises. 
Table 3.1. U.S. Macroeconomic News Announcements

\begin{tabular}{|c|c|c|c|c|}
\hline Announcement & Source $^{1}$ & Obs. $^{2}$ & Frequency & Announcement Time ${ }^{3}$ \\
\hline \multicolumn{5}{|l|}{ Real Activity } \\
\hline GDP & BEA & 211 & monthly & 8:30 AM \\
\hline Initial unemployment claims & ETA & 973 & weekly & 8:30 AM \\
\hline Nonfarm employment & BLS & 225 & monthly & 8:30 AM \\
\hline Unemployment Rate & BLS & 224 & monthly & 8:30 AM \\
\hline ADP employment & ADP/MALLC & 121 & monthly & 8:15 AM \\
\hline Advance retail sales & $\mathrm{BC}$ & 184 & monthly & 8:30 AM \\
\hline Existing home sales & NAR & 127 & monthly & 10:00 AM \\
\hline Industrial production & FRB & 224 & monthly & 9:15 AM \\
\hline Capacity utilization & FRB & 223 & monthly & 9:15 AM \\
\hline Personal income & BEA & 224 & monthly & 8:30 AM \\
\hline Consumer Credit & FRB & 224 & monthly & 3:00 PM \\
\hline \multicolumn{5}{|l|}{ Consumption } \\
\hline New home sales & $\mathrm{BC}$ & 223 & monthly & 10:00 AM \\
\hline Personal Spending & BEA & 223 & monthly & 8:30 AM \\
\hline \multicolumn{5}{|l|}{ Investment } \\
\hline Durable goods orders & $\mathrm{BC}$ & 230 & monthly & 8:30 AM \\
\hline Construction spending & $\mathrm{BC}$ & 157 & monthly & 10:00 AM \\
\hline Factory orders & $\mathrm{BC}$ & 224 & monthly & 10:00 AM \\
\hline Wholesale inventories & $\mathrm{BC}$ & 221 & monthly & 10:00 AM \\
\hline \multicolumn{5}{|l|}{ Government Purchases } \\
\hline Government budget & USDT & 223 & monthly & 2:00 PM \\
\hline \multicolumn{5}{|l|}{ Net Exports } \\
\hline Trade balance & BEA & 225 & monthly & 8:30 AM \\
\hline \multicolumn{5}{|l|}{ Prices } \\
\hline Consumer price index & BLS & 225 & monthly & 8:30 AM \\
\hline Producer price index & BLS & 192 & monthly & 8:30 AM \\
\hline \multicolumn{5}{|l|}{ Forward Looking } \\
\hline ISM Manufacturing & ISM & 225 & monthly & 10:00 AM \\
\hline ISM Non-manufacturing & ISM & 104 & monthly & 10:00 AM \\
\hline Consumer confidence & $\mathrm{CB}$ & 224 & monthly & 10:00 AM \\
\hline U. of Michigan Conf-Prelim & TRUM & 220 & monthly & 9:55 AM \\
\hline U. of Michigan Conf-Final & TRUM & 221 & monthly & 9:55 AM \\
\hline Housing starts & $\mathrm{BC}$ & 220 & monthly & 8:30 AM \\
\hline Pending home sales & NAR & 136 & monthly & 10:00 AM \\
\hline Building permits & $\mathrm{BC}$ & 168 & monthly & 8:30 AM \\
\hline Empire Manufacturing & FRBNY & 167 & monthly & 8:30 AM \\
\hline Philadelphia Fed Business Outlook & FRBP & 225 & monthly & 10:00 AM \\
\hline Chicago Purchasing Manager Index & NAPM & 224 & monthly & $9: 45 \mathrm{AM}$ \\
\hline Index of leading indicators & $\mathrm{CB}$ & 224 & monthly & 10:00 AM \\
\hline
\end{tabular}

${ }^{1}$ Sources: Bureau of Economic Analysis (BEA), Bureau of the Census (BC), Federal Reserve Board (FRB), Bureau of Labor Statistics (BLS), U.S. Department of Treasury (USDT), Federal Reserve Bank of New York (FRBNY), Conference Board (CB), Institute for Supply Management (ISM), Federal Reserve Bank of Philadelphia (FRBP), National Association of Purchasing Management (NAPM).

${ }^{2}$ The total number of observations in the sample

${ }^{3}$ All announcements are in U.S. Eastern Time 
Table 3.2. Market Response to Macroeconomic News Surprises

\begin{tabular}{|c|c|c|}
\hline \multirow[b]{2}{*}{ Announcement } & \multicolumn{2}{|c|}{ E-mini S\&P 500} \\
\hline & $\beta$ & $\mathrm{p}$ value \\
\hline \multicolumn{3}{|l|}{ Real Activity } \\
\hline GDP advance final preliminary & $0.142 * * *$ & $<.0001$ \\
\hline Initial unemployment claims & $-0.051 * * *$ & $<.0001$ \\
\hline Nonfarm employment & $0.136 * *$ & 0.038 \\
\hline Unemployment Rate & $-0.118 * *$ & 0.011 \\
\hline ADP employment & $0.171 * * *$ & $<.0001$ \\
\hline Advance retail sales & $0.106 * * *$ & 0.002 \\
\hline Existing home sales & $0.085^{* * *}$ & $<.0001$ \\
\hline Industrial production & $0.054 * *$ & 0.042 \\
\hline Capacity utilization & -0.01 & 0.609 \\
\hline Personal income & -0.019 & 0.208 \\
\hline Consumer Credit & $0.025 * *$ & 0.048 \\
\hline \multicolumn{3}{|l|}{ Consumption } \\
\hline New home sales & $0.036 * *$ & 0.013 \\
\hline Personal Spending & -0.007 & 0.603 \\
\hline \multicolumn{3}{|l|}{ Investment } \\
\hline Durable goods orders & 0.038 & 0.129 \\
\hline Construction spending & 0.029 & 0.187 \\
\hline Factory orders & $0.043 * * *$ & 0.004 \\
\hline Wholesale inventories & -0.008 & 0.547 \\
\hline \multicolumn{3}{|l|}{ Government Purchases } \\
\hline Government budget & 0.024 & 0.443 \\
\hline \multicolumn{3}{|l|}{ Net Exports } \\
\hline Trade balance & 0.023 & 0.218 \\
\hline \multicolumn{3}{|l|}{ Prices } \\
\hline Consumer price index & $-0.071 * * *$ & 0.003 \\
\hline Producer price index & -0.016 & 0.408 \\
\hline \multicolumn{3}{|l|}{ Forward Looking } \\
\hline ISM Manufacturing & $0.129 * * *$ & $<.0001$ \\
\hline ISM Non-manufacturing & $0.078 * * *$ & 0.005 \\
\hline Consumer confidence & $0.147 * * *$ & $<.0001$ \\
\hline U. of Michigan Conf-Prelim & $0.05^{* *}$ & 0.018 \\
\hline U. of Michigan Conf-Final & 0.006 & 0.76 \\
\hline Housing starts & 0.012 & 0.354 \\
\hline Pending home sales & $0.095 * * *$ & $<.0001$ \\
\hline Building permits & 0.022 & 0.113 \\
\hline Empire Manufacturing & $0.066 * * *$ & $<.0001$ \\
\hline Philadelphia Fed Business Outlook & $0.101 * * *$ & $<.0001$ \\
\hline Chicago Purchasing Manager Index & $0.104 * * *$ & $<.0001$ \\
\hline Index of leading indicators & 0.027 & 0.163 \\
\hline Observations & 3503 & \\
\hline$R^{2}$ & $13.42 \%$ & \\
\hline
\end{tabular}

The table reports estimates for the following model: $R_{t}=a_{1}+\sum_{i=1}^{I} \beta_{i} N e w s_{i t}+\varepsilon_{t}$, where $R_{t}$ is the continuously compounded return of the $\mathrm{S} \& \mathrm{P} 500$ futures. $R_{t}$ is from five minutes before to five minutes after a macroeconomic announcement. News $i t$ is the standardized surprise for the announcement of type $i$. The last column of the table shows the corresponding $p$-values. The null hypothesis is that the given announcement has no significant effect on E-mini S\&P 500 returns. The sample period is from January 1998 to September 2016 . * **, and *** denote significance at $10 \%, 5 \%$, and $1 \%$ levels, respectively. 
Table 3.3. Summary Statistics of Market Moving News Surprises

\begin{tabular}{|c|c|c|c|c|}
\hline \multicolumn{5}{|c|}{ Panel A. Descriptive Statistics } \\
\hline Variable & Mean & S.D. & Minimum & Maximum \\
\hline$R_{t}$ & $\overline{0.002}$ & 0.249 & -1.617 & 2.083 \\
\hline$S_{t}$ & 0.021 & 1.000 & -4.491 & 7.172 \\
\hline AAII Sentiment & 0.640 & 0.097 & 0.218 & 0.809 \\
\hline Investor Intelligence & 0.558 & 0.123 & 0.212 & 0.893 \\
\hline Num. of Obs. & 2901 & & & \\
\hline \multicolumn{5}{|l|}{ Panel B. Correlations } \\
\hline & $\overline{R_{t}}$ & $\overline{S_{t}}$ & $\begin{array}{c}\text { Investor } \\
\text { Intelligence }\end{array}$ & $\begin{array}{c}\text { AAII } \\
\text { Sentiment }\end{array}$ \\
\hline$R_{t}$ & 1 & & & \\
\hline$S_{t}$ & $0.3 * * *$ & & & \\
\hline Investor Intelligence & -0.017 & $0.054 * * *$ & & \\
\hline AAII Sentiment & 0.015 & $0.065^{* * *}$ & $0.443 * * *$ & 1 \\
\hline
\end{tabular}

This table reports the summary statistics for the various variables in our sample. Our sample includes 2,901 macroeconomic news announcements that have statistically significant effect on index futures returns from January 1998 to September 2016. The summary statistics for the overall sample period are reported in Panel A. The Pearson correlation is reported in Panel B. 
Table 3.4. Market Response to Macroeconomic News Surprises Conditional on Investor Sentiment

\begin{tabular}{|c|c|c|c|c|c|c|}
\hline \multicolumn{4}{|c|}{ AAII Sentiment Index } & \multicolumn{3}{|c|}{ Investor Intelligence Sentiment Index } \\
\hline Announcement & Normal & Low & High & Normal & Low & High \\
\hline Intercept & 0.0008 & 0.003 & 0.005 & -0.002 & $0.022 *$ & 0.0004 \\
\hline GDP advance final preliminary & $0.149 * * *$ & -0.023 & -0.098 & 0.071 & 0.092 & 0.028 \\
\hline Initial unemployment claims & $0.061 * * *$ & -0.006 & -0.025 & $0.031 * *$ & $0.068 * *$ & $0.032 *$ \\
\hline Nonfarm employment & 0.108 & 0.137 & -0.025 & 0.056 & 0.126 & $0.188^{*}$ \\
\hline Unemployment Rate & -0.016 & $0.254 * * *$ & 0.041 & 0.053 & $0.177 *$ & 0.040 \\
\hline ADP employment & $0.174 * * *$ & -0.035 & $-0.089 * *$ & $0.162 * *$ & 0.023 & $-0.14 *$ \\
\hline Advance retail sales & $0.086^{* *}$ & 0.034 & $0.108 *$ & $0.079 * *$ & $0.109 * *$ & 0.004 \\
\hline Existing home sales & $0.061 * * *$ & 0.078 & $-0.065^{* *}$ & $0.052 * *$ & 0.109 & 0.031 \\
\hline Industrial production & $0.028 * *$ & 0.051 & -0.014 & 0.022 & 0.054 & 0.01 \\
\hline Consumer Credit & $0.044 *$ & -0.004 & $-0.059 * *$ & 0.018 & 0.055 & -0.023 \\
\hline New home sales & $0.045^{* *}$ & 0.016 & -0.036 & $0.040 * *$ & 0.054 & -0.036 \\
\hline Factory orders & $0.034 *$ & 0.042 & -0.002 & 0.004 & $0.111 * * *$ & 0.018 \\
\hline Consumer price index & $-0.066^{*}$ & -0.044 & 0.012 & $-0.073 * * *$ & 0.01 & -0.036 \\
\hline ISM Manufacturing & $0.112 * * *$ & $0.105 *$ & $-0.098 *$ & $0.107 * * *$ & 0.099 & -0.044 \\
\hline ISM Non-manufacturing & $0.060 * *$ & 0.046 & -0.038 & $0.047 *$ & 0.081 & 0.03 \\
\hline Consumer confidence & $0.159 * * *$ & 0.017 & -0.071 & $0.145^{* * *}$ & 0.048 & -0.054 \\
\hline U. of Michigan Conf-Prelim & 0.044 & -0.018 & $-0.086^{*}$ & 0.035 & -0.002 & -0.042 \\
\hline Pending home sales & $0.076 * * *$ & 0.041 & -0.023 & $0.073 * * *$ & 0.100 & -0.039 \\
\hline Empire Manufacturing & $0.064 * * *$ & 0.041 & 0.001 & $0.056 * *$ & 0.040 & 0.031 \\
\hline Philadelphia Fed Business Outlook & $0.093 * * *$ & $0.08 *$ & -0.066 & $0.066 * *$ & $0.114^{* *}$ & -0.004 \\
\hline Chicago Purchasing Manager Index & $0.116^{* * *}$ & 0.026 & -0.059 & $0.11 * * *$ & 0.097 & $-0.068^{*}$ \\
\hline p-value of Wald Test & & 0.2515 & 0.009 & & 0.0005 & 0.1354 \\
\hline$R^{2}$ & $16.61 \%$ & & & $17.05 \%$ & & \\
\hline $\mathrm{N}$ & 29066 & & & 2901 & & \\
\hline
\end{tabular}


Table 3.5. Average Effect of Investor Sentiment on Market Response to Macroeconomic News

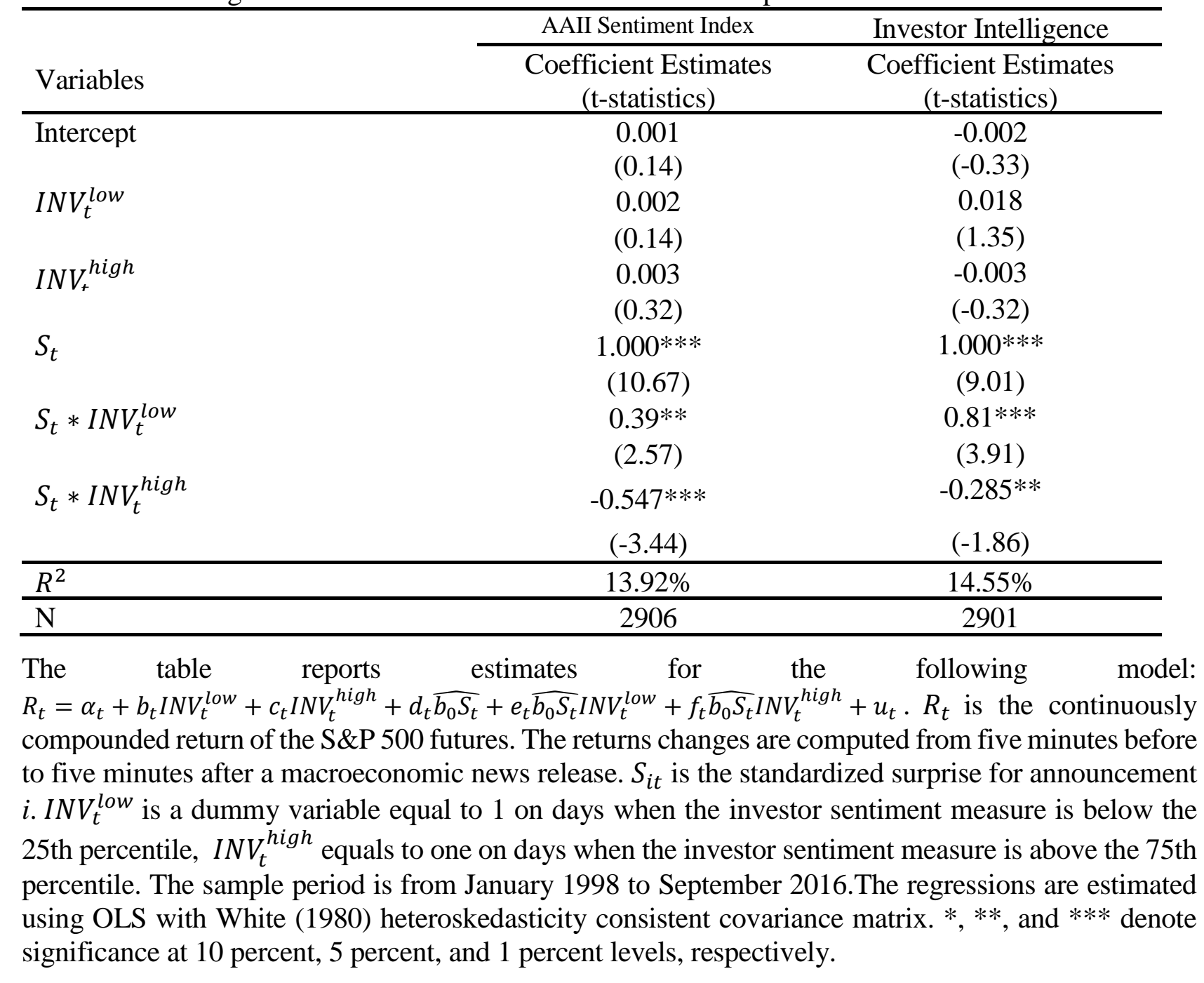


Table 3.6. Market Response to Positive Macroeconomic News Surprises Conditional on Investor Sentiment

\begin{tabular}{|c|c|c|c|c|c|c|}
\hline \multirow[b]{2}{*}{ Announcement } & \multicolumn{3}{|c|}{ AAII Sentiment Index } & \multicolumn{3}{|c|}{ Investor Intelligence Sentiment Index } \\
\hline & Normal & Low & High & Normal & Low & High \\
\hline Intercept & $0.031 * * *$ & -0.017 & -0.007 & $0.022 *$ & 0.029 & -0.008 \\
\hline GDP advance final preliminary & $0.11 * * *$ & $0.088 * *$ & -0.01 & -0.014 & $0.184 * * *$ & $0.13^{* *}$ \\
\hline Initial unemployment claims & $0.029 * *$ & 0.018 & -0.016 & 0.017 & 0.032 & 0.015 \\
\hline Nonfarm employment & 0.15 & $0.378^{*}$ & 0.063 & $0.203 * *$ & $0.061 * *$ & -0.068 \\
\hline Unemployment Rate & -0.06 & 0.164 & 0.051 & 0.006 & 0.152 & -0.068 \\
\hline ADP employment & $0.14 * *$ & -0.021 & -0.118 & 0.052 & $0.139 * *$ & $-0.088 *$ \\
\hline Advance retail sales & $0.04 * *$ & $0.085^{*}$ & $0.085^{*}$ & $0.054 * *$ & $0.083^{* *}$ & -0.023 \\
\hline Existing home sales & 0.04 & 0.156 & $-0.097 * *$ & -0.035 & $0.299 * * *$ & $0.138 *$ \\
\hline Industrial production & -0.01 & $0.106^{* *}$ & -0.021 & 0.007 & 0.04 & 0.002 \\
\hline Consumer Credit & 0.012 & -0.029 & -0.042 & -0.009 & 0.013 & -0.031 \\
\hline New home sales & $0.05^{*}$ & -0.018 & $-0.055^{*}$ & 0.012 & 0.091 & -0.007 \\
\hline Factory orders & -0.01 & $0.112 *$ & 0.027 & 0.003 & 0.074 & 0.001 \\
\hline Consumer price index & $-0.16 * * *$ & 0.112 & 0.092 & -0.065 & $-0.121^{*}$ & 0.007 \\
\hline ISM Manufacturing & 0.07 & $0.181 * *$ & -0.040 & $0.091 * *$ & 0.14 & -0.081 \\
\hline ISM Non-manufacturing & -0.04 & $0.159 * *$ & 0.043 & -0.001 & 0.068 & -0.022 \\
\hline Consumer confidence & -0.01 & $0.177 * * *$ & $0.09 *$ & $0.097 * *$ & -0.021 & -0.059 \\
\hline U. of Michigan Conf-Prelim & -0.02 & -0.044 & -0.066 & -0.048 & -0.034 & -0.001 \\
\hline Pending home sales & 0.06 & 0.06 & 0.041 & 0.049 & 0.161 & 0.016 \\
\hline Empire Manufacturing & $0.05 * * *$ & 0.086 & 0.011 & $0.049 * *$ & -0.016 & 0.054 \\
\hline Philadelphia Fed Business Outlook & 0.03 & 0.073 & -0.014 & 0.019 & 0.042 & 0.033 \\
\hline Chicago Purchasing Manager Index & $0.103 * * *$ & -0.064 & -0.068 & $0.068^{* * *}$ & 0.073 & $-0.06^{*}$ \\
\hline p-value of Wald Test & & 0.0007 & 0.0577 & & 0.0066 & 0.1497 \\
\hline$R^{2}$ & $9.12 \%$ & & & $9.65 \%$ & & \\
\hline $\mathrm{N}$ & 1935 & & & 1931 & & \\
\hline
\end{tabular}

The table reports estimates for the following model: $R_{t}=\alpha_{t}+b_{t} I N V_{t}^{\text {low }}+c_{t} I N V_{t}^{\text {high }}+\sum_{i=1}^{I}\left(d_{i}+e_{i} I N V_{t}^{\text {low }}+f_{i} I N V_{t}^{\text {high }}\right) S_{i t}+\varepsilon_{t}$, where $R_{t}$ is the continuously compounded return of the S\&P 500 futures. $R_{t}$ is from five minutes before to five minutes after a macroeconomic announcement. $S_{i t}$ is the standardized positive surprise for the news announcement $i . I N V_{t}^{\text {low }}$ is a dummy variable equal to 1 on days when the investor sentiment measure is below the 25 th percentile, $I N V_{t}^{\text {high }}$ equals to one on days when the investor sentiment measure is above the 75 th percentile, and $I N V_{t}^{\text {normal }}$ equals to one on days when the investor sentiment is between $25^{\text {th }}$ and $75^{\text {th }}$ percentile. The table also shows the p-values of the Wald joint significance test with the null hypothesis that no significant $e_{i}$ or $f_{i}$. The sample period is from January 1998 to September 2016. *,**, and *** denote significance at $10 \%, 5 \%$, and $1 \%$ levels, respectively. 
Table 3.7. Market Response to Negative Macroeconomic News Surprises Conditional on Investor Sentiment

\begin{tabular}{|c|c|c|c|c|c|c|}
\hline & & \multicolumn{3}{|c|}{ AAII Sentiment Index } & \multicolumn{2}{|c|}{ Investor Intelligence Sentiment Index } \\
\hline Announcement & Normal & Low & High & Normal & Low & High \\
\hline Intercept & $0.027 * *$ & -0.005 & 0.011 & $0.039 * * *$ & -0.027 & -0.013 \\
\hline GDP advance final preliminary & $0.112 * * *$ & 0.01 & 0.066 & $0.154 * * *$ & -0.004 & -0.065 \\
\hline Initial unemployment claims & $0.082 * * *$ & 0.0001 & -0.029 & $0.049 * *$ & $0.070 * *$ & 0.035 \\
\hline Nonfarm employment & $0.205 * *$ & -0.009 & -0.115 & 0.075 & 0.106 & $0.214 * *$ \\
\hline Unemployment Rate & 0.012 & 0.176 & -0.116 & 0.090 & 0.037 & -0.217 \\
\hline ADP employment & $0.135^{* * *}$ & $0.125^{*}$ & $0.238 * *$ & $0.275^{* * *}$ & $-0.093 * *$ & $-0.218 * * *$ \\
\hline Advance retail sales & $0.179 * * *$ & -0.035 & 0.062 & $0.230 * * *$ & -0.055 & -0.118 \\
\hline Existing home sales & $0.087 * * *$ & 0.019 & -0.004 & $0.124 * * *$ & -0.027 & $-0.093^{*}$ \\
\hline Industrial production & $0.062 * * *$ & -0.02 & 0.017 & $0.060 * * *$ & -0.005 & -0.008 \\
\hline Consumer Credit & $0.065^{* * *}$ & 0.039 & -0.041 & $0.075^{* * *}$ & 0.021 & -0.039 \\
\hline New home sales & 0.036 & 0.076 & 0.038 & $0.071 * * *$ & -0.027 & -0.053 \\
\hline Factory orders & $0.054 * *$ & 0.004 & 0.013 & 0.010 & $0.085^{* *}$ & 0.037 \\
\hline Consumer price index & -0.021 & $-0.148^{*}$ & 0.036 & -0.013 & -0.073 & -0.030 \\
\hline ISM Manufacturing & $0.156^{* * *}$ & 0.035 & $-0.183^{*}$ & $0.140 * *$ & 0.023 & -0.005 \\
\hline ISM Non-manufacturing & $0.141 * * *$ & -0.039 & 0.119 & $0.157 * *$ & -0.057 & -0.017 \\
\hline Consumer confidence & $0.273 * * *$ & -0.087 & $-0.163^{*}$ & $0.213 * * *$ & 0.024 & -0.055 \\
\hline U. of Michigan Conf-Prelim & $0.079 *$ & 0.025 & -0.066 & $0.094 * * *$ & -0.016 & -0.058 \\
\hline Pending home sales & $0.060 * *$ & 0.035 & -0.048 & $0.079 * * *$ & 0.044 & $-0.067 * *$ \\
\hline Empire Manufacturing & $0.072 * * *$ & 0.040 & 0.017 & $0.079 * * *$ & 0.020 & 0.008 \\
\hline Philadelphia Fed Business Outlook & $0.13 * *$ & 0.076 & -0.068 & $0.105 * * *$ & 0.105 & -0.027 \\
\hline Chicago Purchasing Manager Index & $0.105^{*}$ & $0.189 *$ & -0.061 & $0.153 * * *$ & 0.026 & -0.034 \\
\hline $\begin{array}{l}p \text {-value of Wald Test } \\
R^{2}\end{array}$ & & 0.3223 & 0.1114 & & 0.271 & $<0.0001$ \\
\hline$R^{2}$ & $17.63 \%$ & & & $16.9 \%$ & & \\
\hline $\mathrm{N}$ & 1742 & & & 1740 & & \\
\hline
\end{tabular}

The table reports estimates for the following model: $R_{t}=\alpha_{t}+b_{t} I N V_{t}^{\text {low }}+c_{t} I N V_{t}^{\text {high }}+\sum_{i=1}^{I}\left(d_{i}+e_{i} I N V_{t}^{\text {low }}+f_{i} I N V_{t}^{\text {high }}\right) S_{i t}+\varepsilon_{t}$, where $R_{t}$ is the continuously compounded return of the S\&P 500 futures. $R_{t}$ is from five minutes before to five minutes after a macroeconomic announcement. $S_{i t}$ is the standardized negative surprise for the news announcement $i . I N V_{t}^{\text {low }}$ is a dummy variable equal to 1 on days when the investor sentiment measure is below the 25 th percentile, $I N V_{t}^{\text {high }}$ equals to one on days when the investor sentiment measure is above the 75 th percentile, and $I N V_{t}^{\text {normal }}$ equals to one on days when the investor sentiment is between $25^{\text {th }}$ and $75^{\text {th }}$ percentile. The table also shows the p-values of the Wald joint significance test with the null hypothesis that no significant $e_{i}$ or $f_{i}$. The sample period is from January 1998 to September 2016. *,**, and *** denote significance at $10 \%, 5 \%$, and $1 \%$ levels, respectively. 
Table 3.8. Average Effect of Investor Sentiment on Market Response to $\underline{\text { Positive }}$ Surprises

\begin{tabular}{lcc}
\hline Variables & AAII Sentiment Index & Investor Intelligence \\
\hline & Coefficient Estimates & Coefficient Estimates \\
$(\mathrm{t}-$-statistics $)$ & $0.022^{* *}$ \\
\hline Intercept & $0.031^{* * *}$ & $(2.54)$ \\
& $(4.27)$ & $0.065^{* * *}$ \\
$I N V_{t}^{\text {low }}$ & $0.045^{* * *}$ & $(3.55)$ \\
& $(2.83)$ & 0.0001 \\
$I N V_{t}^{\text {high }}$ & -0.008 & $(0.01)$ \\
& $(-0.53)$ & $1.00^{* * *}$ \\
$S_{t}$ & $1.00^{* * *}$ & $(4.66)$ \\
& $(5.88)$ & 0.539 \\
$S_{t} * I N V_{t}^{\text {low }}$ & -0.238 & $(1.2)$ \\
& $(-0.76)$ & $-0.633^{* *}$ \\
$S_{t} * I N V_{t}^{\text {high }}$ & $-0.56^{* *}$ & $(-2.22)$ \\
& $(-2.09)$ & $6.26 \%$ \\
\hline$R^{2}$ & $4.00 \%$ & 1931 \\
\hline $\mathrm{N}$ & 1935 & \\
\hline
\end{tabular}

The table reports estimates for the following model: $R_{t}=\alpha_{t}+b_{t} I N V_{t}^{\text {low }}+c_{t} I N V_{t}^{\text {high }}+d_{t} \overline{b_{0} S_{t}}+$ $e_{t} \widehat{b_{0} S_{t}} I N V_{t}^{\text {low }}+f_{t} \widehat{b_{0} S_{t}} I N V_{t}^{\text {high }}+u_{t} . R_{t}$ is the continuously compounded return of the S\&P 500 futures. The returns changes are computed from five minutes before to five minutes after a macroeconomic news release. $S_{i t}$ is the standardized positive surprise for announcement $i . I N V_{t}^{\text {low }}$ is a dummy variable equal to 1 on days when the investor sentiment measure is below the 25 th percentile, $I N V_{t}^{\text {high }}$ equals to one on days when the investor sentiment measure is above the 75th percentile. The sample period is from January 1998 to September 2016.The regressions are estimated using OLS with White (1980) heteroskedasticity consistent covariance matrix. *, **, and *** denote significance at 10 percent, 5 percent, and 1 percent levels, respectively. 
Table 3.9. Average Effect of Investor Sentiment on Market Response to Negative Surprises

\begin{tabular}{lcc}
\hline Variables & AAII Sentiment Index & $\begin{array}{c}\text { Investor Intelligence } \\
\text { Sentiment Index }\end{array}$ \\
\hline & Coefficient Estimates & $\begin{array}{c}\text { Coefficient Estimates } \\
(\mathrm{t} \text {-statistics })\end{array}$ \\
\hline Intercept & $0.027 * * *$ & $0.039^{* * *}$ \\
& $(2.7)$ & $(4.04)$ \\
$I N V_{t}^{\text {low }}$ & -0.02 & $-0.059 * * *$ \\
& $(-1.07)$ & $(-2.88)$ \\
$I N V_{t}^{\text {high }}$ & 0.0002 & $-0.027^{*}$ \\
$S_{t}$ & $(0.01)$ & $(-1.8)$ \\
& $1.00^{* * *}$ & $1.00^{* * *}$ \\
$S_{t} * I N V_{t}^{\text {low }}$ & $(8.55)$ & $(7.84)$ \\
& 0.035 & -0.063 \\
$S_{t} * I N V_{t}^{\text {high }}$ & $(0.2)$ & $(-0.34)$ \\
& $-0.528^{* *}$ & $-0.40 * *$ \\
$R^{2}$ & $(-2.23)$ & $(-2.08)$ \\
\hline $\mathrm{N}$ & $14.33 \%$ & $12.93 \%$ \\
\hline
\end{tabular}

The table reports estimates for the following model: $R_{t}=\alpha_{t}+b_{t} I N V_{t}^{\text {low }}+c_{t} I N V_{t}^{\text {high }}+d_{t} \overline{b_{0} S_{t}}+$ $e_{t} \widehat{b_{0} S_{t}} I N V_{t}^{\text {low }}+f_{t} \widehat{b_{0} S_{t}} I N V_{t}^{\text {high }}+u_{t} . R_{t}$ is the continuously compounded return of the S\&P 500 futures. The returns changes are computed from five minutes before to five minutes after a macroeconomic news release. $S_{i t}$ is the standardized negative surprise for announcement $i . I N V_{t}^{\text {low }}$ is a dummy variable equal to 1 on days when the investor sentiment measure is below the 25 th percentile, IN $V_{t}^{\text {high }}$ equals to one on days when the investor sentiment measure is above the 75th percentile. The sample period is from January 1998 to September 2016.The regressions are estimated using OLS with White (1980) heteroskedasticity consistent covariance matrix. *, **, and *** denote significance at 10 percent, 5 percent, and 1 percent levels, respectively. 
Table 3.10. Average Effect of Investor Sentiment on Market Response to Macroeconomic News Controlling for State of Economy

\begin{tabular}{|c|c|c|c|c|c|c|}
\hline \multirow[b]{2}{*}{ Variables } & \multicolumn{3}{|c|}{ AAII Sentiment Index } & \multicolumn{3}{|c|}{ Investor Intelligence Sentiment Index } \\
\hline & $\begin{array}{l}\text { Coefficients } \\
\text { (t-statistics) }\end{array}$ & $\begin{array}{l}\text { Coefficients } \\
\text { (t-statistics) }\end{array}$ & $\begin{array}{c}\text { Coefficients } \\
\text { (t-statistics) }\end{array}$ & $\begin{array}{c}\text { Coefficients } \\
\text { (t-statistics) }\end{array}$ & $\begin{array}{l}\text { Coefficients } \\
\text { (t-statistics) }\end{array}$ & $\begin{array}{c}\text { Coefficients } \\
\text { (t-statistics) }\end{array}$ \\
\hline \multirow[t]{2}{*}{ Intercept } & -0.002 & -0.001 & 0.0004 & -0.005 & -0.003 & -0.003 \\
\hline & $(-0.38)$ & $(-0.15)$ & $(0.07)$ & $(-0.81)$ & $(-0.43)$ & $(-0.56)$ \\
\hline \multirow[t]{2}{*}{$I N V_{t}^{\text {low }}$} & 0.0002 & -0.002 & 0.001 & 0.015 & 0.012 & 0.017 \\
\hline & $(0.02)$ & $(-0.2)$ & $(0.12)$ & $(1.15)$ & $(0.9)$ & $(1.32)$ \\
\hline \multirow{2}{*}{$I N V_{t}^{h i g h}$} & 0.004 & 0.006 & 0.002 & 0.0003 & -0.001 & -0.0004 \\
\hline & $(0.72)$ & $(0.56)$ & $(0.15)$ & $(0.03)$ & $(-0.18)$ & $(-0.05)$ \\
\hline \multirow[t]{2}{*}{ ECON } & 0.012 & & & 0.012 & & \\
\hline & $(1.12)$ & & & $(1.09)$ & & \\
\hline \multirow[t]{2}{*}{$C F N A I$} & & -0.01 & & & -0.007 & \\
\hline & & $(-1.33)$ & & & $(-0.85)$ & \\
\hline \multirow[t]{2}{*}{$\Delta V I X$} & & & $-0.004 * * *$ & & & $-0.004 * * *$ \\
\hline & & & $(-5.56)$ & & & $(-5.36)$ \\
\hline \multirow[t]{2}{*}{$S_{t}$} & $0.93 * * *$ & $0.915^{* * *} *$ & $1.00 * * *$ & $1.00 * * *$ & $0.99 * * *$ & $1.00 * * *$ \\
\hline & $(9.76)$ & $(9.86)$ & $(10.46)$ & $(7.47)$ & $(8.71)$ & $(9.16)$ \\
\hline \multirow[t]{2}{*}{$S_{t} * I N V_{t}^{\text {low }}$} & $0.356^{* *}$ & $0.342 * *$ & $0.378 * * *$ & $0.80 * * *$ & $0.669 * * *$ & $0.769 * * *$ \\
\hline & $(2.26)$ & $(2.15)$ & $(2.46)$ & $(3.79)$ & $(2.83)$ & $(3.66)$ \\
\hline \multirow[t]{2}{*}{$S_{t} * I N V_{t}^{h i g h}$} & $-0.54 * * *$ & $-0.463 * * *$ & $-0.54^{*}$ & $-0.29 *$ & $-0.26^{*}$ & $-0.30 *$ \\
\hline & $(-3.4)$ & $(-2.92)$ & $(-3.36)$ & $(-1.75)$ & $(-1.65)$ & $(-1.95)$ \\
\hline \multirow[t]{2}{*}{$S_{t} *$ Econ } & 0.217 & & & 0.02 & & \\
\hline & (1.56) & & & $(0.11)$ & & \\
\hline \multirow[t]{2}{*}{$S_{t} * C F N A I$} & & $-0.171^{* *}$ & & & -0.103 & \\
\hline & & $(-2.12)$ & & & $(-0.79)$ & \\
\hline \multirow[t]{2}{*}{$S_{t} * \Delta V I X$} & & & 0.004 & & & 0.004 \\
\hline & & & (0.39) & & & $(0.36)$ \\
\hline$R^{2}$ & $14.17 \%$ & $14.51 \%$ & $15.2 \%$ & $14.64 \%$ & $14.73 \%$ & $15.72 \%$ \\
\hline $\mathrm{N}$ & 2906 & 2906 & 2844 & 2901 & 2901 & 2838 \\
\hline \multicolumn{7}{|c|}{$\begin{array}{l}\text { The table reports estimates for the following model: } R_{t}=\alpha_{t}+b_{t} I N V_{t}^{\text {low }}+c_{t} I N V_{t}^{\text {high }}+d_{t} \widehat{b_{0} S_{t}}+ \\
e_{t} \widehat{b_{0} S_{t}} I N V_{t}^{\text {low }}+f_{t} \widehat{b_{0} S_{t}} I N V_{t}^{\text {high }}+g_{t} \widehat{b_{0} S_{t}} \text { econ }+u_{t} \cdot R_{t} \text { is the continuously compounded ten- } \\
\text { minute return of the E-mini S\&P } 500 \text { around macroeconomic news release. } S_{i t} \text { is the standardized } \\
\text { surprise for announcement } i . I N V_{t}^{\text {low }} \text { and } I N V_{t}^{\text {high }} \text { are dummy variables equal to } 1 \text { on days when } \\
\text { the investor sentiment measure is below the } 25 \text { th percentile and above the } 75 \text { th percentile, } \\
\text { respectively. Three control variables are used for robustness check: the smoothed U.S. recession } \\
\text { probability, the Chicago Fed National Activity Index (CFNAI), and the VIX. The regressions are } \\
\text { estimated using OLS with White (1980) heteroskedasticity consistent covariance matrix. *, **, and } \\
* * * \text { denote significance at } 10 \text { percent, } 5 \text { percent, and } 1 \text { percent levels, respectively. }\end{array}$} \\
\hline
\end{tabular}


Table 3.11. Average Effect of Investor Sentiment on Market Response to Positive Macroeconomic News Controlling for State of Economy

\begin{tabular}{|c|c|c|c|c|c|c|}
\hline & \multicolumn{3}{|c|}{ AAII Sentiment Index } & \multicolumn{3}{|c|}{ Investor Intelligence Sentiment Index } \\
\hline Variables & $\begin{array}{l}\text { Coefficients } \\
\text { (t-statistics) }\end{array}$ & $\begin{array}{l}\text { Coefficients } \\
\text { (t-statistics) }\end{array}$ & $\begin{array}{l}\text { Coefficients } \\
\text { (t-statistics) }\end{array}$ & $\begin{array}{l}\text { Coefficients } \\
\text { (t-statistics) }\end{array}$ & $\begin{array}{l}\text { Coefficients } \\
\text { (t-statistics) }\end{array}$ & $\begin{array}{l}\text { Coefficients } \\
\text { (t-statistics) }\end{array}$ \\
\hline Intercept & $\begin{array}{c}0.025 * * * \\
(3.3)\end{array}$ & $\begin{array}{c}0.028 * * * \\
(3.84)\end{array}$ & $\begin{array}{c}0.034 * * * \\
(4.55)\end{array}$ & $\begin{array}{l}0.018^{*} \\
(1.72)\end{array}$ & $\begin{array}{l}0.02 * * \\
(2.32)\end{array}$ & $\begin{array}{c}0.023 * * * \\
(2.7)\end{array}$ \\
\hline$I N V_{t}^{\text {low }}$ & $\begin{array}{l}0.04 * * \\
(2.52)\end{array}$ & $\begin{array}{c}0.035 * * \\
(2.2)\end{array}$ & $\begin{array}{c}0.042 * * \\
(2.5)\end{array}$ & $\begin{array}{c}0.061 * * * \\
(3.42)\end{array}$ & $\begin{array}{c}0.05^{* * * *} \\
(2.75)\end{array}$ & $\begin{array}{c}0.061 * * * \\
(3.32)\end{array}$ \\
\hline$I N V_{+}^{\text {high }}$ & $\begin{array}{c}-0.009 \\
(-0.6)\end{array}$ & $\begin{array}{r}-0.002 \\
(0.16)\end{array}$ & $\begin{array}{l}-0.012 \\
(-0.83)\end{array}$ & $\begin{array}{l}0.003 \\
(0.26)\end{array}$ & $\begin{array}{l}0.003 \\
(0.28)\end{array}$ & $\begin{array}{c}0.0004 \\
(0.03)\end{array}$ \\
\hline ECON & $\begin{array}{l}0.035 \\
(2.49)\end{array}$ & & & $\begin{array}{l}0.019 \\
(1.2)\end{array}$ & & \\
\hline CFNAI & & $\begin{array}{c}-0.029 * * \\
(-2.54)\end{array}$ & & & $\begin{array}{c}-0.024 * * * \\
(-2.76)\end{array}$ & \\
\hline$\Delta V I X$ & & & $\begin{array}{c}-0.005 * * * \\
(-4.54)\end{array}$ & & & $\begin{array}{c}-0.004 * * * \\
(-3.97)\end{array}$ \\
\hline$S_{t}$ & $\begin{array}{c}0.72 * * * \\
(4.17)\end{array}$ & $\begin{array}{c}0.802 * * * \\
(5.11)\end{array}$ & $\begin{array}{c}0.99 * * * \\
(5.73)\end{array}$ & $\begin{array}{c}0.718 * * * \\
(3.16)\end{array}$ & $\begin{array}{c}0.938 * * * \\
(4.94)\end{array}$ & $\begin{array}{c}0.96 * * * \\
(4.51)\end{array}$ \\
\hline$S_{t} * I N V_{t}^{\text {low }}$ & $\begin{array}{c}-0.265 \\
(0.9)\end{array}$ & $\begin{array}{l}-0.325 \\
(-1.15)\end{array}$ & $\begin{array}{l}-0.242 \\
(-0.71)\end{array}$ & $\begin{array}{l}0.311 \\
(0.74)\end{array}$ & $\begin{array}{l}0.188 \\
(0.46)\end{array}$ & $\begin{array}{l}0.569 \\
(1.28)\end{array}$ \\
\hline$S_{+} * I N V_{+}^{h i g h}$ & $\begin{array}{l}-0.467 * \\
(-1.75)\end{array}$ & $\begin{array}{c}-0.34 \\
(-1.31)\end{array}$ & $\begin{array}{c}-0.539 * * \\
(-2.07)\end{array}$ & $\begin{array}{l}-0.398 \\
(-1.36)\end{array}$ & $\begin{array}{l}-0.478 * \\
(-1.77)\end{array}$ & $\begin{array}{c}-0.598 * * \\
(-2.04)\end{array}$ \\
\hline$S_{t} *$ Econ & $\begin{array}{c}0.713 * * * \\
(3.05)\end{array}$ & & & $\begin{array}{c}0.99 * * * \\
(2.76)\end{array}$ & & \\
\hline$S_{t} * C F N A I$ & & $\begin{array}{l}-0.4 * * * \\
(-3.34)\end{array}$ & & & $\begin{array}{c}-0.546^{* * * *} \\
(-2.76)\end{array}$ & \\
\hline$S_{t} * \Delta V I X$ & & & $\begin{array}{l}-0.007 \\
(-1.17) \\
\end{array}$ & & & $\begin{array}{l}-0.005 \\
(-0.24) \\
\end{array}$ \\
\hline$R^{2}$ & $5.31 \%$ & $6.25 \%$ & $3.49 \%$ & $7.36 \%$ & $8.11 \%$ & $7.3 \%$ \\
\hline $\mathrm{N}$ & 1929 & 1929 & 1890 & 1925 & 1925 & 1886 \\
\hline
\end{tabular}

The table reports estimates for the following model: $R_{t}=\alpha_{t}+b_{t} I N V_{t}^{\text {low }}+c_{t} I N V_{t}^{\text {high }}+d_{t} \widehat{b_{0} S_{t}}+$ $e_{t} \widehat{b_{0} S_{t}} I N V_{t}^{\text {low }}+f_{t} \widehat{b_{0} S_{t}} I N V_{t}^{\text {high }}+g_{t} \widehat{b_{0} S_{t}}$ econ $+u_{t}$. $R_{t}$ is the continuously compounded ten-minute return of the E-mini S\&P 500 around positive macroeconomic news surprises. $S_{i t}$ is the standardized positive surprise for announcement $i . I N V_{t}^{\text {low }}$ is a dummy variable equal to 1 on days when the investor sentiment measure is below the 25 th percentile, IN $V_{t}^{\text {high }}$ equals to one on days when the investor sentiment measure is above the 75th percentile. Three control variables are used for robustness check: the smoothed U.S. recession probability, the Chicago Fed National Activity Index (CFNAI), and the VIX. The sample period is from January 1998 to September 2016.The regressions are estimated using OLS with White (1980) heteroskedasticity consistent covariance matrix. *, **, and $* * *$ denote significance at 10 percent, 5 percent, and 1 percent levels, respectively. 
Table 3.12. Average Effect of Investor Sentiment on Market Response to Negative Macroeconomic News Controlling for State of Economy

\begin{tabular}{|c|c|c|c|c|c|c|}
\hline & \multicolumn{3}{|c|}{ AAII Sentiment Index } & \multicolumn{3}{|c|}{ Investor Intelligence Sentiment Index } \\
\hline Variables & Coefficients & Coefficients & Coefficients & Coefficients & Coefficient & Coefficients \\
\hline Intercept & $\begin{array}{c}0.034 * * * \\
(3.25)\end{array}$ & $\begin{array}{c}0.027 * * * \\
(2.61)\end{array}$ & $\begin{array}{c}0.026^{* * * *} \\
(2.59)\end{array}$ & $\begin{array}{c}0.049 * * * \\
(4.58)\end{array}$ & $\begin{array}{c}0.041^{* * * *} \\
(4.27)\end{array}$ & $\begin{array}{c}0.036 * * * * \\
(3.83)\end{array}$ \\
\hline$I N V_{t}^{\text {low }}$ & $\begin{array}{l}-0.015 \\
(0.84)\end{array}$ & $\begin{array}{l}-0.016 \\
(-0.88)\end{array}$ & $\begin{array}{l}-0.024 \\
(-1.29)\end{array}$ & $\begin{array}{c}-0.05 * * \\
(-2.51)\end{array}$ & $\begin{array}{c}-0.041^{* *} \\
(-1.96)\end{array}$ & $\begin{array}{c}-0.061 * * * \\
(-2.99)\end{array}$ \\
\hline$I N V_{t}^{\text {high }}$ & $\begin{array}{l}0.001 \\
(0.04)\end{array}$ & $\begin{array}{l}-0.001 \\
(-0.04)\end{array}$ & $\begin{array}{l}0.001 \\
(0.06)\end{array}$ & $\begin{array}{c}-0.036^{* *} \\
(-2.35)\end{array}$ & $\begin{array}{c}-0.029 * * \\
(-2.03)\end{array}$ & $\begin{array}{c}-0.025^{*} \\
(-1.68)\end{array}$ \\
\hline ECON & $\begin{array}{l}-0.029 \\
(-1.61)\end{array}$ & & & $\begin{array}{l}-0.032 \\
(-1.79)\end{array}$ & & \\
\hline CFNAI & & $\begin{array}{l}0.006 \\
(0.57)\end{array}$ & & & $\begin{array}{l}0.015 \\
(1.52)\end{array}$ & \\
\hline$\Delta V I X$ & & & $\begin{array}{c}-0.002 * * \\
(-2.03)\end{array}$ & & & $\begin{array}{c}-0.004 * * * \\
(-3.36)\end{array}$ \\
\hline$S_{t}$ & $\begin{array}{c}1.06 * * * \\
(8.07)\end{array}$ & $\begin{array}{c}0.99 * * * * \\
(7.47)\end{array}$ & $\begin{array}{c}1.00 * * * * \\
(8.58)\end{array}$ & $\begin{array}{c}1.15 * * * \\
(7.84)\end{array}$ & $\begin{array}{c}1.04 * * * \\
(8.01)\end{array}$ & $\begin{array}{c}1.00 * * * \\
(7.99)\end{array}$ \\
\hline$S_{t} * I N V_{t}^{\text {low }}$ & $\begin{array}{l}0.054 \\
(0.29)\end{array}$ & $\begin{array}{l}0.025 \\
(0.14)\end{array}$ & $\begin{array}{l}-0.014 \\
(-0.08)\end{array}$ & $\begin{array}{c}0.06 \\
(0.34)\end{array}$ & $\begin{array}{l}0.119 \\
(0.59)\end{array}$ & $\begin{array}{l}-0.101 \\
(-0.54)\end{array}$ \\
\hline$S_{t}$ & $\begin{array}{c}-0.538^{* *} \\
(-2.26)\end{array}$ & $\begin{array}{c}-0.522^{* *} \\
(-2.15)\end{array}$ & $\begin{array}{c}-0.487 * * \\
(-2.06)\end{array}$ & $\begin{array}{c}-0.538^{* * * *} \\
(-2.64)\end{array}$ & $\begin{array}{c}-0.432^{* *} \\
(-2.29)\end{array}$ & $\begin{array}{c}-0.418^{* *} \\
(-2.17)\end{array}$ \\
\hline$S_{t} *$ Econ & $\begin{array}{l}-0.161 \\
(-0.92)\end{array}$ & & & $\begin{array}{c}-0.369 * * \\
(-2.08)\end{array}$ & & \\
\hline$S_{t} * C F N A I$ & & $\begin{array}{c}-0.02 \\
(-0.24)\end{array}$ & & & $\begin{array}{c}0.127 * * \\
(2.31)\end{array}$ & \\
\hline$S_{t} * \Delta V I X$ & & & $\begin{array}{l}0.019 * \\
(1.86)\end{array}$ & & & $\begin{array}{l}-0.002 \\
(-0.19)\end{array}$ \\
\hline$R^{2}$ & $14.61 \%$ & $14.54 \%$ & $15.96 \%$ & $13.36 \%$ & $13.37 \%$ & $14.11 \%$ \\
\hline $\mathrm{N}$ & 1736 & 1736 & 1701 & 1734 & 1734 & 1699 \\
\hline
\end{tabular}

The table reports estimates for the following model: $R_{t}=\alpha_{t}+b_{t} I N V_{t}^{\text {low }}+c_{t} I N V_{t}^{\text {high }}+d_{t} \widehat{b_{0} S_{t}}+$ $e_{t} \widehat{b_{0} S_{t}} I N V_{t}^{\text {low }}+f_{t} \widehat{b_{0} S_{t}} I N V_{t}^{\text {high }}+g_{t} \widehat{b_{0} S_{t}}$ econ $+u_{t} . R_{t}$ is the continuously compounded ten-minute return of the E-mini S\&P 500 around negative macroeconomic news surprises. $S_{i t}$ is the standardized positive surprise for announcement $i . I N V_{t}^{\text {low }}$ is a dummy variable equal to 1 on days when the investor sentiment measure is below the 25 th percentile, $I N V_{t}^{\text {high }}$ equals to one on days when the investor sentiment measure is above the 75th percentile. Three control variables are used for robustness check: the smoothed U.S. recession probability, the Chicago Fed National Activity Index (CFNAI), and the VIX. The sample period is from January 1998 to September 2016. The regressions are estimated using OLS with White (1980) heteroskedasticity consistent covariance matrix. *, **, and *** denote significance at 10 percent, 5 percent, and 1 percent levels, respectively. 
Figure 3.1. Time Variation in Investor Sentiment Index

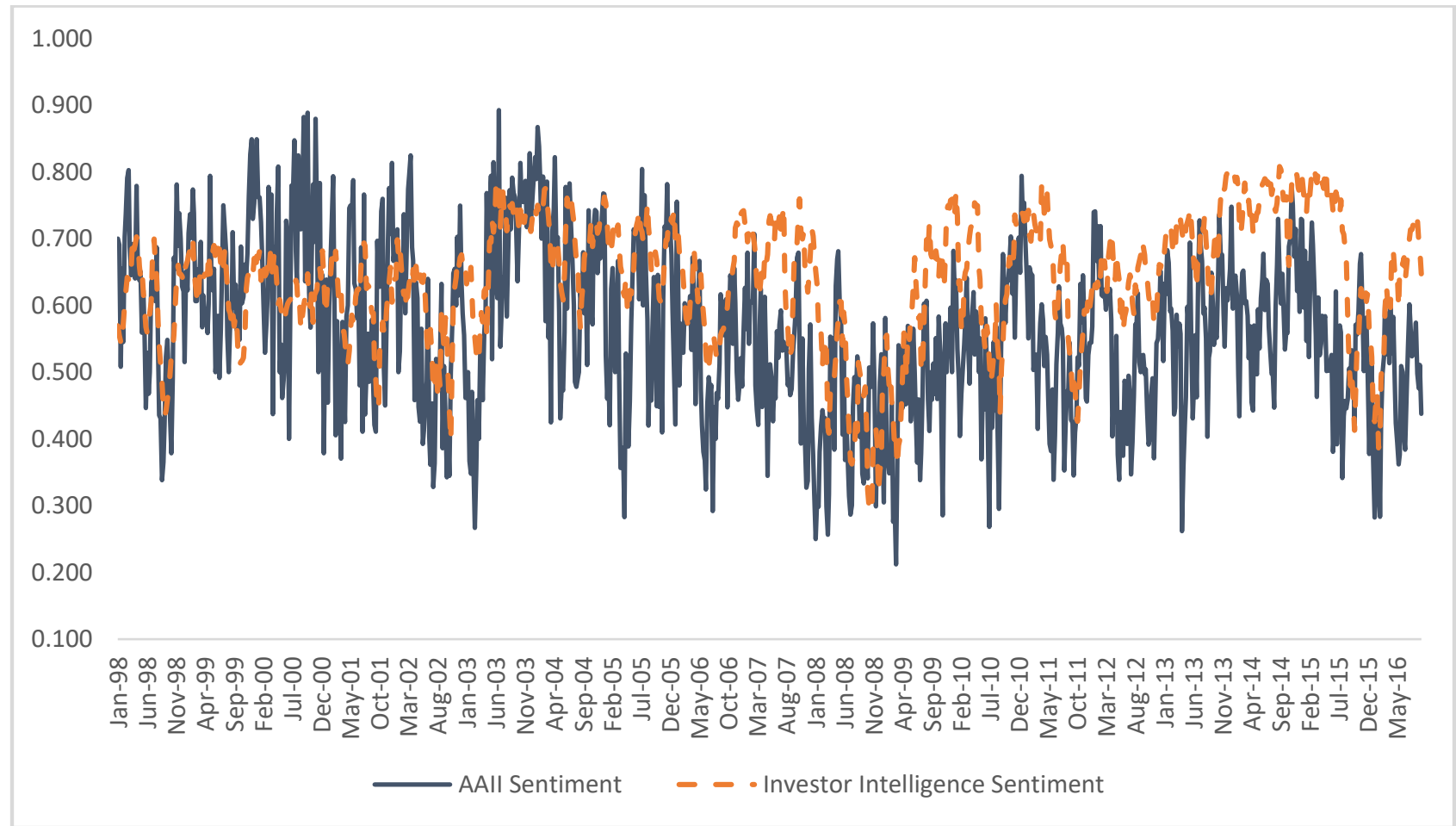

Figure 3.1 plots the weekly survey of individual investors conducted by the American Association of Individual Investors (AAII) and Investor Intelligence from January 1998 to September 2016. Following Fisher and Statman (2006) and Kurov (2008), we compute sentiment index as a ratio of the percentage of bullish investors to the sum of the percentage of bullish and bearish investors. We then define low investor sentiment when it is below its $25^{\text {th }}$ percentile, define high investor sentiment if it is above its $75^{\text {th }}$ percentile, and normal investor sentiment if it is between $25^{\text {th }}$ percentile and $75^{\text {th }}$ percentile. 
Figure 3.2. Evidence of the Impact of Investor Sentiment on Market Return

Panel A. Cumulative Average Returns based on AAII Sentiment Levels

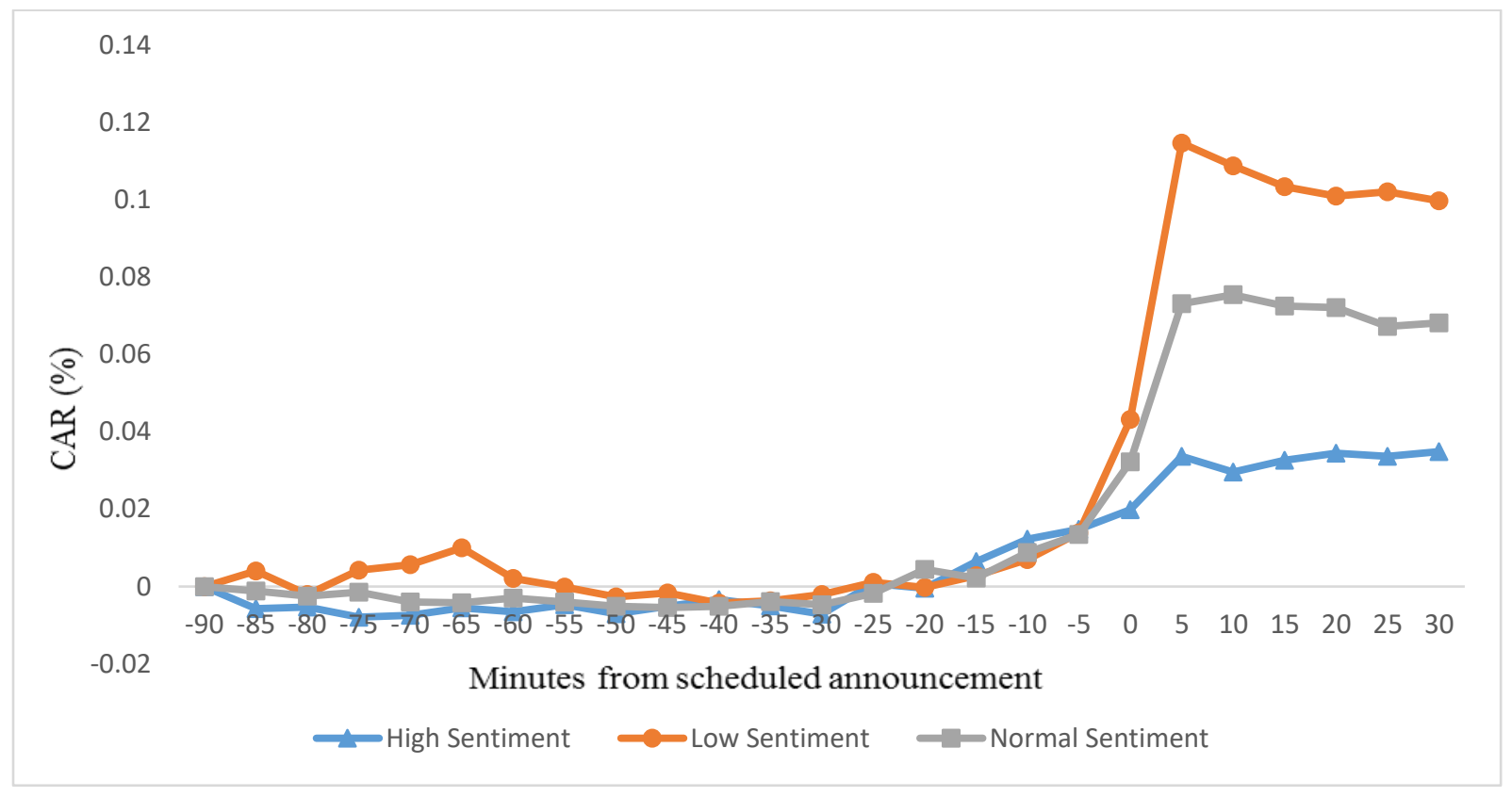

Panel B. Cumulative Average Returns based on Investor Intelligence Sentiment Levels

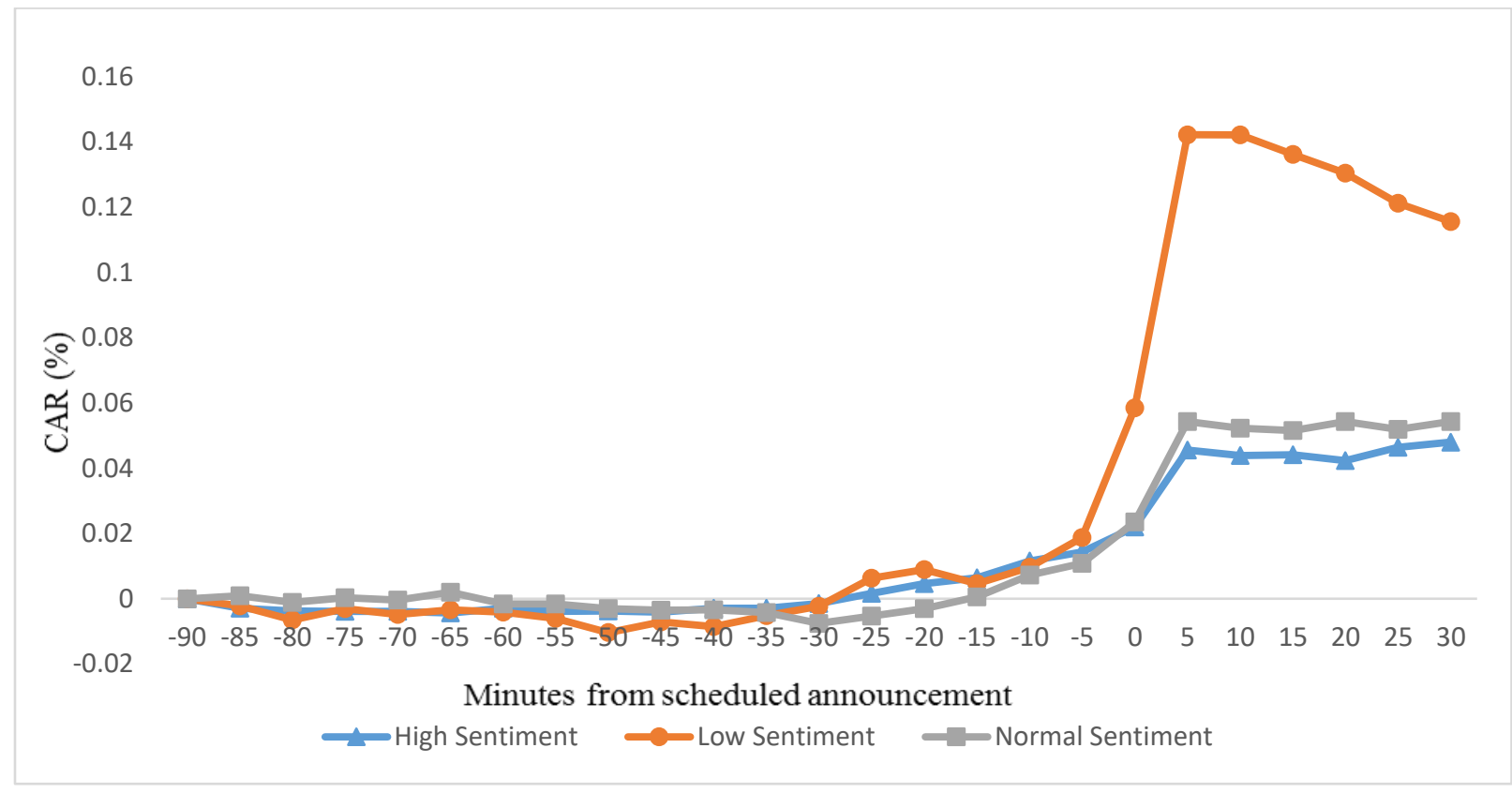

Figure 3.2 shows the cumulative average return of E-mini S\&P 50090 minutes before and 30 minutes after the macroeconomic news announcements. CAR is conditional on time periods of normal, high and low investor sentiment. The sample period is from January 1998 to September 2016. 


\section{BIBLIOGRAPHY}

Adrian, T. and H. S. Shin, 2008. Liquidity, Monetary Policy, and Financial Cycles, Current Issues in Economics and Finance 14(1), Federal Reserve Bank of New York.

Andersen, Torben G., Bollerslev, Tim, Diebold, Francis X., Ebens, Heiko, 2001. The distribution of realized stock return volatility. Journal of Financial Economics 61, 43-76.

Andersen, T., Bollerslev, T., Diebold, F., Vega, C., 2003. Micro effects of macro announcements: Real-time price discovery in foreign exchange. American Economic Review, 93, 38-62.

Ang, A., Hodrick, R. J., Xing, Y. And Zhang, X., 2006. The Cross-Section of Volatility and Expected Returns. The Journal of Finance, 61: 259-299.

Baker, M., Wurgler, J., 2006. Investor sentiment and the cross-section of stock returns. Journal of Finance 61, 1645-1680.

Bakshi, Gurdip, Kapadia, Nikunj, 2003a. Delta-hedged gains and the negative market volatility risk premium. Review of Financial Studies 16, 527-566.

Bakshi, Gurdip, Kapadia, Nikunj, 2003b. Volatility Risk Premiums Embedded in Individual Equity Options: Some New Insights. Journal of Derivatives, pp. 45-54

Bakshi, Gurdip, and Dilip Madan. 2006. A theory of volatility spreads. Management Science 52 (12): 1945-56.

Balduzzi, P., Elton, E., Green, C., 2001. Economic news and bond prices: Evidence from the U.S. treasury market. Journal of Financial and Quantitative Analysis, 36, 523-543.

Bansal, R., and A. Yaron. "Risks for the Long Run: A Potential Resolution of Asset Pricing Puzzles." The Journal of Finance 59 (2004), 1481-1509.

Barro, Robert J. 2006. Rare Disasters and Asset Markets in the Twentieth Century. Quarterly Journal of Economics, 121(3): 823-866.

Barro, R. J. and Jin, T. (2011), On the Size Distribution of Macroeconomic Disasters. Econometrica, 79: $1567-1589$.

Barro, R. and J.F. Ursua, 2012. Rare Macroeconomic Disasters, Annual Review of Economics, 4 (1): 83-109.

Bates, David S., 1988. Pricing options on jump-diffusion process. Working Paper. Rodney L. White Center, Wharton School.

Bates, David S., 2000. Post-'87 crash fears in the S\&P 500 futures option market, Journal of Econometrics, Volume 94, Issues 1-2, Pages 181-238. 
Bekaert, G. and Hoerova, M., 2014. The VIX, the variance premium and stock market volatility. Journal of Econometrics, 183,181-192.

Bekaert, G. and Hoerova, M. and Lo Duca, 2013. Marco, Risk, Uncertainty and Monetary Policy. Journal of Monetary Economics, Vol. 60, Vol. 7, pp. 771-788.

Bernanke, B.S., Kuttner, K.N., 2005. What explains the stock market's reaction to federal reserve policy? Journal of Finance 60 (3), 1221-1257.

Bernanke, B.S., Boivin, J., Eliasz, P., 2005. Measuring the effects of monetary policy: a factoraugmented vector autoregressive (favar) approach. The Quarterly Journal of Economics 120 (1), $387-422$.

Bernile, G., Hu, J., \& Tang, Y. 2016. Can information be locked-up? Informed trading ahead of macro-news announcements. Journal of Financial Economics, forthcoming.

Bjørnland, H. C., Leitemo, K., 2009. Identifying the interdependence between US monetary policy and the stock market, Journal of Monetary Economics, Volume 56, Issue 2, Pages 275-282.

Black, Fischer and Myron Scholes, 1973. "The Pricing of Options and Corporate Liabilities," Journal of Political Economy 81:3, May/June, 637-654.

Black, F., 1986, Noise. The Journal of Finance, 41: 528-543.

Blanchard, O., Quah, D., 1989. The Dynamic Effects of Aggregate Demand and Supply Disturbances. American Economic Review, 79, 655-673.

Bloom, N., 2009. The Impact of Uncertainty Shocks, Econometrica, Vol. 77, No. 3, pp. 623-685.

Bloom, Nicholas and Floetotto, Max and Jaimovich, Nir and Saporta Eksten, Itay and Terry, Stephen., 2014. Really Uncertain Business Cycles. US Census Bureau Center for Economic Studies Paper No. CES-WP-14-18.

Bollerslev, T, and Hao Zhou. 2002. Estimating stochastic volatility diffusion using conditional moments of integrated volatility. Journal of Econometrics 109 (1): 33-65.

Bollerslev, T.; J. Marrone; L. Xu; and H. Zhou., 2014. "Stock Return Predictability and Variance Risk Premia: Statistical Inference nd International Evidence." Journal of Financial and Quantitative Analysis Vol.49, No.3, pp.633-661.

Bollerslev, T.; N. Sizova; and G. Tauchen., 2012. "Volatility in Equilibrium: Asymmetries and Dynamic Dependencies." Review of Finance 16, 31-80.

Bollerslev, T.; G. Tauchen; and H. Zhou., 2009. "Expected Stock Returns and Variance Risk Premia." Review of Financial Studies 22 (11): 4463-4492. 
Bollerslev, T., and V. Todorov., 2011. "Tails, Fears and Risk Premia.” Journal of Finance 66, $2165-$ 2211.

Bollerslev, T., and V. Todorov., 2014. “Time-Varying Jump Tails.” Journal of Econometrics Volume 183,Issue 2 PP 168-180.

Bollerslev, T., V. Todorov, and L. Xu. 2015. Tail risk premia and return predictability. Journal of Financial Economics 118 (1): 113-34.

Bollerslev, T., V. Todorov, and L. Xu., 2015. Tail risk premia and return predictability. Journal of Financial Economics 118 (1): 113-34.

Boivin, J., Giannoni, M.P., Mihov, I., 2009. Sticky prices and monetary policy: evidence from disaggregated us data. The American Economic Review 99 (1), 350-384.

Boyd, J. H., Hu, J., and Jagannathan, R., 2005. The stock market's reaction to unemployment news: Why bad news is usually good for stocks. Journal of Finance, 60(2), 649-672.

Brown, G. W., and M. T. Cliff. 2005. Investor sentiment and asset valuation. Journal of Business, 78: 405-440.

Cairns, A.J.G., Blake, D. and Dowd, K. 2006a. A Two-Factor Model for Stochastic Mortality: Theory and Calibration. Journal of Risk and Insurance, 73: 687-718

Cairns, A.J.G., Blake, D. and Dowd, K. 2006b. Pricing Death: Frameworks for the Valuation and Securitization of Mortality Risk. Working paper.

Campbell, John Y., 1993, Intertemporal asset pricing without consumption data, American Economic Review 83, 487-512.

Campbell, John Y., 1996, Understanding risk and return, Journal of Political Economy 104, 298345.

Campbell, J. Y.; S. Giglio; C. Polk; and R. Turley. 2013 “An Intertemporal CAPM with Stochastic Volatility." working paper, Harvard University, University of Chicago and London School of Economics.

Chauvet, M. 1998. An Econometric Characterization of Business Cycles with Factor Structure and Markov Switching. International Economic Review, 39, 4, 969-996.

Chen, H. and Dou, W. and Kogan, L., 2015. Measuring the 'Dark Matter' in Asset Pricing Models. Working paper.

Chow, Victor, Wanjun Jiang, and Jingrui Li., 2016. Realized VIX, Polynomial Variation, and Tail Risk Premium. Working paper.

Christiano, L J., Eichenbaum, M., Evans, C L., 1999. Monetary Policy Shocks: What Have we 
Learned and to What End? In Taylor, J B and Woodford, M (eds.), Handbook of Macroeconomics. Vol. 1A. New York: Elsevier Science, 1999, 65-148.

Conrad, J., B. Cornell, and W. Landsman. 2002. When is bad news really bad news? Journal of Finance, 57: 2507-2532.

Cox, John C., Jonathan E. Ingersoll, and Stephen A. Ross. 1985. "A Theory of the Term Structure of Interest Rates". Econometrica 53 (2). 385-407.

Cox, S. H., Y. Lin, and H. Pedersen, 2010, Mortality Risk Modeling: Application to Insurance Securitization, Insurance: Mathematics and Economics, 46: 242-253.

Dahl, M., 2004, Stochastic Mortality in Life Insurance: Market Reserves and Mortality-Linked Insurance Contracts, Insurance: Mathematics and Economics, 35: 113-136.

Davidson, L., Froyen, R., 1982. Monetary Policy and Stock Returns: Are Stock Markets Efficient? Working paper, Federal Reserve at St. Louis.

DeLong, J. B., Andrei Shleifer, Lawrence H. Summers, and Robert J. Waldmann. 1990. Noise Trader Risk in Financial Markets. Journal of Political Economy, 98(4): 703-38.

Deng, Y. and Brockett, Patrick L. and MacMinn, R. D., 2012. Longevity/Mortality Risk Modeling and Securities Pricing. Journal of Risk and Insurance, Vol. 79, Issue 3, pp. 697-721.

Drechsler, I.,Yaron,A.,2011.What's vol got to do with it. Review of Financial Studies 24(1), 1-45.

Duffie, D. and Epstein, L., 1992a, Asset pricing with stochastic differential utility, Review of Financial Studies, 5, 411-436.

Duffie, D. and Epstein, L., 1992b. Stochastic differential utility, Econometrica 60, 353-394.

Duffie, Darrell, Jun Pan, and Kenneth Singleton, 2000, Transform analysis and asset pricing for affine jump-diffusions, Econometrica, 68, 1343-1376.

Ehrmann, M., \& Fratzscher, M., 2004. Taking Stock: Monetary Policy Transmission to Equity Markets. Journal of Money, Credit and Banking, 36(4), 719-737.

Epstein, Larry, and Stan Zin, 1989, Substitution, risk aversion and the temporal behavior of consumption and asset returns: A theoretical framework, Econometrica, 57, 937-969.

Epstein, L. G. and Zin, S. E., 1991. Substitution, risk aversion, and the temporal behavior of consumption and asset returns: an empirical analysis, Journal of Political Economy 99, 263-286.

Eraker, Bjørn. 2004. Do stock prices and volatility jump? Reconciling evidence from spot and option prices. The Journal of Finance 59 (3): 1367-403.

Eraker, B., and I. Shaliastovich. "An Equilibrium Guide to Designing Affine Pricing Models." Mathematical Finance 18 (2008), 519-543. 
Fisher, K.L. and M. Statman, 2006. Market timing in regressions and reality, Journal of Financial Research, 29, 293-304.

Heston, Steven, 1993. A closed-form solution for options with stochastic volatility with applications to bond and currency options. Review of Financial Studies, 6, 327-343.

Hribar, P., and J. McInnis. 2012. Investor sentiment and analysts' earnings forecast errors. Management Science, 58: 293-307.

Huang D, Jiang F, Tu J, Zhou G. 2015. Investor Sentiment Aligned: A Powerful Predictor of Stock Returns. The Review of Financial Studies, 28 (3), 791-837.

Gabaix, Xavier, 2008, Linearity-generating processes: A modelling tool yielding closed forms for asset prices, Working paper, New York University.

Gabaix, Xavier, 2012, An exactly solved framework for ten puzzles in macro-finance, Quarterly Journal of Economics, 127, 645-700.

Gilbert, T., 2011. Information aggregation around macroeconomic announcements: Revisions matter. Journal of Financial Economics, 101, 114-131.

Glick, R., Leduc, S., 2012. Central bank announcements of asset purchases and the impact on global financial and commodity markets. Journal of International Money and Finance 31 (8), 20782101.

Gourio, Franc sois, 2008a, Disasters and recoveries, American Economic Review Papers and Proceedings, 98, 68-73.

Gourio, Franc sois, 2008b, Time-series predictability in the disaster model, Finance Research Letters, $5,191-203$.

Gürkaynak, R. S., Sack, B., \& Swanson, E., 2007. Market-based measures of monetary policy expectations. Journal of Business and Economic Statistics, 25, 201-212.

Hamilton, J D., 1994. Time Series Analysis. Princeton University Press, Princeton, New Jersey.

Huber, P. J., 1973. Robust regression: Asymptotics, conjectures and Monte Carlo. Annals of Statistics, 1, 799-821.

Ioannidis, C., and Kontonikas, A., 2006. Monetary Policy and the Stock Market: Some International evidence, Working Papers, Business School - Economics, University of Glasgow.

Kaplanski, G., and H. Levy. 2010. Sentiment and stock prices: The case of aviation disasters. Journal of Financial Economics, 95: 174-210.

Kontonikas, A., MacDonald, R., and Saggu, A., 2013. Stock market reaction to fed funds rate surprises: State dependence and the financial crisis. Journal of Banking and Finance, 37, 4025-4037. 
Krishnamurthy, A., Vissing-Jorgensen, A., 2011. The effects of quantitative easing on interest rates: Channels and implications for policy. Brookings Papers on Economic Activity. pp. 215-287.

Kurov, Alexander, 2008. Investor Sentiment, Trading Behavior and Informational Efficiency in Index Futures Markets. Financial Review. 43 (1), 107-27.

Kurov, Alexander, 2010. Investor Sentiment and the Stock Market's Reaction to Monetary Policy. Journal of Banking \& Finance 34.1, 139-49.

Kurov, A., and Gu, C., 2016. Monetary Policy and Stock Prices: Does the 'Fed Put' Work When It Is Most Needed? Journal of Futures Markets, 36: 1210-1230.

Kurov, A. and R. Stan, 2016. Monetary Policy Uncertainty and the Market Reaction to Macroeconomic News. Working paper.

Gürkaynak, R. S., Sack, B., \& Swanson, E., 2007. Market-based measures of monetary policy expectations. Journal of Business and Economic Statistics, 25, 201-212.

Lee, Charles M.C., 2001. Market efficiency and accounting research: a discussion of 'capital market research in accounting' by S.P. Kothari. Journal of Accounting and Economics, Volume 31, Issues 1-3, Pages 233-253.

Liu, Jun, Jun Pan, and Tan Wang, 2005. “An equilibrium model of rare-event premia and its implication for option smirks," Review of Financial Studies, 18, 131-164.

Lutz, C., 2015. The impact of conventional and unconventional monetary policy on investor sentiment, Journal of Banking \& Finance, Volume 61, Pages 89-105.

Merton, Robert C. 1971. "Optimal Consumption and Portfolio Rules in a Continuous-Time Model," Journal of Economic Theory 3:4, Dec., 373-413.

Merton, Robert C., 1976. Option Pricing when Underlying Stock Returns are Discontinuous, Journal of Financial Economics 3:1/2, Jan./March, 125-144.

Mian, G. and S. Sankaraguruswamy, 2012. Investor Sentiment and Stock Market Response to Earnings News. The Accounting Review, Vol. 87, No. 4, pp. 1357-1384.

Neri, S., 2004. Monetary Policy and Stock Prices. Bank of Italy Working paper No. 513, July 2004.

Pan, J., 2002. "The Jump-Risk Premia Implicit in Options: Evidence from an Integrated Time-Series Study." Journal of Financial Economics 63, 3-50.

Patelis, A D., 1997. Stock Return Predictability and the Role of Monetary Policy. The Journal of Finance 52 (5), 1951-1972.

Rigobon, R., Sack, B., 2004. The impact of monetary policy on asset prices. Journal of Monetary Economics 51(8), 1553-1575. 
Rigobon, R., and B. Sack, 2008. Noisy macroeconomic announcements, monetary policy, and asset prices. In J. Y. Campbell (Ed.), Asset Prices and Monetary Policy (pp. 335-370). Chicago: University of Chicago Press.

Rajan, R., 2006. Has Finance Made the World Riskier? European Financial Management, Vol. 12, No. 4, pp. 499-533.

Rietz, Thomas A., 1988. “The equity risk premium: A solution”, Journal of Monetary Economics $22,117-131$.

Santa-Clara, P., and S. Yan., 2010. "Crashes, Volatility and the Equity Premium: Lessons from S\&P 500 Options." Review of Economics and Statistics 92, 435-451.

Shiller, R.J., 1984. Stock prices and social dynamics. The Brookings Papers on Economic Activity $2,457-510$.

Shefrin, H. and M. Statman, 1994, Behavioral capital asset pricing theory, Journal of Financial and Quantitative Analysis, 29, 323-49.

Sims, C A., 1980. Macroeconomics and Reality. Econometrica 48, 1-48.

Sims, C.A., 1992. Interpreting the macroeconomic time series facts: the effects of monetary policy. European Economic Review 36 (5), 975-1000.

Stambaugh RF, Yu J, Yuan Y. 2012. The short of it: Investor sentiment and anomalies. Journal of Financial Economics, 104 (2), 288-302.

Stock, J., and Watson, M., 2001. Vector Autoregressions. The Journal of Economic Perspectives, 15(4), 101-115.

Stock, J H., Watson, M W., 2003. Forecasting Output and Inflation: The Role of Asset Prices. Journal of Economic Literature, Vol. XLI, pp. 788-829.

Swanson, E., Williams, J., 2014. Measuring the effect of the zero lower bound on medium- and longer-term interest rates. American Economic Review, 104, 3154-3185.

T., Tauchen, G., Zhou, H., 2009. Expected stock returns and variance risk premia. Review of Financial Studies 22(11), 4463-4492.

Thorbecke, W., 1997. On stock market returns and monetary policy. Journal of Finance 52 (2), 635654.

Todorov, Viktor., 2010. Variance risk-premium dynamics: The role of jumps. The Review of Financial Studies 23 (1): 345-83.

Wachter, J. A., 2006. A Consumption-Based Model of the Term Structure of Interest Rates. Journal of Financial Economics 79, 365-399. 
Wachter, J. A., 2013. Can time-varying risk of rare disasters explain aggregate stock market volatility? Journal of Finance 68, 987-1035.

White, H. 1980. A Heteroskedasticity-Consistent Covariance Matrix Estimator and a Direct Test for Heteroskedasticity. Econometrica, 48(4), 817-838.

Wright, J.H., 2012. What does monetary policy do to long-term interest rates at the zero lower bound? The Economic Journal 122 (564), F447-F466.

Xu, Lai., 2014. Tail Risk and Equity Risk Premia. Working Paper. 


\section{APPENDIX A}

\section{Supplementary Appendix to "Risk Premium, and Decomposition of Risk Aversion"}

This appendix provides additional details of model derivation and proofs of propositions

Proof of Proposition 1. We conjecture that the solution to the HJB equation is

$$
J(W, \lambda)=f(\lambda) \frac{W^{1-\lambda}}{1-\gamma}
$$

The value function satisfies

$$
\begin{aligned}
\sup _{\theta_{t}, C_{t}}\left\{J _ { W } \left(W_{t} \theta_{t}\right.\right. & \left.\left(\mu-r_{f}+\frac{A^{\prime}(t)+1}{A(t)}\right)+W_{t} r_{f}-C_{t}\right)+J_{\lambda} \varkappa\left(\mu_{\lambda}-\lambda_{t}\right)+\frac{1}{2} J_{W W} W_{t}^{2} \theta_{t}^{2} \sigma^{2} \\
& +\frac{1}{2} J_{\lambda \lambda} \sigma_{\lambda}^{2} \lambda_{t}+\lambda_{t} E_{v}\left[J\left(\lambda_{t}, W_{t}\left(1+\theta_{t}\left(e^{Z_{t}}-1\right)\right)\right)-J\left(\lambda_{t}, W_{t}\right)\right] \\
& \left.+f\left(C_{t}, J\right)\right\}=0
\end{aligned}
$$

In equilibrium, $\theta=1$ and $C=A^{-1} W$. Substituting these policy functions into (A1) implies

$$
\begin{aligned}
J_{W} W_{t} \mu+J_{\lambda} \varkappa( & \left.\mu_{\lambda}-\lambda_{t}\right)+\frac{1}{2} J_{W W} W_{t}^{2} \theta_{t}^{2} \sigma^{2}+\frac{1}{2} J_{\lambda \lambda} \sigma_{\lambda}^{2} \lambda_{t} \\
& +\lambda_{t} E_{v}\left[J\left(\lambda_{t}, W_{t}\left(e^{Z_{t}}\right)\right)-J\left(\lambda_{t}, W_{t}\right)\right]+f\left(C_{t}, J\right)=0
\end{aligned}
$$

By definition

$$
f(C, V)=\frac{\delta C^{1-\gamma}}{1-\gamma}-\delta V
$$

, and

$$
C=A^{-1} W
$$

Given the consumption-wealth ratio, it follows that

$$
f(C(W), J(\lambda, W))=\frac{\delta\left(A^{-1} W\right)^{1-\gamma}}{1-\gamma}-\delta \frac{W^{1-\lambda}}{1-\gamma} f(\lambda)
$$




$$
=\frac{\delta W^{1-\gamma}}{1-\gamma}\left(A(t)^{\lambda-1}-f(\lambda)\right)
$$

Substituting Equation (A1) and (A6) into (A3) implies

$$
\begin{aligned}
W^{1-\gamma} f\left(\lambda_{t}\right) \mu+ & W^{1-\gamma} f^{\prime}\left(\lambda_{t}\right)(1-\gamma)^{-1} \mathcal{H}\left(\mu_{\lambda}-\lambda_{t}\right)-\frac{1}{2} \gamma W^{1-\gamma} f\left(\lambda_{t}\right) \sigma^{2} \\
& +\frac{1}{2} W^{1-\gamma} f^{\prime \prime}\left(\lambda_{t}\right)(1-\gamma)^{-1} \sigma_{\lambda}^{2} \lambda_{t} \\
& +\lambda_{t} E_{v}\left[\frac{\left(W e^{Z_{t}}\right)^{1-\lambda}}{1-\gamma} f(\lambda)-\frac{W^{1-\lambda}}{1-\gamma} f(\lambda)\right]+\frac{\delta W^{1-\gamma}}{1-\gamma}\left(A(t)^{\lambda-1}-f(\lambda)\right) \\
& =0
\end{aligned}
$$

Rearrange Equation (A7) and multiply both sides by $W^{-(1-\gamma)}$

$$
\begin{gathered}
f\left(\lambda_{t}\right) \mu+f^{\prime}\left(\lambda_{t}\right)(1-\gamma)^{-1} \mathcal{H}\left(\mu_{\lambda}-\lambda_{t}\right)-\frac{1}{2} \gamma f\left(\lambda_{t}\right) \sigma^{2}+\frac{1}{2} f^{\prime \prime}\left(\lambda_{t}\right)(1-\gamma)^{-1} \sigma_{\lambda}^{2} \lambda_{t} \\
+f\left(\lambda_{t}\right)(1-\gamma)^{-1} \lambda_{t} E_{v}\left[e^{(1-\gamma) Z}-1\right]+\delta(1-\gamma)^{-1}\left(A(t)^{\lambda-1}-f(\lambda)\right) \\
=0
\end{gathered}
$$

Conjecture that $f(\lambda)=e^{a+b \lambda}$ solves Equation (A8). Substitute $e^{a+b \lambda}$ into A(8) implies

$$
\begin{gathered}
e^{a+b \lambda} \mu+b e^{a+b \lambda}(1-\gamma)^{-1} \mathcal{H}\left(\mu_{\lambda}-\lambda_{t}\right)-\frac{1}{2} \gamma e^{a+b \lambda} \sigma^{2}+\frac{1}{2} b^{2} e^{a+b \lambda}(1-\gamma)^{-1} \sigma_{\lambda}^{2} \lambda_{t} \\
+e^{a+b \lambda}(1-\gamma)^{-1} \lambda_{t} E_{v}\left[e^{(1-\gamma) Z}-1\right]+\delta(1-\gamma)^{-1}\left(A(t)^{\lambda-1}-e^{a+b \lambda}\right) \\
=0
\end{gathered}
$$

Rearrange Equation (A9) and multiply both sides by $e^{-(a+b \lambda)}$

$$
\begin{aligned}
\mu+b(1-\gamma)^{-1} & \varkappa\left(\mu_{\lambda}-\lambda_{t}\right)-\frac{1}{2} \gamma \sigma^{2}+\frac{1}{2} b^{2}(1-\gamma)^{-1} \sigma_{\lambda}^{2} \lambda_{t} \\
& +(1-\gamma)^{-1} \lambda_{t} E_{v}\left[e^{(1-\gamma) Z}-1\right]+\delta(1-\gamma)^{-1}\left(A(t)^{\lambda-1} / e^{a+b \lambda}-1\right) \\
& =0
\end{aligned}
$$

Collecting terms in $\lambda_{t}$ results in the following equation for $b$ 


$$
-b \varkappa+\frac{1}{2} b^{2} \sigma_{\lambda}^{2}+\lambda_{t} E_{v}\left[e^{(1-\gamma) Z}-1\right]=0
$$

Solving for $b$ implies

$$
b=\frac{\varkappa \pm \sqrt{\varkappa^{2}+\sigma_{\lambda}^{2} \lambda_{t} E_{v}\left[e^{(1-\gamma) Z}-1\right]}}{\sigma_{\lambda}^{2}}
$$

Collecting constant terms of equation () in the following characterization of $a$ in terms of $b$

$$
\begin{gathered}
\mu+b(1-\gamma)^{-1} \varkappa \mu_{\lambda}-\frac{1}{2} \gamma \sigma^{2}+\delta(1-\gamma)^{-1}\left(A(t)^{\lambda-1} / e^{a+b \lambda}-1\right)=0 \\
e^{-a-b \lambda}=\frac{(1-\gamma) A(t)^{1-\lambda}}{\delta}\left(\mu-\frac{1}{2} \gamma \sigma^{2}\right)+\frac{A(t)^{1-\lambda}}{\delta} b \varkappa \mu_{\lambda}-A(t)^{1-\lambda}=0 \\
a=-\ln \left(\frac{(1-\gamma) A(t)^{1-\lambda}}{\delta}\left(\mu-\frac{1}{2} \gamma \sigma^{2}\right)+\frac{A(t)^{1-\lambda}}{\delta} b \varkappa \mu_{\lambda}-A(t)^{1-\lambda}\right)-b \lambda
\end{gathered}
$$

Proof of Proposition 2. We assume that stock price is the claim to future dividends. It can be expressed as

$$
F\left(D_{t}, \lambda_{t}\right)=E_{t}\left[\int_{t}^{\infty} \frac{\pi_{s}}{\pi_{t}} D_{s} d_{s}\right]
$$

Following Wachter (2013), we have ${ }^{14}$

$$
\pi_{t} F_{t}+\int_{0}^{t} \pi_{u} D_{u} d_{u}=E_{t}\left[\pi_{s} F_{s}+\int_{0}^{s} \pi_{u} D_{u} d_{u}\right]
$$

and $\pi_{t} F_{t}+\int_{0}^{t} \pi_{u} D_{u} d_{u}$ is a martingale. Furthermore,

\footnotetext{
${ }^{14}$ For detailed derivation of equation A17 and A18, please see Wachter (2013) paper.
} 


$$
\begin{aligned}
\pi_{t} F_{t}+\int_{0}^{t} \pi_{s} D_{s} d_{s} & \\
& =\int_{0}^{t} \pi_{s} F_{s}\left(\mu_{F, s}+\mu_{\pi, s}+\frac{D_{s}}{F_{s}}+\sigma_{\pi, s} \sigma_{F, s}^{T}+\lambda_{s} E_{v}\left[e^{(\phi-\gamma) Z}-1\right]\right) d s \\
& +\int_{0}^{t} \pi_{s} F_{s}\left(\sigma_{F, s}+\sigma_{\pi, s}\right) d B_{S}+\sum_{0<s_{i} \leq t}\left(\pi_{s_{i}} F_{s_{i}}-\pi_{s_{i}-} F_{s_{i}-}\right) \\
& \left.-\int_{0}^{t} \pi_{s} F_{s} \lambda_{s} E_{v}\left[e^{(\phi-\gamma) Z}-1\right] d s\right)
\end{aligned}
$$

where $s_{i}=\inf \left\{s: N_{s}=i\right\}$. Because the second and third terms on the right hand side of Equation (A18) are martingales, the first term must also be a martingale, and it follows that the integrand of this term must equal zero

$$
\mu_{F, t}+\mu_{\pi, t}+\frac{D_{t}}{F_{t}}+\sigma_{\pi, t} \sigma_{F, t}^{T}+\lambda_{t} E_{v}\left[e^{(\phi-\gamma) Z}-1\right]=0
$$

To further decompose the disasters into quadratic variation and tail variation, I apply Taylor expansion to $e^{(\phi-\gamma) Z}-1$, and it can be rewritten as

$$
e^{(\phi-\gamma) Z}-1=\left[1+(\phi-\gamma) Z+\frac{1}{2 !}((\phi-\gamma) Z)^{2}+\frac{1}{3 !}((\phi-\gamma) Z)^{3}+\frac{1}{4 !}((\phi-\gamma) Z)^{4}+\cdots-1\right]
$$

Equation (A19) can be rewritten as

$$
\begin{aligned}
\mu_{F, t}+\mu_{\pi, t}+\frac{D_{t}}{F_{t}}+\sigma_{\pi, t} \sigma_{F, t}^{T}+\lambda_{t} E_{v}\left[(\phi-\gamma) Z+\frac{1}{2}((\phi-\gamma) Z)^{2}\right] \\
+\lambda_{t} E_{v}\left[\frac{1}{3 !}((\phi-\gamma) Z)^{3}+\frac{1}{4 !}((\phi-\gamma) Z)^{4}+\cdots\right]=0
\end{aligned}
$$

We define $\lambda_{t} E_{v}\left[(\phi-\gamma) Z+\frac{1}{2}((\phi-\gamma) Z)^{2}\right]$ captures the large instantaneous changes in prices from quadratic variation, and $\lambda_{t} E_{v}\left[\frac{1}{3 !}((\phi-\gamma) Z)^{3}+\frac{1}{4 !}((\phi-\gamma) Z)^{4}+\cdots\right]$ captures the large instantaneous changes in prices from higher moments (tail) variation.

Substituting $\mu_{\pi, t}=-r_{f}-\lambda_{t} E_{v}\left[\left(e^{-\gamma_{J} Z}-1\right)\right]$ into above equation and rearrange gives 


$$
\begin{aligned}
\mu_{F, t}+\frac{D_{t}}{F_{t}}-r_{f} & =-\sigma_{\pi, t} \sigma_{F, t}^{T}-\lambda_{t}\left(E_{v}\left[(\phi-\gamma) Z+\frac{1}{2}((\phi-\gamma) Z)^{2}\right]\right. \\
& \left.-E_{v}\left[\frac{1}{3 !}((\phi-\gamma) Z)^{3}+\frac{1}{4 !}((\phi-\gamma) Z)^{4}+\cdots\right]-E_{v}\left[e^{-\gamma Z}-1\right]\right)=0
\end{aligned}
$$

The left hand side of above equation is the instantaneous equity premium conditional on no disasters occurring. The instantaneous equity premium in population is given by this quantity, plus the expected percentage change if a disaster occurs. That is, if $r_{t}$ is defined as

$$
r_{t}=\mu_{F, t}+\frac{D_{t}}{F_{t}}+\lambda_{t} E_{v}\left[e^{\phi Z}-1\right]
$$

The equity premium for power utility can be computed as

$$
\begin{aligned}
r_{t}-r_{f}=\phi \gamma \sigma^{2} & +\lambda_{t}\left(E_{v}\left[e^{\phi Z}-1\right]+E_{v}\left[(\phi-\gamma) Z+\frac{1}{2}((\phi-\gamma) Z)^{2}\right]\right. \\
& \left.+E_{v}\left[\frac{1}{3 !}((\phi-\gamma) Z)^{3}+\frac{1}{4 !}((\phi-\gamma) Z)^{4}+\cdots\right]+E_{v}\left[e^{-\gamma Z}-1\right]\right)
\end{aligned}
$$

Applying Taylor expansion to $\left[e^{\phi Z}-1\right]$ and $\left[e^{-\gamma Z}-1\right]$, and equation A25 can be rewritten as

$$
\begin{aligned}
r_{t}-r_{f}=\phi \gamma \sigma^{2} & +\lambda_{t} E_{v}\left[(\phi-\gamma) Z+\frac{1}{2}((\phi-\gamma) Z)^{2}+\phi Z+(\phi Z)^{2}-\gamma Z+(\gamma Z)^{2}\right] \\
& +\lambda_{t} E_{v}\left[\frac{1}{3 !}((\phi-\gamma) Z)^{3}+\frac{1}{4 !}((\phi-\gamma) Z)^{4}+\frac{1}{3 !}(\phi Z)^{3}+\frac{1}{4 !}(\phi Z)^{4}\right. \\
& \left.-\frac{1}{3 !}(\gamma Z)^{3}+\frac{1}{4 !}(\gamma Z)^{4}+\cdots\right]
\end{aligned}
$$

Consolidating the terms on the right hand side of Equation A24,

$$
\begin{aligned}
r_{t}-r_{f}=\phi \gamma \sigma^{2} & +\lambda_{t} E_{v}\left[2(\phi-\gamma) Z+(\phi Z)^{2}-\phi \gamma Z^{2}+(\gamma Z)^{2}\right] \\
& +\lambda_{t} E_{v}\left[\frac{1}{3 !}((\phi-\gamma) Z)^{3}+\frac{1}{4 !}((\phi-\gamma) Z)^{4}+\frac{1}{3 !}(\phi Z)^{3}+\frac{1}{4 !}(\phi Z)^{4}\right. \\
& \left.-\frac{1}{3 !}(\gamma Z)^{3}+\frac{1}{4 !}(\gamma Z)^{4}+\cdots\right]
\end{aligned}
$$


where $\phi \lambda \sigma^{2}$ is the equity premium in the standard model with normally distributed consumption growth, and the second and third term are the impact factor that arises from the risk of a disaster. Specifically, $\lambda_{t} E_{v}\left[2(\phi-\gamma) Z+(\phi Z)^{2}-\phi \gamma Z^{2}+(\gamma Z)^{2}\right]$ captures the large changes in equity risk premium from quadratic variation, and $\lambda_{t} E_{v}\left[\frac{1}{3 !}((\phi-\gamma) Z)^{3}+\frac{1}{4 !}((\phi-\gamma) Z)^{4}+\frac{1}{3 !}(\phi Z)^{3}+\right.$ $\left.\frac{1}{4 !}(\phi Z)^{4}-\frac{1}{3 !}(\gamma Z)^{3}+\frac{1}{4 !}(\gamma Z)^{4}+\cdots\right]$ captures the large instantaneous changes in equity risk premium from tail variation. To simplify the equation, let $\lambda_{t} E_{v}[\Pi]$ denote $\lambda_{t} E_{v}\left[\frac{1}{3 !}((\phi-\gamma) Z)^{3}+\right.$ $\left.\frac{1}{4 !}((\phi-\gamma) Z)^{4}+\frac{1}{3 !}(\phi Z)^{3}+\frac{1}{4 !}(\phi Z)^{4}-\frac{1}{3 !}(\gamma Z)^{3}+\frac{1}{4 !}(\gamma Z)^{4}+\cdots\right]$ as the jumps in price from tail variation. And the equity risk premium can be rewritten as

$$
r_{t}-r_{f}=\phi \gamma \sigma^{2}+\lambda_{t} E_{v}\left[2(\phi-\gamma) Z+(\phi Z)^{2}-\phi \gamma Z^{2}+(\gamma Z)^{2}\right]+\lambda_{t} E_{v}[\Pi]
$$




\section{APPENDIX B}

\section{Supplementary Appendix to "The Impact of Monetary Policy Surprises on Aggregate Tail Risk Aversion"}

B.1 This appendix provides additional details of a simplified version of how volatility and tail risk aversion components are defined and derived.

Let $R_{t+1}=\frac{P_{t+1}-P_{t}}{P_{t}}$ be the forward arithmetic return, and $r_{t+1}=\ln \left(\frac{P_{t+1}-P_{t}}{P_{t}}\right)$ be the logarithmic forward return over a holding period from t to t+1. I assume that asset returns follow Merton's (1976) diffusion-jump process,

$$
\begin{aligned}
& R_{t+1}=\int_{t}^{t+1}\left[\alpha-\lambda \mu_{J}\right] d t+\int_{t}^{t+1} \sigma d B_{t}+\int_{t}^{t+1} \int_{\mathbb{R}^{0}} e^{x}-1 \mu[d x, d t] \\
& r_{t+1}=\int_{t}^{t+1}\left[\alpha-\frac{1}{2} \sigma^{2}-\lambda \mu_{J}\right] d t+\int_{t}^{t+1} \sigma d B_{t}+\int_{t}^{t+1} \int_{\mathbb{R}^{0}} x \mu[d x, d t]
\end{aligned}
$$

where $\alpha$ is the instantaneous expected return of the asset, $\sigma$ is the volatility, $\lambda$ is the jump intensity, $B_{t}$ is the standard Brownian motion, $\mathbb{R}^{0}$ is the real line excluding zero, and $\mu[d x, d t]$ is the Poisson random measure for the compound Poisson process.

Taking the square of Equation A2 and by the Brownian motion properties, the quadratic returns, $r_{t+1}^{2}$, can be expressed as a sum of two decomposed components. The decomposed process of return variability is the quadratic variation $(\mathbb{Q V})$, and $r_{t+1}^{2}$ is the future realized outcome of the quadratic variation $\left(R V_{t+1}\right)$.

$$
\begin{aligned}
V U_{t+1}=R V_{t+1} & =\mathbb{Q} \mathbb{V}_{[t, t+1]}=r_{t+1}^{2}=\int_{t}^{t+1} \sigma^{2} d t+\int_{t}^{t+1} x^{2} \mu(d x, d t) \\
& =\mathbb{C} \mathbb{V}_{[t, t+1]}+\mathbb{\mathbb { Q }} \mathbb{V}_{[t, t+1]}
\end{aligned}
$$


where $\mathbb{C V}$ is the integrated value of continuously instant variance, and $\mathbb{Q} \mathbb{Q}$ is the integrated value of jump quadratic variability.

Following Bollerslev, Todorov, and Xu (2015), we can define that

$$
V R A_{t+1}=E_{t}^{\mathbb{Q}}\left(\mathbb{Q} \mathbb{V}_{[t, t+1]}\right)-E_{t}^{\mathbb{P}}\left(\mathbb{Q} \mathbb{V}_{[t, t+1]}\right)=V_{t}^{B K M}-E_{t}^{\mathbb{P}}\left(\mathbb{Q} \mathbb{V}_{[t, t+1]}\right)
$$

where $\mathbb{Q}, \mathbb{P}$ are (options based) risk-neutral space and physical probability space, respectively, and $V_{t}^{B K M}$ is an unbiased ex-ante estimate of quadratic variation. It serves as a risk premium proxy for ordinary price fluctuation with volatility jumps, and can be considered as rational risk-averse investors' compensation for holding risky assets.

Following Chow, Jiang, and Li (2016), we analogously extend the $\mathbb{Q V}$ to a generalized format of return variation expressed by a composite form of a higher order of the stochastic process. It is defined as the polynomial variation $(\mathbb{P} \mathbb{V}$, hereafter) of returns,

$\mathbb{P} \mathbb{V}_{[t, t+1]}=\int_{t}^{t+1} \sigma^{2}\left(d W_{t}\right)^{n}+\sum_{n=2}^{\infty} \frac{2}{n !} \int_{t}^{t+1} \int_{R^{0}} x^{n} \mu[d x, d t]=\mathbb{C} \mathbb{V}_{[t, t+1]}+\mathbb{J} \mathbb{P} \mathbb{V}_{[t, t+1]}$

The significance of the $\mathbb{P V}$ is that it redefines the VIX as a risk-neutral forward looking measure of the polynomial variation of log-returns. The $\mathbb{P V}$ is defined as a linear combination of all possible orders of return variability in a polynomial form, and $\mathbb{P} \mathbb{V}_{[t, t+1]}=\mathbb{Q} \mathbb{V}_{[t, t+1]}$ if $n=2$. $\mathbb{J P V} \mathbb{V}_{[t, t+1]}$ denotes the total predictable jumps of the $\mathbb{P V}$. Statistically, the difference between $\mathbb{P V}$ and $\mathbb{Q V}$ captures the tail thickness and other characteristics of the log-return distribution. The difference is defined as the tail variation ( $\mathbb{T} \mathbb{V}$, hereafter) or the physical measure of tail uncertainty (TU) of returns, 


$$
\begin{gathered}
T U_{t+1}=\mathbb{P V}_{[t, t+1]}-\mathbb{Q} \mathbb{V}_{[t, t+1]}=R V I X_{t+1}^{2}-R V_{t+1}=\sum_{n=2}^{\infty} \frac{2}{n !} \int_{t}^{t+1} \int_{R^{0}} x^{n} \mu[d x, d t] \\
=\sum_{n=3}^{\infty} \frac{2}{n !} r_{t+1}^{n}
\end{gathered}
$$

The expected TU is a polynomial sum of all higher order moments of an asset's log-return distribution.

$$
T R A_{t+1}=E_{t}^{\mathbb{Q}}\left(T U_{t+1}\right)-E_{t}^{\mathbb{P}}\left(T U_{t+1}\right)=\left(V I X_{t}^{2}-V_{t}^{B K M}\right)-E_{t}^{\mathbb{P}}\left(T U_{t+1}\right)
$$

where $E_{t}^{\mathbb{P}}\left(T U_{t+1}\right)=E_{t}^{\mathbb{P}}\left(\mathbb{P} \mathbb{V}_{[t, t+1]}\right)-E_{t}^{\mathbb{P}}\left(R V_{t+1}\right)=\sum_{n=3}^{\infty} \frac{2}{n !} E_{t}^{\mathbb{P}}\left(r_{t+1}^{n}\right)$

It serves as a compensation for expected tail jumps, and can be considered as rational risk-averse investors' required compensation for holding risky assets during rare events. 
B.2 This appendix provides additional impulse response functions using Structural VAR . Overall the responses to shocks are relatively short lived, and the results are consistent with previous literature.

Figure B.2.1 Impulse Responses to Stock Price with Long-run restriction on Monetary

Tail Risk Aversion

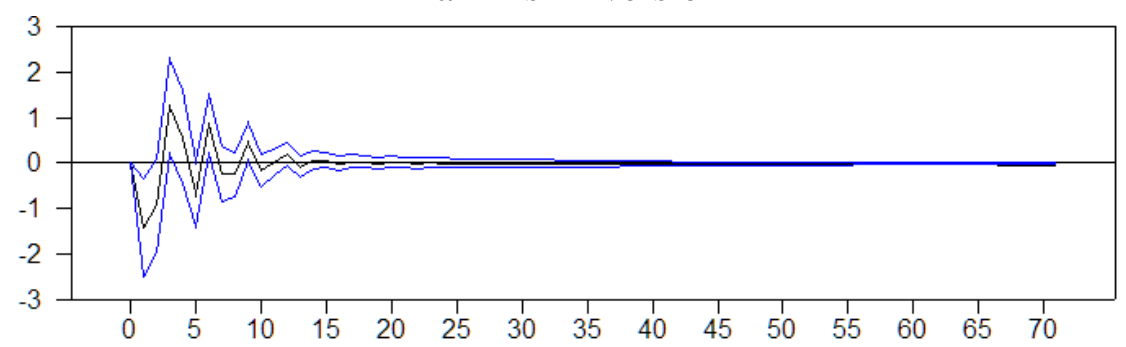

Stock Returns

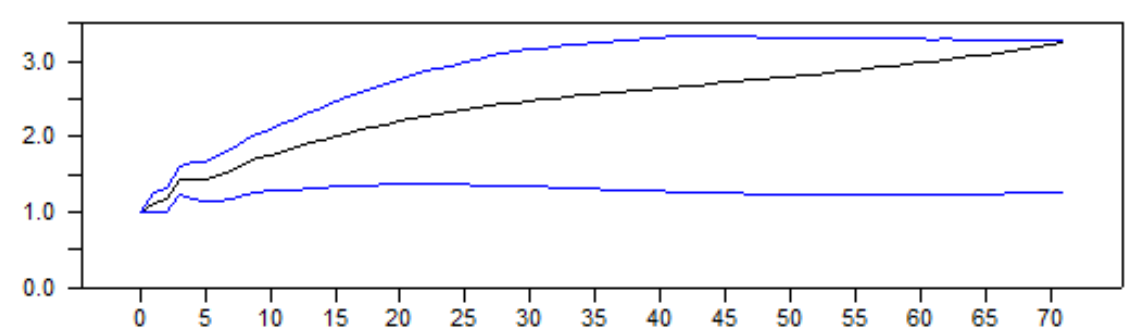
shock.
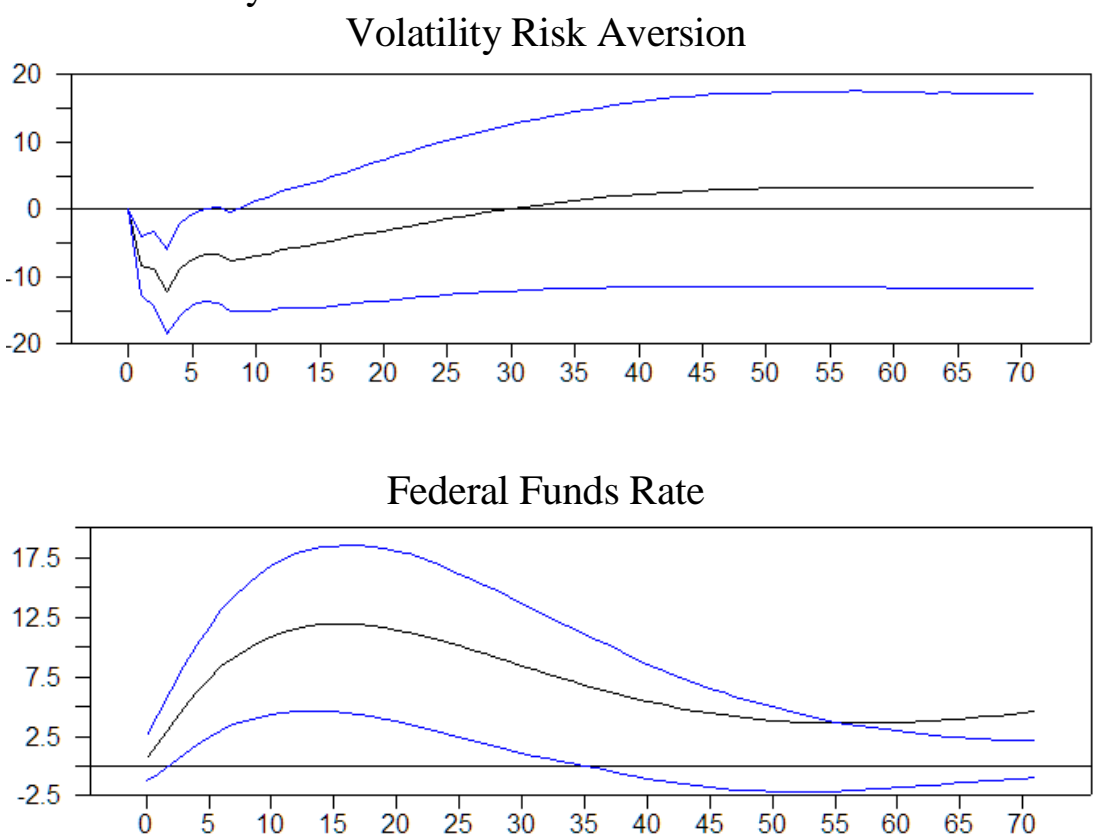
Figure B.2.2 Impulse Responses to Monetary Policy with Long-run restriction on Monetary

Tail Risk Aversion

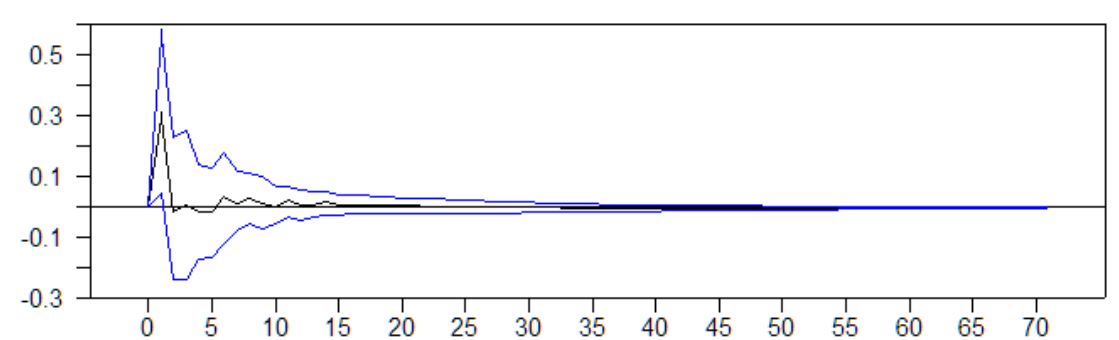

Stock Returns
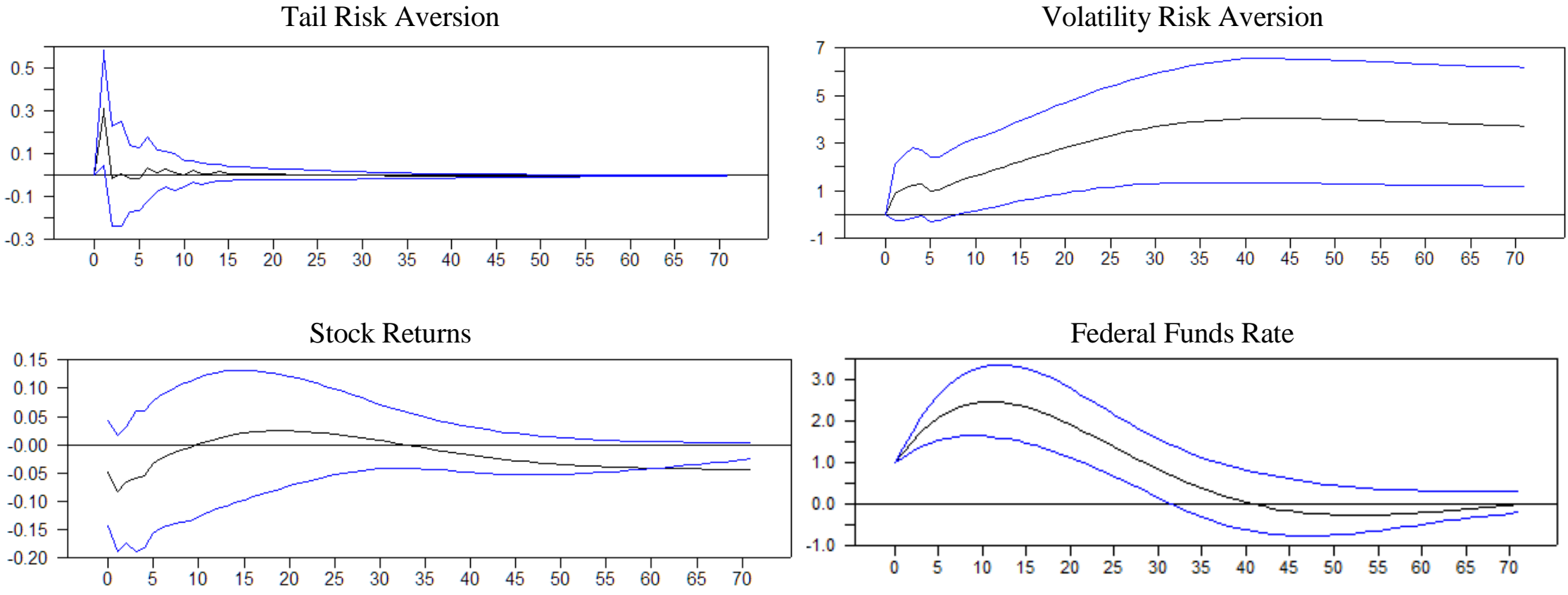

Figure B.2.2. Impulse responses for the federal funds rate, the stock prices, volatility risk aversion and tail risk aversion from a monetary policy shock.

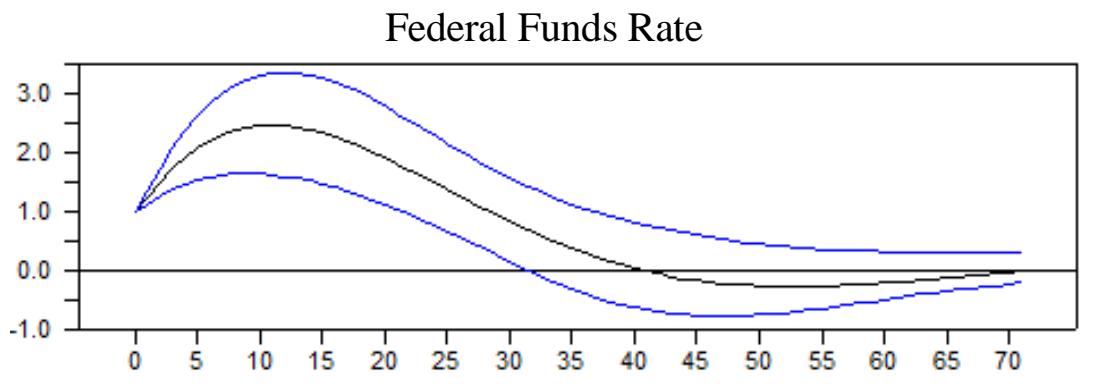


Figure B.2.3 Impulse Responses to Tail Risk Aversion with Long-run restriction on Monetary
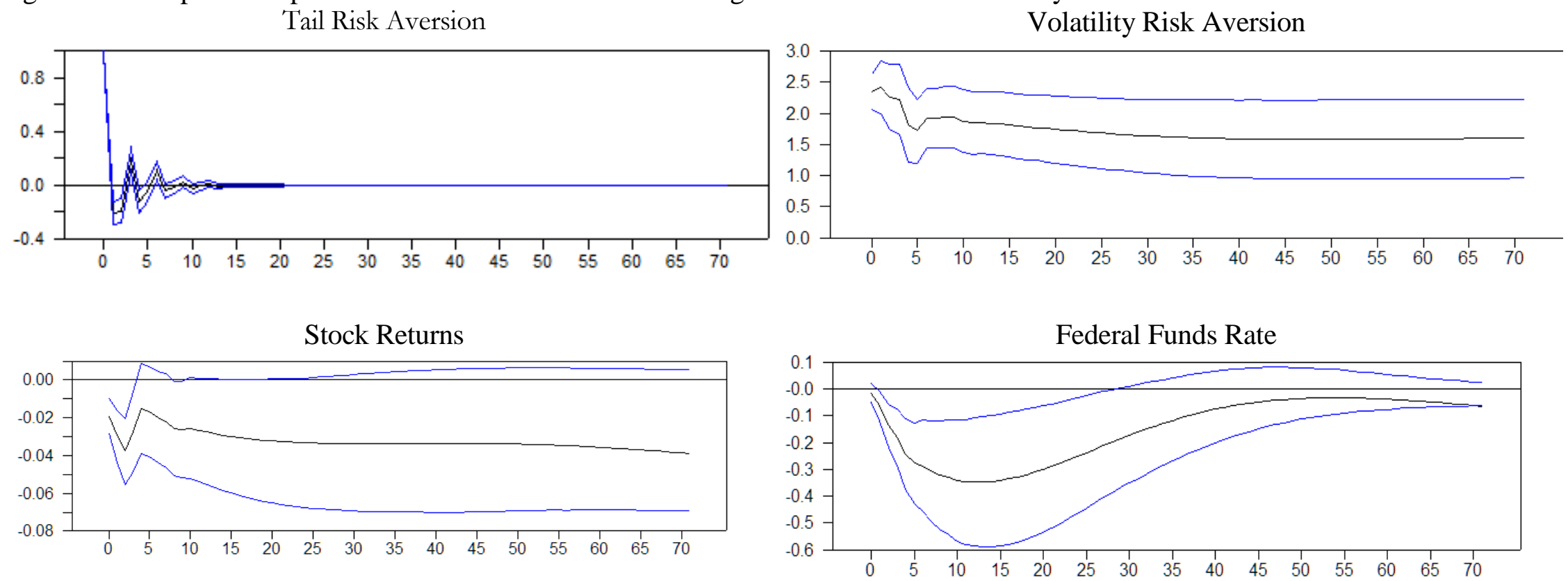

Figure B.2.3. Impulse responses for the federal funds rate, volatility risk aversion, the stock prices, and inflation from the tail risk aversion shock. 
Figure B.2.4 Impulse Responses to Volatility Risk Aversion with Long-run restriction on Monetary

Tail Risk Aversion

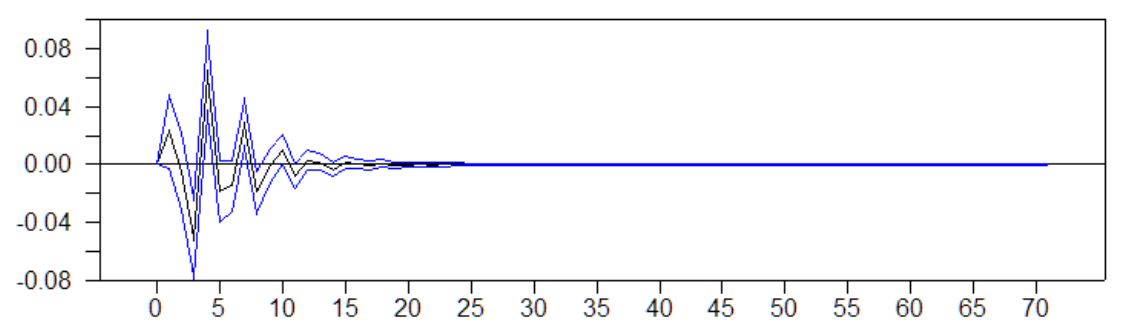

Stock Returns

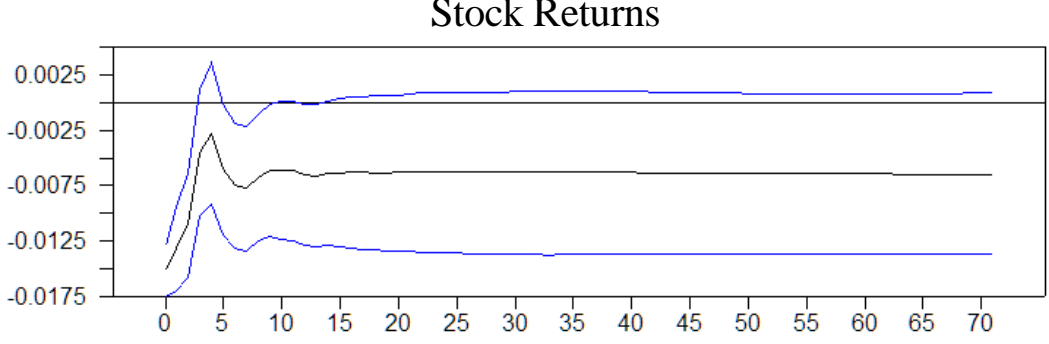

Volatility Risk Aversion

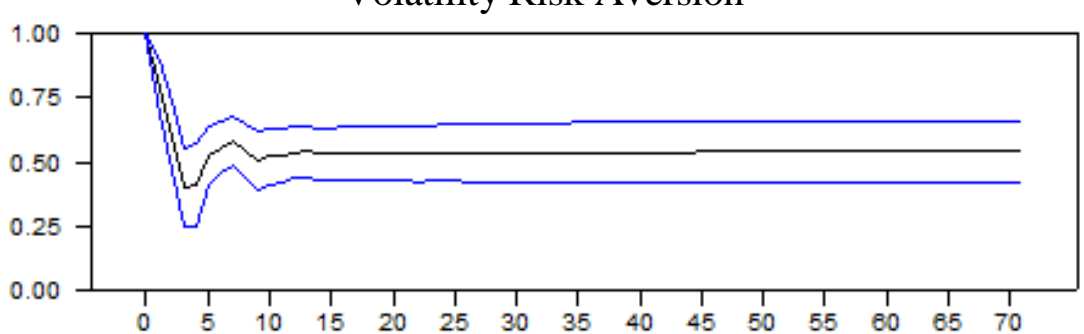

Federal Funds Rate

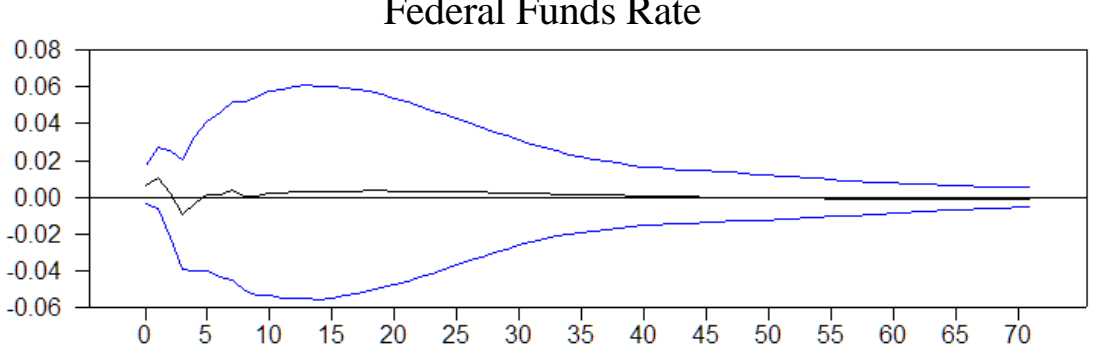

Figure B.2.4. Impulse responses for tail risk aversion, federal funds rate, stock prices, and inflation from the volatility risk aversion shock. 
Figure B.2.5. Impulse Responses to Stock Price with Long-run restriction on Tail Risk Aversion

Tail Risk Aversion

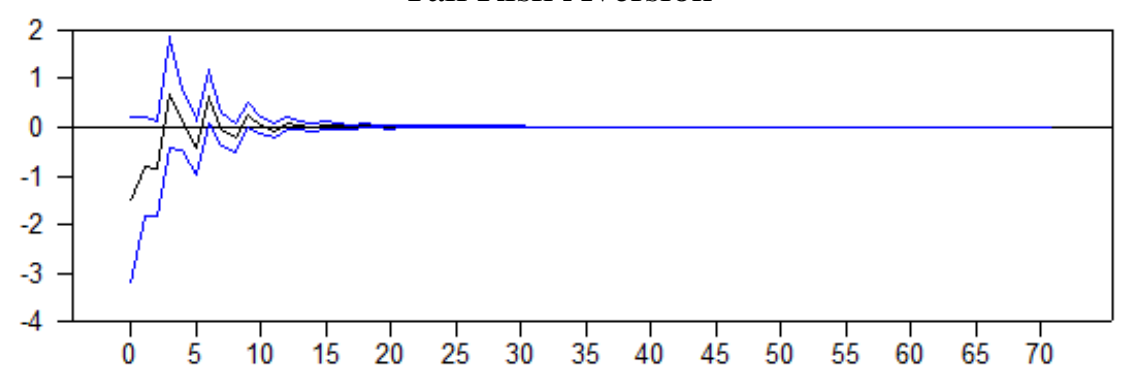

Stock Returns

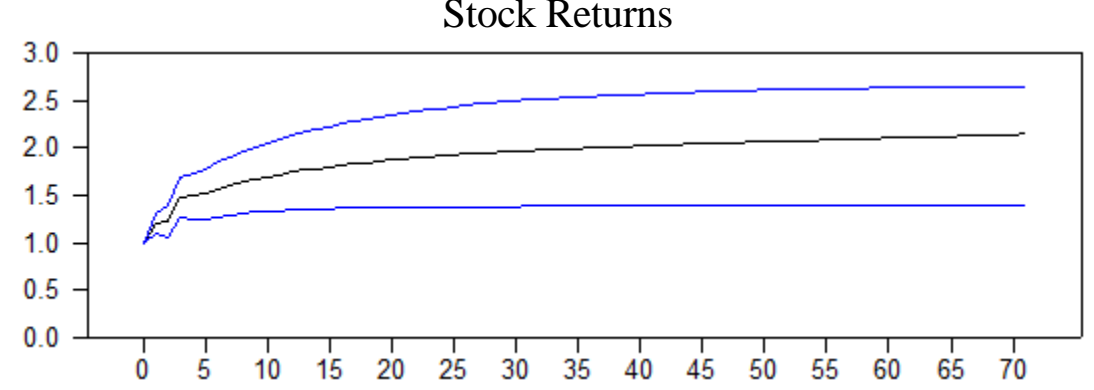

Volatility Risk Aversion

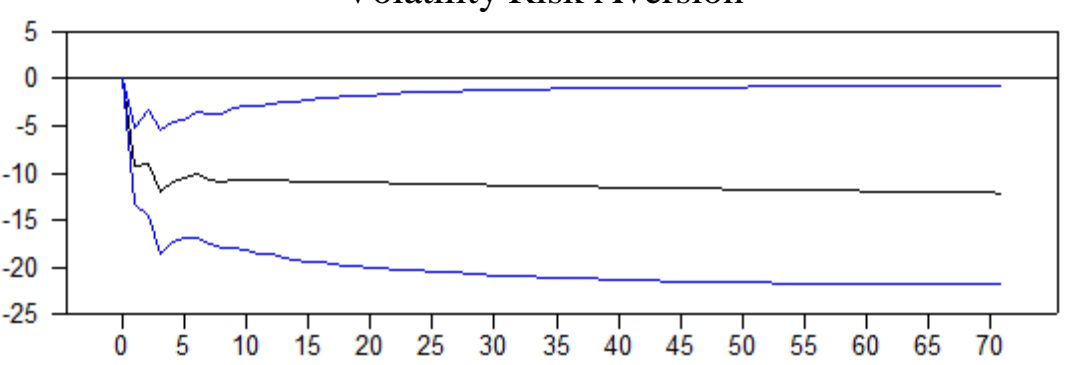

Federal Funds Rate

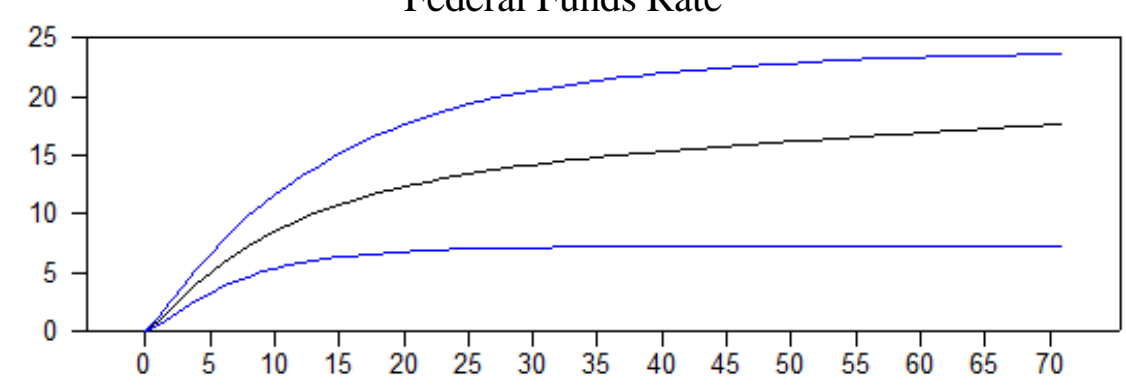

Figure B.2.5. Impulse responses for the federal funds rate, the stock prices, volatility risk aversion and tail risk aversion from a stock price shock with long-run restriction on tail risk aversion. The time period for the VAR analysis is January 1994 to December 2014. 
Figure B.2.6. Impulse Responses to Monetary Policy with Long-run restriction on Tail Risk Aversion

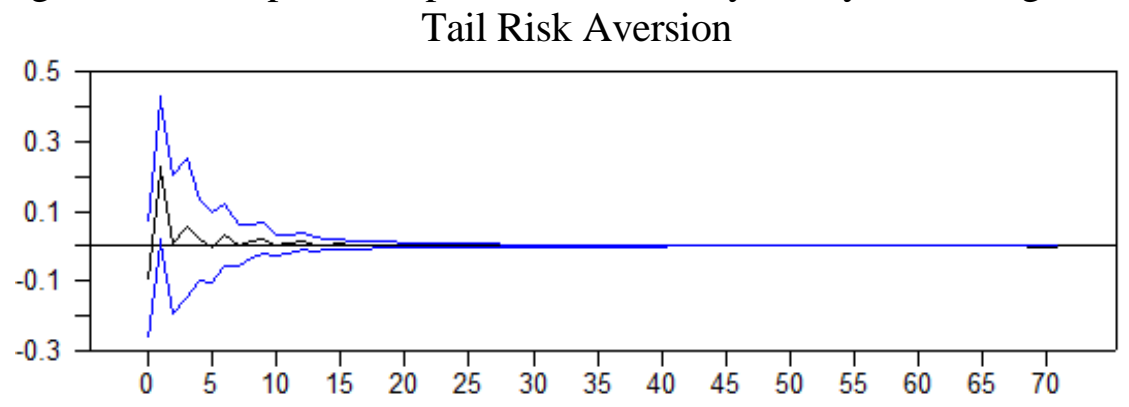

Volatility Risk Aversion

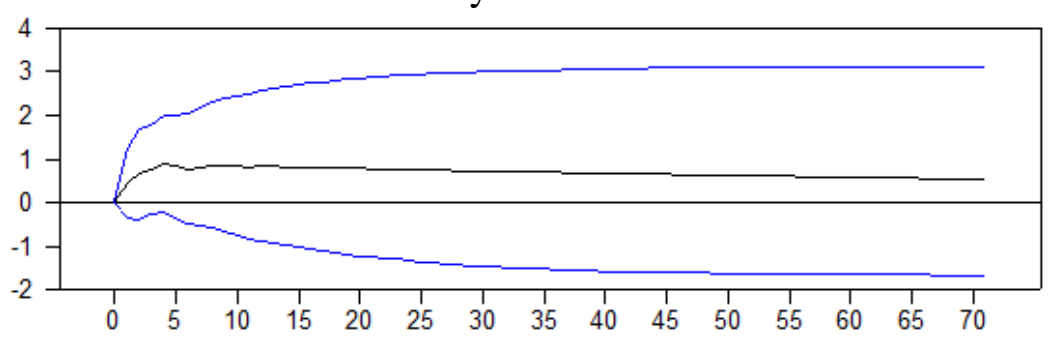

Stock Returns
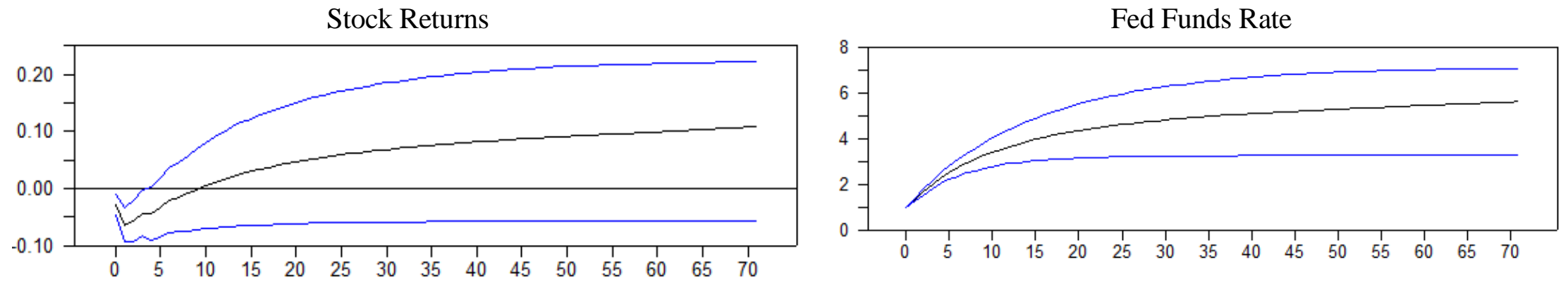

Figure B.2.6. Impulse responses for the federal funds rate, the stock prices, volatility risk aversion and tail risk aversion from a monetary policy shock with long-run restriction on tail risk aversion. The time period for the VAR analysis is January 1994 to December 2014. 
Figure B.2.7. Impulse Responses to Tail Risk Aversion with Long-run restriction on Tail Risk Aversion

Tail Risk Aversion

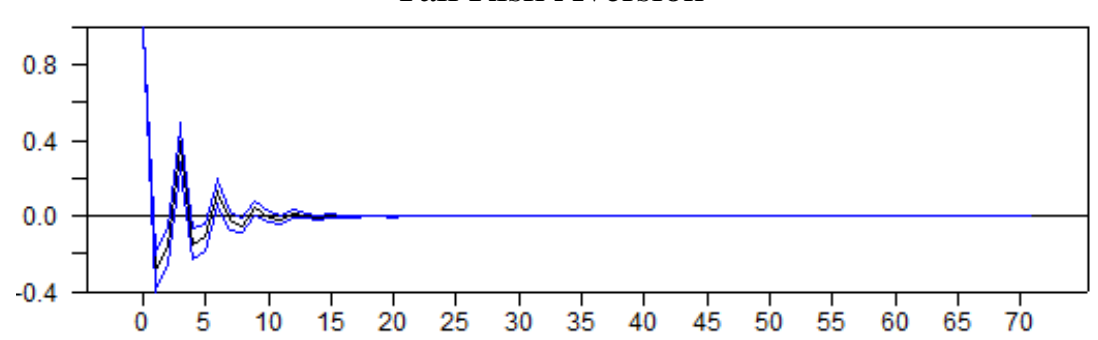

Stock Returns

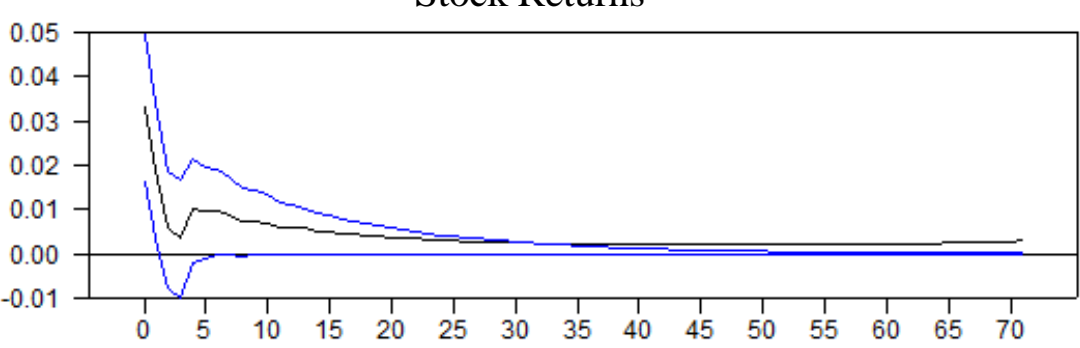

Volatility Risk Aversion

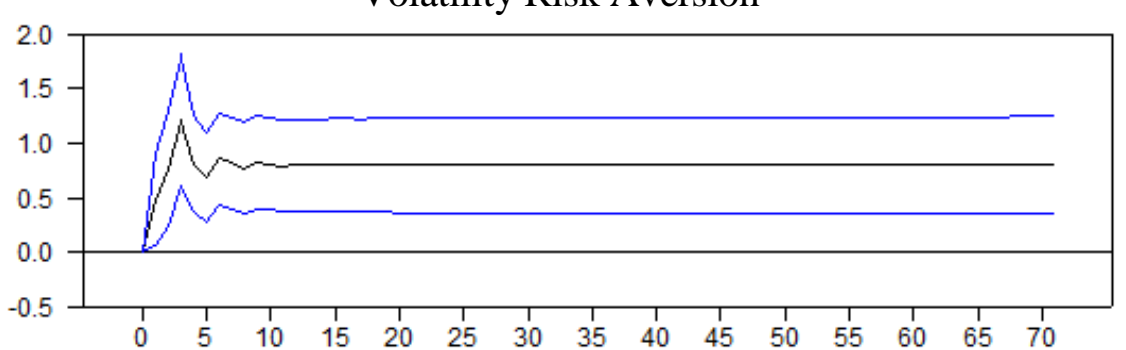

Federal Funds Rate

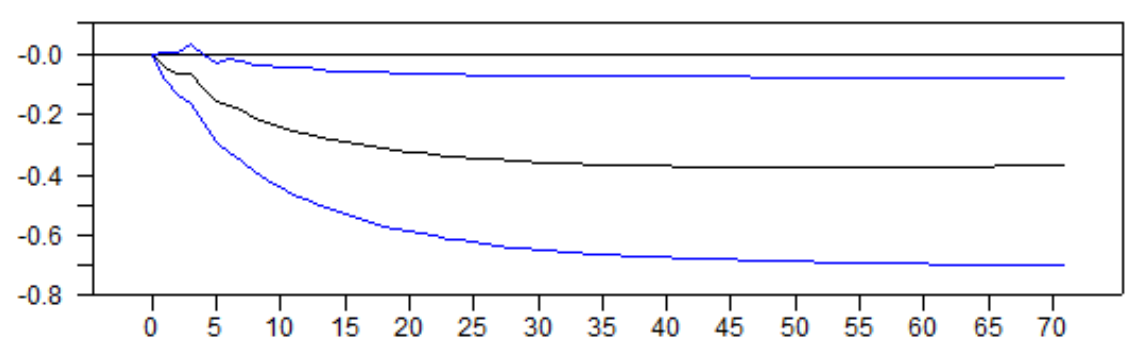

Figure B.2.7. Impulse responses for the federal funds rate, volatility risk aversion, the stock prices, and inflation from the tail risk aversion shock with long-run restriction on tail risk aversion. The time period for the VAR analysis is January 1994 to December 2014. 
Figure B.2.8. Impulse Responses to Volatility Risk Aversion with Long-run restriction on Tail Risk Aversion

Tail Risk Aversion

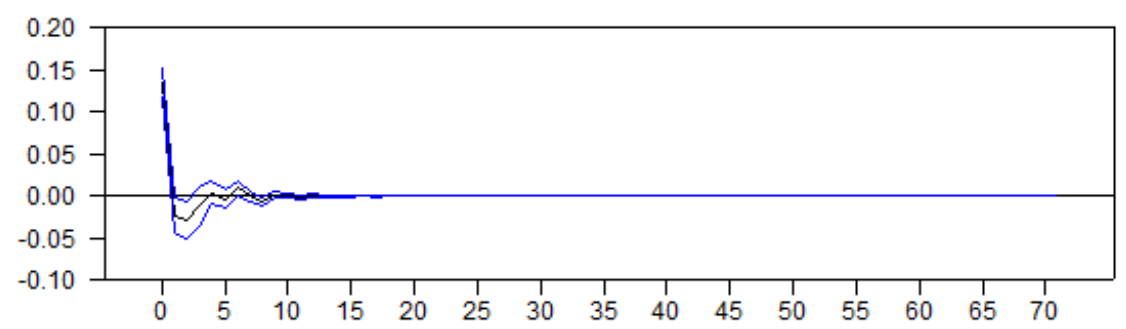

Stock Returns

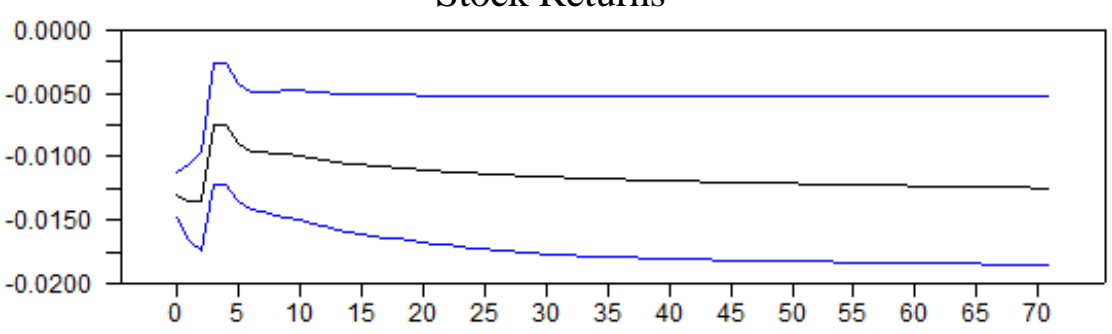

Volatility Risk Aversion

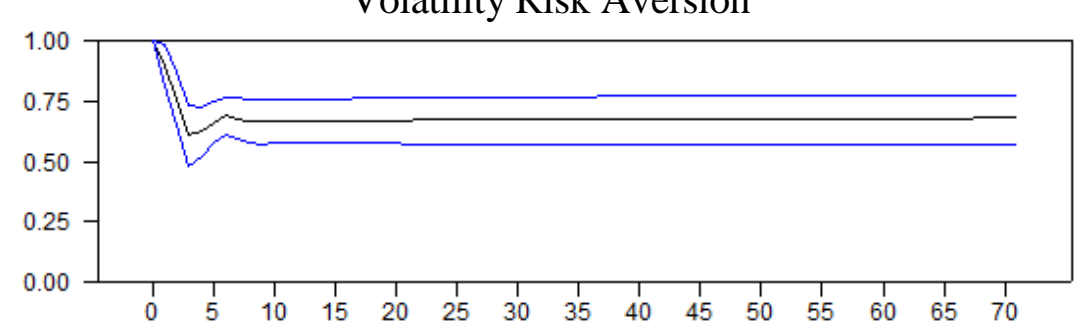

Federal Funds Rate

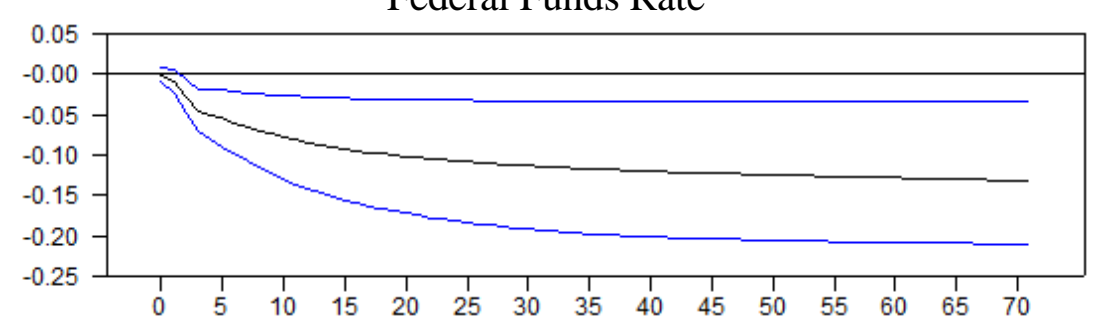

Figure B.2.8. Impulse responses for tail risk aversion, federal funds rate, stock prices, and federal funds rate from the volatility risk aversion shock with long-run restriction on tail risk aversion. The time period for the VAR analysis is January 1994 to December 2014. 


\section{Appendix C}

\section{Supplementary Appendix to "Does Investor Sentiment Affect the Market Reaction to Macroeconomic News?"}

Appendix C1 This appendix provides a derivation of dividend constant growth model with noise trader incorporated.

Taking partial derivative of Equation (5) yields the following equation

$$
\frac{d P}{d u}=\frac{d P}{d r} \frac{d r}{d u}+\frac{d P}{d \pi} \frac{d \pi}{d u}+\frac{d P}{d \phi} \frac{d \phi}{d u}+\frac{d P}{d g} \frac{d g}{d u}+\frac{d P}{d \hat{g}} \frac{d \hat{g}}{d u}
$$

We assume that the risk premium investors required to invest in risky assets, the cost of arbitrage, and dividend growth rate are not affected by news surprises, then $\frac{d \pi}{d u}=\frac{d \phi}{d u}=\frac{d g}{d u}=0$. In order to simplify the derivation steps, we follow Boyd et al. (2005) and define that components of stock price response that is strictly due to a change in the expected interest rate on long-term risk-free claims $r$ and the growth rate of shares demanded by noise traders $\hat{g}$.

$$
\left.\frac{d P}{d u}\right|_{d \pi=d \phi=d g=0}=\left[-\frac{D(1+g)}{(r+\pi+\phi-g)^{2}}-\frac{\phi Y(1+\widehat{g})}{(r+\pi+\phi-\widehat{g})^{2}}\right] \frac{d r}{d u}+\frac{\phi Y(r+\pi+\phi-\widehat{g})+\phi Y(1+\hat{g})}{(r+\pi+\phi-\hat{g})^{2}} \frac{d \widehat{g}}{d u}
$$

Consolidating Equation (A2), we have

$$
\left.\frac{d P}{d u}\right|_{d \pi=d \phi=d g=0}=-\left[\frac{D(1+g)}{(r+\pi+\phi-g)^{2}}+\frac{\phi Y(1+\widehat{g})}{(r+\pi+\phi-\widehat{g})^{2}}\right] \frac{d r}{d u}+\frac{\phi Y(1+r+\pi+\phi)}{(r+\pi+\phi-\widehat{g})^{2}} \frac{d \widehat{g}}{d u}
$$

Divide both sides of Equation (A3) by P,

$$
\left.\frac{d P / P}{d u}\right|_{d \pi=d \phi=d g=0}=-\left[\frac{D(1+g)}{P(r+\pi+\phi-g)^{2}}+\frac{\phi Y(1+\widehat{g})}{P(r+\pi+\phi-\widehat{g})^{2}}\right] \frac{d r}{d u}+\frac{\phi Y(1+r+\pi+\phi)}{P(r+\pi+\phi-\widehat{g})^{2}} \frac{d \widehat{g}}{d u}
$$

\footnotetext{
${ }^{15}$ Under efficient market model, $\phi$ equals to zero. If $\phi=0$, the efficient market model emerges, and Equation (A4) becomes $\frac{d P / P}{d u}=-\frac{D(1+g)}{P(r+\pi-g)^{2}}\left[\frac{d r}{d u}+\frac{d \pi}{d u}-\left(1+\frac{r+\pi-g}{1+g}\right) \frac{d g}{d u}\right]$. Rewrite Equation (4) as $P /[D(1+g)]=1 /(r+\pi-$ $g$ ) and substitute into previous equation, then we have $\frac{d P / P}{d u}=-\frac{P}{D} \frac{1}{1+g}\left[\frac{d r}{d u}+\frac{d \pi}{d u}-\left(1+\frac{D}{P}\right) \frac{d g}{d u}\right]$. Equation (A4) becomes exactly the same as Equation (3a) in Boyd, Hu, and Jagannathan (2005).
} 
Both Shiller (1984) and Lee (2001) show that the market clears when total shares demanded equals to supplied, such that $Q_{t}+Y_{t} / P_{t}=1$, and the total shares demanded by noise traders is $Y_{t} / P_{t}=$ $1-Q_{t}$ when the market clears. We can rewrite Equation (A4)

$$
\left.\frac{d P / P}{d u}\right|_{d \pi=d \phi=d g=0}=-\left[\frac{D(1+g)}{P(r+\pi+\phi-g)^{2}}+\frac{\phi\left(1-Q_{t}\right)(1+\widehat{g})}{(r+\pi+\phi-\widehat{g})^{2}}\right] \frac{d r}{d u}+\left[\frac{\phi\left(1-Q_{t}\right)(1+r+\pi+\phi)}{(r+\pi+\phi-\widehat{g})^{2}}\right] \frac{d \widehat{g}}{d u}
$$

To show the components of stock price response to a change in the expected interest rate on longterm risk-free claims $r$ and the growth rate of shares demanded by noise traders $\hat{g}$ separately, we can rewrite Equation (C5),

$$
\begin{aligned}
& \left.\frac{d P / P}{d u}\right|_{d \pi=d \phi=d g=d \widehat{g}=0}=-\left[\frac{D(1+g)}{P(r+\pi+\phi-g)^{2}}+\frac{\phi\left(1-Q_{t}\right)(1+\widehat{g})}{(r+\pi+\phi-\widehat{g})^{2}}\right] \frac{d r}{d u} \\
& \left.\frac{d P / P}{d u}\right|_{d r=d \pi=d \phi=d g=0}=\left[\frac{\phi\left(1-Q_{t}\right)(1+r+\pi+\phi)}{(r+\pi+\phi-\widehat{g})^{2}}\right] \frac{d \widehat{g}}{d u}
\end{aligned}
$$

In general, when good news surprises hit markets, it indicates improving future economic conditions. Rational investors would expect Federal Reserve to raise short-term Federal Funds rate, which leads an increase in risk-free rate, and it implies that $d r / d u>0$. 
Appendix C.2 Supplementary Tables without independent sentiment dummy variables

Table C2.1. Response of E-mini S\&P 500 to Macroeconomic News Surprises Conditional on Investor Sentiment

\begin{tabular}{|c|c|c|c|c|c|c|}
\hline \multirow[b]{2}{*}{ Announcement } & \multicolumn{3}{|c|}{ AAII Sentiment Index } & \multicolumn{2}{|c|}{ Investor Intelligence } & Sentiment Index \\
\hline & $b_{i}$ & $c_{i}$ & $d_{i}$ & $b_{i}$ & $c_{i}$ & $d_{i}$ \\
\hline GDP advance final preliminary & $0.149 * * *$ & -0.023 & -0.098 & 0.071 & 0.091 & 0.028 \\
\hline Initial unemployment claims & $0.061 * * *$ & -0.006 & -0.025 & $0.031 * *$ & $0.069 * *$ & $0.033^{*}$ \\
\hline Nonfarm employment & 0.108 & 0.135 & -0.026 & 0.058 & 0.119 & $0.189 * *$ \\
\hline Unemployment Rate & -0.016 & $0.255^{*} * *$ & 0.043 & 0.051 & $0.177 *$ & 0.041 \\
\hline ADP employment & $0.174 * * *$ & -0.037 & $-0.086 * *$ & $0.162 * * *$ & 0.024 & $-0.142 *$ \\
\hline Advance retail sales & $0.086 * *$ & 0.034 & $0.107 *$ & $0.079 * *$ & $0.107 * *$ & 0.005 \\
\hline Existing home sales & $0.061 * * *$ & 0.078 & $-0.065^{* *}$ & $0.052 * *$ & 0.100 & 0.030 \\
\hline Industrial production & $0.028 * *$ & 0.051 & -0.014 & 0.022 & 0.054 & 0.009 \\
\hline Consumer Credit & $0.044 *$ & -0.004 & $-0.058 * *$ & 0.018 & 0.055 & -0.022 \\
\hline New home sales & $0.045^{* *}$ & 0.016 & -0.035 & $0.040 * *$ & 0.052 & -0.036 \\
\hline Factory orders & $0.034 *$ & 0.042 & -0.001 & 0.004 & $0.109 * * *$ & 0.019 \\
\hline Consumer price index & $-0.066 *$ & -0.045 & 0.012 & $-0.073 * * *$ & 0.008 & -0.036 \\
\hline ISM Manufacturing & $0.112 * * *$ & $0.105^{*}$ & $-0.097 *$ & $0.107 * * *$ & 0.099 & -0.044 \\
\hline ISM Non-manufacturing & $0.060 * *$ & 0.046 & -0.035 & $0.046 *$ & 0.081 & 0.032 \\
\hline Consumer confidence & $0.159 * * *$ & 0.017 & -0.071 & $0.144 * * *$ & 0.046 & -0.054 \\
\hline U. of Michigan Conf-Prelim & 0.044 & -0.018 & $-0.087 *$ & 0.035 & -0.006 & -0.042 \\
\hline Pending home sales & $0.076 * * *$ & 0.042 & -0.023 & $0.072 * * *$ & 0.100 & -0.039 \\
\hline Empire Manufacturing & $0.064 * * *$ & 0.041 & 0.002 & $0.058 * *$ & 0.040 & 0.027 \\
\hline Philadelphia Fed Business Outlook & $0.093 * * *$ & $0.079 *$ & -0.066 & $0.066^{* *}$ & $0.110^{*}$ & -0.006 \\
\hline Chicago Purchasing Manager Index & $0.116^{* * *} *$ & 0.026 & -0.059 & $0.109 * * *$ & 0.097 & $-0.068 *$ \\
\hline$R^{2}$ & \multicolumn{2}{|c|}{$16.61 \%$} & & \multicolumn{3}{|c|}{$16.93 \%$} \\
\hline $\mathrm{N}$ & \multicolumn{2}{|c|}{2906} & & \multicolumn{3}{|c|}{2901} \\
\hline
\end{tabular}

The table reports estimates for the following model: $R_{t}=\alpha+\sum_{i=1}^{I}\left(b_{i}+c_{i} I N V_{t}^{\text {low }}+d_{i} I N V_{t}^{\text {high }}\right) S_{i t}+\varepsilon_{t}$, where $R_{t}$ is the continuously compounded ten-minute return of the E-mini S\&P 500. $S_{i t}$ is the standardized surprise for the news announcement $i$. IN $V_{t}^{\text {low }}$ is a dummy variable equal to 1 on days when the investor sentiment measure is below the 25 th percentile, $I N V_{t}^{\text {high }}$ equals to one on days when the investor sentiment measure is above the 75 th percentile, and $I N V_{t}^{\text {normal }}$ equals to one on days when the investor sentiment is between $25^{\text {th }}$ and $75^{\text {th }}$ percentile. The sample period is from January 1998 to September 2016. *,**, and *** denote significance at $10 \%, 5 \%$, and $1 \%$ levels, respectively. 
Table C2.2. Average Effect of Investor Sentiment on Market Response to Macroeconomic News

\begin{tabular}{|c|c|c|}
\hline & AAII Sentiment Index & $\begin{array}{l}\text { Investor Intelligence } \\
\text { Sentiment Index }\end{array}$ \\
\hline Variables & $\begin{array}{c}\text { Coefficient Estimates } \\
\text { (t-statistics) }\end{array}$ & $\begin{array}{c}\text { Coefficient Estimates } \\
\text { (t-statistics) }\end{array}$ \\
\hline Intercept & $\begin{array}{l}0.002 \\
(0.46)\end{array}$ & $\begin{array}{l}0.002 \\
(0.44)\end{array}$ \\
\hline$S_{t}$ & $\begin{array}{c}1.000 * * * \\
(10.66)\end{array}$ & $\begin{array}{c}1.000 * * * \\
(8.93)\end{array}$ \\
\hline$I N V_{t}^{\text {low }} * S_{t}$ & $\begin{array}{c}0.39 * * * \\
(2.56)\end{array}$ & $\begin{array}{c}0.80 * * * \\
(3.86)\end{array}$ \\
\hline$I N V_{t}^{h i g h} * S_{t}$ & $\begin{array}{c}-0.546^{* * * *} \\
(-3.43) \\
\end{array}$ & $\begin{array}{l}-0.29^{*} \\
(-1.89) \\
\end{array}$ \\
\hline$R^{2}$ & $13.91 \%$ & $14.45 \%$ \\
\hline $\mathrm{N}$ & 2906 & 2901 \\
\hline
\end{tabular}

The table reports estimates for the following model: $R_{t}=\alpha+b \sum_{i=1}^{20} \widehat{b_{0} S_{l t}}+c \sum_{i=1}^{20} \widehat{b_{0} S_{l t}} I N V_{t}^{\text {low }}+$ $d \sum_{i=1}^{20} \widehat{b_{0} S_{l t}} I N V_{t}^{h i g h}+u_{t} . R_{t}$ is the continuously compounded return of the S\&P 500 futures. The returns changes are computed from five minutes before to five minutes after a macroeconomic news release. $S_{i t}$ is the standardized surprise for announcement $i . I N V_{t}^{\text {low }}$ is a dummy variable equal to 1 on days when the investor sentiment measure is below the 25 th percentile, $I N V_{t}^{\text {high }}$ equals to one on days when the investor sentiment measure is above the 75th percentile. The sample period is from January 1998 to September 2016.The regressions are estimated using OLS with White (1980) heteroskedasticity consistent covariance matrix. *, **, and $* * *$ denote significance at 10 percent, 5 percent, and 1 percent levels, respectively. 
Table C.2.3. Market Response to Positive Macroeconomic News Surprises Conditional on Investor Sentiment

\begin{tabular}{|c|c|c|c|c|c|c|}
\hline \multirow[b]{2}{*}{ Announcement } & \multicolumn{3}{|c|}{ AAII Sentiment Index } & \multicolumn{3}{|c|}{ Investor Intelligence Sentiment Index } \\
\hline & Normal & Low & High & Normal & Low & High \\
\hline GDP advance final preliminary & $0.11^{* * *}$ & $0.19 * * *$ & -0.01 & -0.017 & $0.184 * * *$ & $0.1058 * * *$ \\
\hline Initial unemployment claims & $0.03 * *$ & $0.04 * *$ & 0.01 & 0.013 & $0.065 * * *$ & 0.0182 \\
\hline Nonfarm employment & 0.15 & $0.52 * * *$ & $0.21 * *$ & 0.201 & $0.282 * *$ & 0.1265 \\
\hline Unemployment Rate & -0.05 & 0.10 & -0.01 & 0.003 & 0.170 & -0.0699 \\
\hline ADP employment & $0.14 * *$ & $0.10 * * *$ & 0.01 & 0.045 & $0.205 * * *$ & $-0.0509 *$ \\
\hline Advance retail sales & $0.04 * *$ & $0.12 * * *$ & $0.13 * * *$ & $0.052 * *$ & $0.154 * * *$ & 0.0164 \\
\hline Existing home sales & 0.05 & $0.19 * *$ & $-0.05^{* *}$ & -0.038 & $0.286 * * *$ & 0.0938 \\
\hline Industrial production & -0.01 & $0.09 * *$ & $-0.03 * *$ & 0.002 & 0.064 & -0.0050 \\
\hline Consumer Credit & 0.02 & -0.02 & $-0.03^{*}$ & -0.013 & 0.026 & $-0.0517 * * *$ \\
\hline New home sales & $0.05 *$ & 0.02 & -0.01 & 0.008 & $0.124 * *$ & -0.0008 \\
\hline Factory orders & -0.01 & $0.09 *$ & 0.02 & -0.001 & $0.096 * *$ & -0.0078 \\
\hline Consumer price index & $-0.16 * * *$ & -0.06 & -0.08 & -0.068 & $-0.169 * * *$ & -0.0676 \\
\hline ISM Manufacturing & 0.07 & $0.24 * * *$ & 0.03 & $0.088 * *$ & $0.251 * *$ & -0.0004 \\
\hline ISM Non-manufacturing & -0.04 & $0.11 *$ & 0.00 & -0.004 & 0.088 & -0.0345 \\
\hline Consumer confidence & -0.01 & $0.16^{* * *}$ & $0.07 * *$ & $0.093 * *$ & $0.093^{*}$ & 0.0284 \\
\hline U. of Michigan Conf-Prelim & -0.02 & -0.08 & $-0.09 * * *$ & -0.054 & -0.063 & $-0.0592 *$ \\
\hline Pending home sales & 0.07 & 0.12 & $0.10 * * *$ & 0.045 & $0.228 * *$ & $0.0579 * *$ \\
\hline Empire Manufacturing & $0.05^{* * *}$ & $0.13 * *$ & $0.06 * *$ & $0.044^{*}$ & $0.048 * *$ & $0.0927 * * *$ \\
\hline Philadelphia Fed Business Outlook & 0.04 & $0.09 * *$ & 0.02 & 0.015 & $0.081^{*}$ & $0.0417 *$ \\
\hline Chicago Purchasing Manager Index & $0.11 * * *$ & 0.03 & 0.03 & $0.064 * *$ & $0.159 * * *$ & -0.0024 \\
\hline$R^{2}$ & $9.09 \%$ & & & $9.52 \%$ & & \\
\hline $\mathrm{N}$ & 1935 & & & 1931 & & \\
\hline
\end{tabular}

The table reports estimates for the following model: $R_{t}=\alpha+\sum_{i=1}^{I}\left(b_{i}+c_{i} I N V_{t}^{\text {low }}+d_{i} I N V_{t}^{\text {high }}\right) S_{i t}+\varepsilon_{t}$, where $R_{t}$ is the continuously compounded return of the S\&P 500 futures. $R_{t}$ is from five minutes before to five minutes after a macroeconomic announcement. $S_{i t}$ is the standardized positive surprise for the news announcement $i . I N V_{t}^{\text {low }}$ is a dummy variable equal to 1 on days when the investor sentiment measure is below the 25 th percentile, $I N V_{t}^{\text {high }}$ equals to one on days when the investor sentiment measure is above the 75 th percentile, and $I N V_{t}^{\text {normal }}$ equals to one on days when the investor sentiment is between $25^{\text {th }}$ and $75^{\text {th }}$ percentile. The sample period is from January 1998 to September 2016. *,**, and *** denote significance at 10\%, 5\%, and $1 \%$ levels, respectively. 
Table C.2.4. Market Response to Negative Macroeconomic News Surprises Conditional on Investor Sentiment

\begin{tabular}{|c|c|c|c|c|c|c|}
\hline \multirow[b]{2}{*}{ Announcement } & \multicolumn{3}{|c|}{ AAII Sentiment Index } & \multicolumn{3}{|c|}{ Investor Intelligence Sentiment Index } \\
\hline & Normal & Low & High & Normal & Low & High \\
\hline GDP advance final preliminary & $0.113 * * *$ & $0.127 * * *$ & $0.172 * *$ & $0.147 * * *$ & $0.160 * * *$ & $0.091 * * *$ \\
\hline Initial unemployment claims & $0.082 * * *$ & $0.086 * * *$ & $0.046 * * *$ & $0.043 * *$ & $0.131 * * *$ & $0.086 * * *$ \\
\hline Nonfarm employment & $0.206^{* *}$ & $0.200 * * *$ & 0.086 & 0.070 & $0.189 * *$ & $0.291 * * *$ \\
\hline Unemployment Rate & 0.013 & $0.191 * *$ & -0.112 & 0.082 & 0.136 & -0.125 \\
\hline ADP employment & $0.136 * * *$ & $0.267 * * *$ & $0.319 * * *$ & $0.262 * * *$ & $0.190 * * *$ & $0.060 *$ \\
\hline Advance retail sales & $0.180 * * *$ & $0.148 * * *$ & $0.231 * * *$ & $0.219 * * *$ & $0.185^{* * *}$ & $0.115 * *$ \\
\hline Existing home sales & $0.087 * * *$ & $0.108 * *$ & $0.070 * *$ & $0.119 * * *$ & $0.105^{* *}$ & 0.036 \\
\hline Industrial production & $0.063 * * *$ & $0.046 * *$ & $0.067 * * *$ & $0.052 * * *$ & $0.069 * *$ & $0.055^{* * *}$ \\
\hline Consumer Credit & $0.066 * * *$ & $0.108 * *$ & 0.015 & $0.067 * * *$ & $0.108 * *$ & $0.039 * *$ \\
\hline New home sales & 0.037 & $0.116^{* * *}$ & 0.065 & $0.065^{* * *}$ & 0.057 & 0.022 \\
\hline Factory orders & $0.055^{* *}$ & $0.062 *$ & 0.061 & 0.003 & $0.105^{* * *}$ & $0.049 * *$ \\
\hline Consumer price index & -0.021 & $-0.165 * *$ & 0.009 & -0.021 & -0.078 & -0.041 \\
\hline ISM Manufacturing & $0.157 * * *$ & $0.195 * * *$ & -0.038 & $0.131 * *$ & $0.173 * * *$ & $0.137 * * *$ \\
\hline ISM Non-manufacturing & $0.142 * * *$ & 0.105 & $0.236^{*}$ & $0.147 * *$ & 0.108 & $0.142 * * *$ \\
\hline Consumer confidence & $0.274 * * *$ & $0.190 * * *$ & 0.102 & $0.204 * * *$ & $0.248 * * *$ & $0.160 * *$ \\
\hline U. of Michigan Conf-Prelim & $0.080^{*}$ & 0.109 & 0.006 & $0.086^{* *}$ & 0.091 & 0.038 \\
\hline Pending home sales & $0.060 * *$ & $0.097 * * *$ & 0.001 & $0.072 * * *$ & $0.129 * * *$ & 0.014 \\
\hline Empire Manufacturing & $0.072 * * *$ & $0.117 * * *$ & $0.075^{* *}$ & $0.071 * * *$ & $0.113 *$ & $0.089 * * *$ \\
\hline Philadelphia Fed Business Outlook & $0.130 * *$ & $0.208 * * *$ & 0.050 & $0.098 * *$ & $0.221 * * *$ & $0.080 * *$ \\
\hline Chicago Purchasing Manager Index & $0.105^{*}$ & $0.297 * * *$ & 0.037 & $0.145^{* * *}$ & $0.190 * *$ & $0.121 * *$ \\
\hline$\overline{R^{2}}$ & $17.61 \%$ & & & $16.82 \%$ & & \\
\hline $\mathrm{N}$ & 1742 & & & 1740 & & \\
\hline
\end{tabular}

The table reports estimates for the following model: $R_{t}=\alpha+\sum_{i=1}^{I}\left(b_{i}+c_{i} I N V_{t}^{\text {low }}+d_{i} I N V_{t}^{\text {high }}\right) S_{i t}+\varepsilon_{t}$, where $R_{t}$ is the continuously compounded return of the S\&P 500 futures. $R_{t}$ is from five minutes before to five minutes after a macroeconomic announcement. $S_{i t}$ is the standardized negative surprise for the news announcement $i . I N V_{t}^{\text {low }}$ is a dummy variable equal to 1 on days when the investor sentiment measure is below the 25 th percentile, $I N V_{t}^{\text {high }}$ equals to one on days when the investor sentiment measure is above the 75 th percentile, and $I N V_{t}^{\text {normal }}$ equals to one on days when the investor sentiment is between $25^{\text {th }}$ and $75^{\text {th }}$ percentile. The sample period is from January 1998 to September 2016. *,**, and *** denote significance at 10\%, 5\%, and 1\% levels, respectively. 
Table C.2.5. Average Effect of Investor Sentiment on Market Response to Positive Macroeconomic News

\begin{tabular}{|c|c|c|}
\hline \multirow[t]{2}{*}{ Variables } & AAII Sentiment Index & Investor Intelligence Sentiment \\
\hline & $\begin{array}{l}\text { Coefficient Estimates } \\
\text { (t-statistics) }\end{array}$ & $\begin{array}{l}\text { Coefficient Estimates } \\
\text { (t-statistics) }\end{array}$ \\
\hline Intercept & $\begin{array}{c}0.039 * * * \\
(6.28)\end{array}$ & $\begin{array}{c}0.041 \text { *** } \\
(6.81)\end{array}$ \\
\hline$S_{t}$ & $\begin{array}{c}0.91 * * * \\
(5.53)\end{array}$ & $\begin{array}{c}0.923 * * * \\
(4.33)\end{array}$ \\
\hline$S_{t} * I N V_{t}^{\text {low }}$ & & $\begin{array}{c}0.878^{* *} \\
(1.97)\end{array}$ \\
\hline$S_{t} * I N V_{t}^{h i g h}$ & $\begin{array}{l}-0.56^{* * *} \\
(-2.24)\end{array}$ & $\begin{array}{c}-0.687 * * \\
(-2.51)\end{array}$ \\
\hline$\overline{R^{2}}$ & $3.5 \%$ & $4.97 \%$ \\
\hline $\mathrm{N}$ & 1935 & 1931 \\
\hline \multicolumn{3}{|c|}{$\begin{array}{l}\text { The table reports estimates for the following model: } R_{t}=\alpha+b \sum_{i=1}^{20} \widehat{b_{0} S_{l t}}+ \\
c \sum_{i=1}^{20} \widehat{b_{0} S_{l t}} I N V_{t}^{\text {low }}+d \sum_{i=1}^{20} \widehat{b_{0} S_{l t}} I N V_{t}^{\text {high }}+u_{t} . R_{t} \text { is the continuously compounded return of } \\
\text { the } \mathrm{S} \& \mathrm{P} 500 \text { futures. The returns changes are computed from five minutes before to five minutes } \\
\text { after a macroeconomic news release. } S_{i t} \text { is the standardized positive surprise for announcement } i \text {. } \\
I N V_{t}^{\text {low }} \text { is a dummy variable equal to } 1 \text { on days when the investor sentiment measure is below the } \\
\text { 25th percentile, } I N V_{t}^{\text {high }} \text { equals to one on days when the investor sentiment measure is above the } \\
75 \text { th percentile. The sample period is from January } 1998 \text { to September } 2016 \text {. The regressions are } \\
\text { estimated using OLS with White (1980) heteroskedasticity consistent covariance matrix. *, **, and } \\
* * * \text { denote significance at } 10 \text { percent, } 5 \text { percent, and } 1 \text { percent levels, respectively. }\end{array}$} \\
\hline
\end{tabular}


Table C.2.6. Average Effect of Investor Sentiment on Market Response to Negative Macroeconomic News

\begin{tabular}{lcc}
\hline Variables & AAII Sentiment Index & Investor Intelligence \\
\hline & $\begin{array}{c}\text { Coefficient Estimates } \\
\text { (t-statistics) }\end{array}$ & $\begin{array}{c}\text { Coefficient Estimates } \\
\text { (t-statistics) }\end{array}$ \\
\hline Intercept & $0.022^{* * *}$ & $0.013^{*}$ \\
& $(2.93)$ & $(1.77)$ \\
$S_{t}$ & $0.97^{* * *}$ & $0.90^{* * *}$ \\
& $(9.35)$ & $(7.43)$ \\
$S_{t} * I N V_{t}^{\text {low }}$ & 0.128 & 0.232 \\
& $(0.91)$ & $(1.43)$ \\
$S_{t} * I N V_{t}^{\text {high }}$ & $-0.526^{* * *}$ & $-0.255^{*}$ \\
& $(-2.99)$ & $(-1.67)$ \\
\hline$R^{2}$ & $14.27 \%$ & $12.31 \%$ \\
\hline $\mathrm{N}$ & 1742 & 1740 \\
\hline
\end{tabular}

The table reports estimates for the following model: $R_{t}=\alpha+b \sum_{i=1}^{20} \widehat{b_{0} S_{l t}}+$ $c \sum_{i=1}^{20} \widehat{b_{0} S_{l t}} I N V_{t}^{\text {low }}+d \sum_{i=1}^{20} \widehat{b_{0} S_{l t}} I N V_{t}^{\text {high }}+u_{t} . R_{t}$ is the continuously compounded return of the $S \& P 500$ futures. The returns changes are computed from five minutes before to five minutes after a macroeconomic news release. $S_{i t}$ is the standardized negative surprise for announcement $i$. $I N V_{t}^{\text {low }}$ is a dummy variable equal to 1 on days when the investor sentiment measure is below the 25th percentile, $I N V_{t}^{\text {high }}$ equals to one on days when the investor sentiment measure is above the 75th percentile. The sample period is from January 1998 to September 2016.The regressions are estimated using OLS with White (1980) heteroskedasticity consistent covariance matrix. *, **, and *** denote significance at 10 percent, 5 percent, and 1 percent levels, respectively. 
Table C.2.7. Average Effect of Investor Sentiment on Market Response to Macroeconomic News Controlling for State of Economy

\begin{tabular}{|c|c|c|c|c|c|c|}
\hline \multirow[b]{2}{*}{ Variables } & \multicolumn{3}{|c|}{ AAII Sentiment Index } & \multicolumn{3}{|c|}{ Investor Intelligence Sentiment Index } \\
\hline & $\begin{array}{l}\text { Coefficients } \\
\text { (t-statistics) }\end{array}$ & $\begin{array}{l}\text { Coefficients } \\
\text { (t-statistics) }\end{array}$ & $\begin{array}{l}\text { Coefficients } \\
\text { (t-statistics) }\end{array}$ & $\begin{array}{l}\text { Coefficients } \\
\text { (t-statistics) }\end{array}$ & $\begin{array}{c}\text { Coefficient } \\
\text { s }\end{array}$ & $\begin{array}{l}\text { Coefficient } \\
\text { s }\end{array}$ \\
\hline \multirow[t]{2}{*}{ Intercept } & 0.002 & 0.002 & 0.002 & 0.002 & 0.002 & 0.002 \\
\hline & $(0.5)$ & $(0.56)$ & $(0.5)$ & $(0.43)$ & $(0.44)$ & $(0.48)$ \\
\hline \multirow[t]{2}{*}{$S_{t}$} & $0.93 * * *$ & $0.912 * * *$ & $1.00 * * *$ & $1.00 * * *$ & $0.99 * * *$ & $1.00 * * *$ \\
\hline & $(9.74)$ & $(9.83)$ & $(10.43)$ & $(7.4)$ & $(8.65)$ & $(8.92)$ \\
\hline \multirow{2}{*}{$S_{t} * I N V_{t}^{\text {low }}$} & $0.356^{* *}$ & $0.347 * *$ & $0.411 * * *$ & $0.78 * * *$ & $0.66 * * *$ & $0.782 * * *$ \\
\hline & $(2.25)$ & $(2.16)$ & $(2.65)$ & $(3.73)$ & $(2.8)$ & $(3.72)$ \\
\hline \multirow[t]{2}{*}{$S_{t} * I N V_{t}^{\text {high }}$} & $-0.55 * * *$ & $-0.461 * * *$ & $-0.55^{*}$ & $-0.29 *$ & $-0.26 *$ & $-0.316^{* *}$ \\
\hline & $(-3.42)$ & $(-2.92)$ & $(-3.39)$ & $(-1.74)$ & $(-1.64)$ & $(-2.04)$ \\
\hline \multirow[t]{2}{*}{$S_{t} *$ Econ } & 0.215 & & & 0.023 & & \\
\hline & (1.54) & & & $(0.12)$ & & \\
\hline \multirow[t]{2}{*}{$S_{t} * C F N A I$} & & $-0.167 * *$ & & & -0.103 & \\
\hline & & $(-2.02)$ & & & $(-0.77)$ & \\
\hline \multirow[t]{2}{*}{$S_{t} * \Delta V I X$} & & & 0.005 & & & 0.004 \\
\hline & & & $(0.53)$ & & & $(0.36)$ \\
\hline$R^{2}$ & $14.11 \%$ & $14.4 \%$ & $14.08 \%$ & $14.59 \%$ & $14.58 \%$ & $14.53 \%$ \\
\hline $\mathrm{N}$ & 2906 & 2906 & 2844 & 2901 & 2901 & 2838 \\
\hline
\end{tabular}

The table reports estimates for the following model: $R_{t}=\alpha+b \sum_{i=1}^{20} \widehat{b_{0} S_{l t}}+$ $c \sum_{i=1}^{20} \widehat{b_{0} S_{l t}} I N V_{t}^{\text {low }}+d \sum_{i=1}^{20} \widehat{b_{0} S_{l t}} I N V_{t}^{\text {high }}+e \sum_{i=1}^{20} \widehat{b_{0} S_{l t}}$ econ $+u_{t} \cdot R_{t}$ is the continuously compounded return of the $\mathrm{S} \& \mathrm{P} 500$ futures. The returns changes are computed from five minutes before to five minutes after a macroeconomic news release. $S_{i t}$ is the standardized surprise for announcement $i . I N V_{t}^{\text {low }}$ is a dummy variable equal to 1 on days when the investor sentiment measure is below the 25 th percentile, $I N V_{t}^{\text {high }}$ equals to one on days when the investor sentiment measure is above the 75 th percentile, and $I N V_{t}^{\text {normal }}$ equals to one on days when the investor sentiment is between $25^{\text {th }}$ and $75^{\text {th }}$ percentile. Two different measures of the state of the economy are tested: the smoothed U.S. recession probability and the Chicago Fed National Activity Index (CFNAI). A high smoothed U.S. recession probability indicates economic contraction. A zero value of CFNAI indicates that the economy is expanding; positive values indicate above-average growth; and negative values indicate below-average growth. The sample period is from January 1998 to September 2016. The CFNAI used in regression is revised in May 2016. The regressions are estimated using OLS with White (1980) heteroskedasticity consistent covariance matrix. *, **, and *** denote significance at 10 percent, 5 percent, and 1 percent levels, respectively. 
Table C.2.8. Average Effect of Investor Sentiment on Market Response to Positive Macroeconomic News Controlling for State of Economy

\begin{tabular}{|c|c|c|c|c|c|c|}
\hline & \multicolumn{3}{|c|}{ AAII Sentiment Index } & \multicolumn{3}{|c|}{ Investor Intelligence Sentiment Index } \\
\hline Variables & $\begin{array}{l}\text { Coefficients } \\
\text { (t-statistics) }\end{array}$ & $\begin{array}{l}\text { Coefficients } \\
\text { (t-statistics) }\end{array}$ & $\begin{array}{l}\text { Coefficients } \\
\text { (t-statistics) }\end{array}$ & $\begin{array}{l}\text { Coefficients } \\
\text { (t-statistics) }\end{array}$ & $\begin{array}{l}\text { Coefficients } \\
\text { (t-statistics) }\end{array}$ & $\begin{array}{l}\text { Coefficients } \\
\text { (t-statistics) }\end{array}$ \\
\hline Intercept & $\begin{array}{c}0.04 * * * \\
(6.54)\end{array}$ & $\begin{array}{c}0.041^{* * * *} \\
(8.2)\end{array}$ & $\begin{array}{c}0.041 * * * \\
(6.39)\end{array}$ & $\begin{array}{c}0.041 * * * \\
(6.93)\end{array}$ & $\begin{array}{c}0.042 * * * \\
(6.98)\end{array}$ & $\begin{array}{c}0.043^{* * *} \\
\text { (7) }\end{array}$ \\
\hline$S_{t}$ & $\begin{array}{c}0.586^{* * * *} \\
(3.57)\end{array}$ & $\begin{array}{c}0.671 * * * \\
(4.52)\end{array}$ & $\begin{array}{c}0.87 * * * \\
(5.33)\end{array}$ & $\begin{array}{c}0.605^{* * *} \\
(2.71)\end{array}$ & $\begin{array}{c}0.85^{* * *} \\
(4.53)\end{array}$ & $\begin{array}{c}0.874 * * * \\
(4.12)\end{array}$ \\
\hline$S_{t} * I N V_{t}^{\text {low }}$ & $\begin{array}{l}-0.011 \\
(-0.04)\end{array}$ & $\begin{array}{l}-0.072 \\
(-0.28)\end{array}$ & $\begin{array}{c}0.12 \\
(0.37)\end{array}$ & $\begin{array}{c}0.621 \\
(1.5)\end{array}$ & $\begin{array}{l}0.454 \\
(1.13)\end{array}$ & $\begin{array}{c}0.909 * * \\
(2.09)\end{array}$ \\
\hline$S_{t} * I N V_{t}^{\text {high }}$ & $\begin{array}{l}-0.476^{*} \\
(-1.89)\end{array}$ & $\begin{array}{l}-0.306 \\
(-1.26)\end{array}$ & $\begin{array}{c}-0.543 * * \\
(-2.25)\end{array}$ & $\begin{array}{l}-0.428 \\
(-1.54)\end{array}$ & $\begin{array}{c}-0.538 * * \\
(-2.07)\end{array}$ & $\begin{array}{c}-0.676^{* *} \\
(-2.41)\end{array}$ \\
\hline$S_{t} *$ Econ & $\begin{array}{c}0.872 * * * \\
(3.99)\end{array}$ & & & $\begin{array}{c}1.124 * * * \\
(3.24)\end{array}$ & & \\
\hline$S_{t} * C F N A I$ & & $\begin{array}{c}-0.50 * * * \\
(-4.37)\end{array}$ & & & $\begin{array}{c}-0.623^{* * *} \\
(-3.08)\end{array}$ & \\
\hline$S_{t} * \Delta V I X$ & & & $\begin{array}{l}-0.027 \\
(-1.35)\end{array}$ & & & $\begin{array}{c}-0.03 \\
(-1.33)\end{array}$ \\
\hline$\overline{R^{2}}$ & $4.53 \%$ & $5.09 \%$ & $3.68 \%$ & $5.96 \%$ & $6.16 \%$ & $5.08 \%$ \\
\hline $\mathrm{N}$ & 1929 & 1929 & 1890 & 1925 & 1925 & 1886 \\
\hline $\begin{array}{l}\text { The table } \\
c \sum_{i=1}^{20} \widehat{b_{0} S_{l t}} I N \\
\text { compounded re } \\
\text { before to five } \mathrm{n} \\
\text { for announcem } \\
\text { measure is belo } \\
\text { measure is ab } \\
\text { 2016.The regre } \\
\text { covariance mat } \\
\text { respectively. }\end{array}$ & $\begin{array}{l}\text { reports estin } \\
V_{t}^{\text {low }}+d \sum_{i=1}^{20} \\
\text { turn of the } \mathrm{S} \& \\
\text { inutes after a r } \\
\text { ent } i . I N V_{t}^{\text {low }} \mathrm{i} \\
\text { w the } 25 \text { th per } \\
\text { ve the } 75 \text { th } \mathrm{p} \\
\text { ssions are esti } \\
\text { rix. *, **, and }\end{array}$ & $\begin{array}{l}\text { lates for } \\
\widehat{b_{0} S_{l t}} I N V_{t}^{\text {hig }} \\
\mathrm{P} 500 \text { futures } \\
\text { nacroeconomi } \\
\text { s a dummy va } \\
\text { centile, } I N V_{t}^{h} \\
\text { ercentile. The } \\
\text { mated using } \\
* * * \text { denote sig }\end{array}$ & $\begin{array}{l}\text { he followi } \\
+e \sum_{i=1}^{20} \widehat{b_{0}} \\
\text { The returns } \\
\text { news releas } \\
\text { iable equal t } \\
\text { gh equals to } \\
\text { sample peri } \\
\text { LS with Wl } \\
\text { ificance at } 1\end{array}$ & $\begin{array}{l}\text { model: } \\
\text { econ }+u_{t} \text {. } \\
\text { anges are cor } \\
S_{i t} \text { is the stan } \\
1 \text { on days wh } \\
\text { e on days wh } \\
\text { is from Jan } \\
\text { e (1980) het } \\
\text { ercent, } 5 \text { per }\end{array}$ & $\begin{array}{l}t=\alpha+b \sum \\
Q_{t} \text { is the } \mathrm{c} \\
\text { puted from } \mathrm{f} \\
\text { ardized posit } \\
\mathrm{n} \text { the investo } \\
\mathrm{n} \text { the investo } \\
\text { ary } 1998 \text { to } \\
\text { oskedasticity } \\
\mathrm{nt} \text {, and } 1 \text { pei }\end{array}$ & $\begin{array}{l}\widehat{b_{0} S_{l t}}+ \\
\text { inuously } \\
\text { minutes } \\
\text { surprise } \\
\text { entiment } \\
\text { entiment } \\
\text { ptember } \\
\text { onsistent } \\
\text { tl levels, }\end{array}$ \\
\hline
\end{tabular}


Table C.2.9. Average Effect of Investor Sentiment on Market Response to Negative Macroeconomic News Controlling for State of Economy

\begin{tabular}{|c|c|c|c|c|c|c|}
\hline \multirow[b]{2}{*}{ Variables } & \multicolumn{3}{|c|}{ AAII Sentiment Index } & \multicolumn{3}{|c|}{ Investor Intelligence Sentiment Index } \\
\hline & $\begin{array}{l}\text { Coefficients } \\
\text { (t-statistics) }\end{array}$ & $\begin{array}{l}\text { Coefficients } \\
\text { (t-statistics) }\end{array}$ & $\begin{array}{l}\text { Coefficients } \\
\text { (t-statistics) }\end{array}$ & $\begin{array}{l}\text { Coefficients } \\
\text { (t-statistics) }\end{array}$ & $\begin{array}{l}\text { Coefficients } \\
\text { (t-statistics) }\end{array}$ & $\begin{array}{l}\text { Coefficients } \\
\text { (t-statistics) }\end{array}$ \\
\hline Intercept & $\begin{array}{c}0.022^{* * *} \\
(2.94)\end{array}$ & $\begin{array}{c}0.021^{* * * *} \\
(2.76)\end{array}$ & $\begin{array}{c}0.021 * * * \\
(2.82)\end{array}$ & $\begin{array}{c}0.015^{* *} \\
(2.04)\end{array}$ & $\begin{array}{c}0.016^{* *} \\
(2.2)\end{array}$ & $\begin{array}{l}0.011 \\
(1.52)\end{array}$ \\
\hline$S_{t}$ & $\begin{array}{c}0.99 * * * \\
(8.71)\end{array}$ & $\begin{array}{c}0.949 * * * \\
(8.32)\end{array}$ & $\begin{array}{c}0.98^{* * * *} \\
(9.24)\end{array}$ & $\begin{array}{c}1.00 * * * \\
(7.33)\end{array}$ & $\begin{array}{c}0.949 * * * \\
(7.71)\end{array}$ & $\begin{array}{c}0.902 * * * \\
(7.64)\end{array}$ \\
\hline$S_{t} * I N V_{t}^{\text {low }}$ & $\begin{array}{l}0.125 \\
(0.85)\end{array}$ & $\begin{array}{l}0.106 \\
(0.75)\end{array}$ & $\begin{array}{c}0.09 \\
(0.64)\end{array}$ & $\begin{array}{c}0.304 * \\
(1.9)\end{array}$ & $\begin{array}{c}0.359 * * \\
(2.03)\end{array}$ & $\begin{array}{l}0.188 \\
(1.11)\end{array}$ \\
\hline$S_{t} * I N V_{t}^{\text {high }}$ & $\begin{array}{c}-0.535 * * * \\
(-3.03)\end{array}$ & $\begin{array}{c}-0.513 * * * \\
(-2.88)\end{array}$ & $\begin{array}{c}-0.492 * * * \\
(-2.79)\end{array}$ & $\begin{array}{l}-0.35 * * \\
(-2.14)\end{array}$ & $\begin{array}{c}-0.284^{*} \\
(-1.87)\end{array}$ & $\begin{array}{l}-0.278^{*} \\
(-1.82)\end{array}$ \\
\hline$S_{t} *$ Econ & $\begin{array}{l}-0.032 \\
(-0.23)\end{array}$ & & & $\begin{array}{l}-0.239 \\
(-1.52)\end{array}$ & & \\
\hline$S_{t} * C F N A I$ & & $\begin{array}{l}-0.048 \\
(-0.74)\end{array}$ & & & $\begin{array}{c}0.101^{*} \\
(1.66)\end{array}$ & \\
\hline$S_{t} * \Delta V I X$ & & & $\begin{array}{c}0.028 * * * \\
(3.16)\end{array}$ & & & $\begin{array}{l}0.015 \\
(1.53)\end{array}$ \\
\hline$R^{2}$ & $14.4 \%$ & $14.46 \%$ & $15.61 \%$ & $12.62 \%$ & $12.69 \%$ & $12.68 \%$ \\
\hline $\mathrm{N}$ & 1736 & 1736 & 1701 & 1734 & 1734 & 1699 \\
\hline
\end{tabular}

The table reports estimates for the following model: $R_{t}=\alpha+b \sum_{i=1}^{20} \widehat{b_{0} S_{l t}}+$ $c \sum_{i=1}^{20} \widehat{b_{0} S_{l t}} I N V_{t}^{\text {low }}+d \sum_{i=1}^{20} \widehat{b_{0} S_{l t}} I N V_{t}^{\text {high }}+e \sum_{i=1}^{20} \widehat{b_{0} S_{l t}}$ econ $+u_{t} . R_{t}$ is the continuously compounded return of the S\&P 500 futures. $S_{i t}$ is the standardized negative surprise for announcement $i . I N V_{t}^{\text {low }}$ is a dummy variable equal to 1 on days when the investor sentiment measure is below the 25 th percentile, $I N V_{t}^{\text {high }}$ equals to one on days when the investor sentiment measure is above the 75th percentile. The sample period is from January 1998 to September 2016.The regressions are estimated using OLS with White (1980) heteroskedasticity consistent covariance matrix. ${ }^{*}, * *$, and $* * *$ denote significance at 10 percent, 5 percent, and 1 percent levels, respectively. 
Table C.2.10. Average Effect of Investor Sentiment on Market Response to Macroeconomic News Controlling for State of Economy

\begin{tabular}{|c|c|c|c|c|c|c|}
\hline & \multicolumn{3}{|c|}{ AAII Sentiment Index } & \multicolumn{3}{|c|}{ Investor Intelligence Sentiment Index } \\
\hline Variables & Coefficients & Coefficient & Coefficient & Coefficient & Coefficient & Coefficient \\
\hline \multirow[t]{2}{*}{ Intercept } & -0.002 & -0.001 & -0.023 & -0.005 & -0.003 & -0.018 \\
\hline & $(-0.38)$ & $(-0.15)$ & $(-1.48)$ & $(-0.81)$ & $(-0.43)$ & $(-0.93)$ \\
\hline \multirow[t]{2}{*}{$I N V_{t}^{\text {low }}$} & 0.0002 & -0.002 & -0.006 & 0.015 & 0.012 & 0.011 \\
\hline & $(0.02)$ & $(-0.2)$ & $(-0.46)$ & $(1.15)$ & $(0.9)$ & $(0.81)$ \\
\hline \multirow{2}{*}{$I N V_{t}^{h i g h}$} & 0.004 & 0.006 & 0.002 & 0.0003 & -0.001 & 0.001 \\
\hline & $(0.72)$ & $(0.56)$ & $(0.31)$ & $(0.03)$ & $(-0.18)$ & $(0.17)$ \\
\hline \multirow[t]{2}{*}{ ECON } & 0.012 & & & 0.012 & & \\
\hline & $(1.12)$ & & & $(1.09)$ & & \\
\hline \multirow[t]{2}{*}{ CFNAI } & & -0.01 & & & -0.007 & \\
\hline & & $(-1.33)$ & & & $(-0.85)$ & \\
\hline \multirow[t]{2}{*}{$V I X$} & & & 0.001 & & & 0.001 \\
\hline & & & (1.53) & & & $(0.82)$ \\
\hline \multirow[t]{2}{*}{$S_{t}$} & $0.93 * * *$ & $0.915 * * *$ & 0.184 & $1.00 * * *$ & $0.99 * * *$ & 0.301 \\
\hline & $(9.76)$ & $(9.86)$ & (1.22) & (7.47) & $(8.71)$ & (1.35) \\
\hline \multirow{2}{*}{$S_{t} * I N V_{t}^{\text {low }}$} & $0.356^{* *}$ & $0.342 * *$ & $0.27 *$ & $0.80 * * *$ & $0.669 * * *$ & 0.294 \\
\hline & $(2.26)$ & $(2.15)$ & (1.71) & (3.79) & $(2.83)$ & (1.13) \\
\hline \multirow[t]{2}{*}{$S_{t}$} & $-0.54 * * *$ & $-0.463 * * *$ & $-0.395 * *$ & $-0.29 *$ & $-0.26^{*}$ & -0.134 \\
\hline & $(-3.4)$ & $(-2.92)$ & $(-2.47)$ & $(-1.75)$ & $(-1.65)$ & $(-0.89)$ \\
\hline \multirow[t]{2}{*}{$S_{t} *$ Econ } & 0.217 & & & 0.02 & & \\
\hline & (1.56) & & & $(0.11)$ & & \\
\hline \multirow[t]{2}{*}{$S_{t} * C F N A I$} & & $-0.171 * *$ & & & -0.103 & \\
\hline & & $(-2.12)$ & & & $(-0.79)$ & \\
\hline \multirow{2}{*}{$S_{t} * V I X$} & & & $0.035 * * *$ & & & $0.035 * * *$ \\
\hline & & & $(5.05)$ & & & $(3.14)$ \\
\hline$R^{2}$ & $14.17 \%$ & $14.51 \%$ & $15.92 \%$ & $14.64 \%$ & $14.73 \%$ & $15.47 \%$ \\
\hline $\mathrm{N}$ & 2906 & 2906 & 2844 & 2901 & 2901 & 2838 \\
\hline \multicolumn{7}{|c|}{ 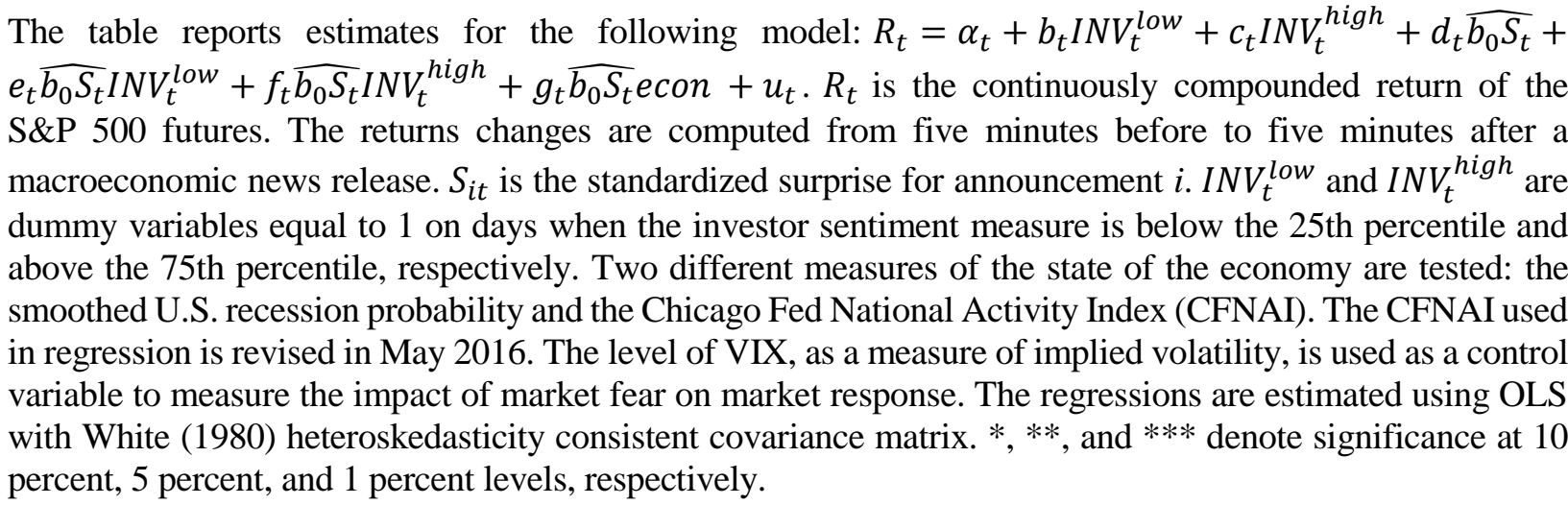 } \\
\hline
\end{tabular}


Table C.2.11. Average Effect of Investor Sentiment on Market Response to Positive Macroeconomic News Controlling for State of Economy

\begin{tabular}{|c|c|c|c|c|c|c|}
\hline \multirow[b]{2}{*}{ Variables } & \multicolumn{3}{|c|}{ AAII Sentiment Index } & \multicolumn{3}{|c|}{ Investor Intelligence Sentiment Index } \\
\hline & $\begin{array}{l}\text { Coefficients } \\
\text { (t-statistics) }\end{array}$ & $\begin{array}{l}\text { Coefficients } \\
\text { (t-statistics) }\end{array}$ & $\begin{array}{l}\text { Coefficients } \\
\text { (t-statistics) }\end{array}$ & $\begin{array}{l}\text { Coefficients } \\
\text { (t-statistics) }\end{array}$ & $\begin{array}{l}\text { Coefficients } \\
\text { (t-statistics) }\end{array}$ & $\begin{array}{l}\text { Coefficients } \\
\text { (t-statistics) }\end{array}$ \\
\hline Intercept & $\begin{array}{c}0.025 * * * \\
(3.3)\end{array}$ & $\begin{array}{c}0.028 * * * \\
(3.84)\end{array}$ & $\begin{array}{c}-0.039 * \\
(-1.66)\end{array}$ & $\begin{array}{c}0.018^{*} \\
(1.72)\end{array}$ & $\begin{array}{l}0.02 * * \\
(2.32)\end{array}$ & $\begin{array}{l}-0.042 \\
(-1.42)\end{array}$ \\
\hline$I N V_{t}^{\text {low }}$ & $\begin{array}{c}0.04 * * \\
(2.52)\end{array}$ & $\begin{array}{c}0.035 * * \\
(2.2)\end{array}$ & $\begin{array}{l}0.032 * \\
(1.91)\end{array}$ & $\begin{array}{c}0.061 * * * \\
(3.42)\end{array}$ & $\begin{array}{c}0.05 * * * \\
(2.75)\end{array}$ & $\begin{array}{c}0.035^{*} \\
(1.91)\end{array}$ \\
\hline$I N V_{+}^{\text {high }}$ & $\begin{array}{l}-0.009 \\
(-0.6)\end{array}$ & $\begin{array}{l}-0.002 \\
(0.16)\end{array}$ & $\begin{array}{l}-0.007 \\
(-0.52)\end{array}$ & $\begin{array}{l}0.003 \\
(0.26)\end{array}$ & $\begin{array}{l}0.003 \\
(0.28)\end{array}$ & $\begin{array}{l}0.013 \\
(1.03)\end{array}$ \\
\hline ECON & $\begin{array}{l}0.035 \\
(2.49)\end{array}$ & & & $\begin{array}{l}0.019 \\
(1.2)\end{array}$ & & \\
\hline CFNAI & & $\begin{array}{c}-0.029 * * \\
(-2.54)\end{array}$ & & & $\begin{array}{c}-0.024 * * * \\
(-2.76)\end{array}$ & \\
\hline$V I X$ & & & $\begin{array}{c}0.004 * * * \\
(2.9)\end{array}$ & & & $\begin{array}{c}0.003 * * \\
(2.3)\end{array}$ \\
\hline$S_{t}$ & $\begin{array}{c}0.72 * * * \\
(4.17)\end{array}$ & $\begin{array}{c}0.802 * * * \\
(5.11)\end{array}$ & $\begin{array}{c}-0.02 \\
(-0.07)\end{array}$ & $\begin{array}{c}0.72 * * * \\
(3.16)\end{array}$ & $\begin{array}{c}0.94 * * * \\
(4.94)\end{array}$ & $\begin{array}{c}0.21 \\
(0.42)\end{array}$ \\
\hline$S_{t} * I N V_{t}^{\text {low }}$ & $\begin{array}{c}-0.265 \\
(0.9)\end{array}$ & $\begin{array}{l}-0.325 \\
(-1.15)\end{array}$ & $\begin{array}{l}-0.51 * \\
(-1.71)\end{array}$ & $\begin{array}{l}0.311 \\
(0.74)\end{array}$ & $\begin{array}{l}0.188 \\
(0.46)\end{array}$ & $\begin{array}{l}0.238 \\
(0.47)\end{array}$ \\
\hline$S_{+} * I N V_{+}^{h i g h}$ & $\begin{array}{c}-0.467 * \\
(-1.75)\end{array}$ & $\begin{array}{c}-0.34 \\
(-1.31)\end{array}$ & $\begin{array}{c}-0.464 * \\
(-1.77)\end{array}$ & $\begin{array}{l}-0.398 \\
(-1.36)\end{array}$ & $\begin{array}{c}-0.478 * \\
(-1.77)\end{array}$ & $\begin{array}{c}-0.41 \\
(-1.41)\end{array}$ \\
\hline$S_{t} *$ Econ & $\begin{array}{c}0.713 * * * \\
(3.05)\end{array}$ & & & $\begin{array}{c}0.99 * * * \\
(2.76)\end{array}$ & & \\
\hline$S_{t} * C F N A I$ & & $\begin{array}{l}-0.4 * * * \\
(-3.34)\end{array}$ & & & $\begin{array}{c}-0.546^{* * *} \\
(-2.76)\end{array}$ & \\
\hline$S_{t} * V I X$ & & & $\begin{array}{c}0.05 * * * \\
(3.25) \\
\end{array}$ & & & $\begin{array}{c}0.038 \\
(1.5) \\
\end{array}$ \\
\hline$R^{2}$ & $5.31 \%$ & $6.25 \%$ & $6.89 \%$ & $7.36 \%$ & $8.11 \%$ & $7.48 \%$ \\
\hline $\mathrm{N}$ & 1929 & 1929 & 1890 & 1925 & 1925 & 1886 \\
\hline
\end{tabular}

The table reports estimates for the following model: $R_{t}=\alpha_{t}+b_{t} I N V_{t}^{\text {low }}+c_{t} I N V_{t}^{\text {high }}+d_{t} \widehat{b_{0} S_{t}}+$ $e_{t} \widehat{b_{0} S_{t}} I N V_{t}^{\text {low }}+f_{t} \widehat{b_{0} S_{t}} I N V_{t}^{\text {high }}+g_{t} \widehat{b_{0} S_{t}}$ econ $+u_{t} . R_{t}$ is the continuously compounded return of the $\mathrm{S} \& \mathrm{P} 500$ futures. The returns changes are computed from five minutes before to five minutes after a macroeconomic news release. $S_{i t}$ is the standardized surprise for announcement $i . I N V_{t}^{\text {low }}$ and $I N V_{t}^{\text {high }}$ are dummy variables equal to 1 on days when the investor sentiment measure is below the 25 th percentile and above the 75th percentile, respectively. Two different measures of the state of the economy are tested: the smoothed U.S. recession probability and the Chicago Fed National Activity Index (CFNAI). The CFNAI used in regression is revised in May 2016. The level of VIX, as a measure of implied volatility, is used as a control variable to measure the impact of market fear on market response. The regressions are estimated using OLS with White (1980) heteroskedasticity consistent covariance matrix. *, **, and *** denote significance at 10 percent, 5 percent, and 1 percent levels, respectively. 
Table C.2.12. Average Effect of Investor Sentiment on Market Response to Negative Macroeconomic News Controlling for State of Economy

\begin{tabular}{|c|c|c|c|c|c|c|}
\hline & \multicolumn{3}{|c|}{ AAII Sentiment Index } & \multicolumn{3}{|c|}{ Investor Intelligence Sentiment Index } \\
\hline Variables & Coefficients & Coefficients & Coefficients & Coefficients & Coefficient & Coefficients \\
\hline Intercept & $\begin{array}{c}0.034 * * * \\
(3.25)\end{array}$ & $\begin{array}{c}0.027 * * * \\
(2.61)\end{array}$ & $\begin{array}{l}0.025 \\
(1.05)\end{array}$ & $\begin{array}{c}0.049 * * * \\
(4.58)\end{array}$ & $\begin{array}{c}0.041 * * * \\
(4.27)\end{array}$ & $\begin{array}{l}0.039 \\
(1.43)\end{array}$ \\
\hline$I N V_{t}^{\text {low }}$ & $\begin{array}{l}-0.015 \\
(0.84)\end{array}$ & $\begin{array}{l}-0.016 \\
(-0.88)\end{array}$ & $\begin{array}{l}-0.017 \\
(-0.89)\end{array}$ & $\begin{array}{l}-0.05^{* * *} \\
(-2.51)\end{array}$ & $\begin{array}{c}-0.041 * * \\
(-1.96)\end{array}$ & $\begin{array}{c}-0.065 * * * \\
(-3.0)\end{array}$ \\
\hline$I N V_{t}^{\text {high }}$ & $\begin{array}{l}0.001 \\
(0.04)\end{array}$ & $\begin{array}{l}-0.001 \\
(-0.04)\end{array}$ & $\begin{array}{l}0.006 \\
(0.35)\end{array}$ & $\begin{array}{c}-0.036^{* * *} \\
(-2.35)\end{array}$ & $\begin{array}{c}-0.029 * * \\
(-2.03)\end{array}$ & $\begin{array}{c}-0.026^{*} \\
(-1.67)\end{array}$ \\
\hline ECON & $\begin{array}{l}-0.029 \\
(-1.61)\end{array}$ & & & $\begin{array}{l}-0.032 \\
(-1.79)\end{array}$ & & \\
\hline CFNAI & & $\begin{array}{l}0.006 \\
(0.57)\end{array}$ & & & $\begin{array}{l}0.015 \\
(1.52)\end{array}$ & \\
\hline VIX & & & $\begin{array}{c}-0.0003 \\
(-0.24)\end{array}$ & & & $\begin{array}{l}-0.0001 \\
(-0.05)\end{array}$ \\
\hline$S_{t}$ & $\begin{array}{c}1.06 * * * \\
(8.07)\end{array}$ & $\begin{array}{c}0.99 * * * \\
(7.47)\end{array}$ & $\begin{array}{c}0.62 * * * \\
(3.03)\end{array}$ & $\begin{array}{c}1.15 * * * \\
(7.84)\end{array}$ & $\begin{array}{c}1.04 * * * \\
(8.01)\end{array}$ & $\begin{array}{c}0.75^{* * * *} \\
(3.11)\end{array}$ \\
\hline$S_{t} * I N V_{t}^{\text {low }}$ & $\begin{array}{l}0.054 \\
(0.29)\end{array}$ & $\begin{array}{l}0.025 \\
(0.14)\end{array}$ & $\begin{array}{l}-0.009 \\
(-0.05)\end{array}$ & $\begin{array}{c}0.06 \\
(0.34)\end{array}$ & $\begin{array}{l}0.119 \\
(0.59)\end{array}$ & $\begin{array}{c}-0.32 \\
(-1.35)\end{array}$ \\
\hline$S_{t}$ & $\begin{array}{c}-0.538 * * \\
(-2.26)\end{array}$ & $\begin{array}{c}-0.522 * * \\
(-2.15)\end{array}$ & $\begin{array}{c}-0.428^{*} \\
(-1.78)\end{array}$ & $\begin{array}{c}-0.538 * * * \\
(-2.64)\end{array}$ & $\begin{array}{c}-0.432 * * \\
(-2.29)\end{array}$ & $\begin{array}{l}-0.35^{*} \\
(-1.89)\end{array}$ \\
\hline$S_{t} *$ Econ & $\begin{array}{l}-0.161 \\
(-0.92)\end{array}$ & & & $\begin{array}{c}-0.369^{* *} \\
(-2.08)\end{array}$ & & \\
\hline$S_{t} * C F N A I$ & & $\begin{array}{c}-0.02 \\
(-0.24)\end{array}$ & & & $\begin{array}{c}0.127 * * \\
(2.31)\end{array}$ & \\
\hline$S_{t} * V I X$ & & & $\begin{array}{c}0.014 * * \\
(2.07)\end{array}$ & & & $\begin{array}{c}0.013 \\
(1.2)\end{array}$ \\
\hline$R^{2}$ & $14.61 \%$ & $14.54 \%$ & $15.15 \%$ & $13.36 \%$ & $13.37 \%$ & $13.34 \%$ \\
\hline $\mathrm{N}$ & 1736 & 1736 & 1701 & 1734 & 1734 & 1699 \\
\hline
\end{tabular}

The table reports estimates for the following model: $R_{t}=\alpha_{t}+b_{t} I N V_{t}^{\text {low }}+c_{t} I N V_{t}^{\text {high }}+d_{t} \widehat{b_{0} S_{t}}+$ $e_{t} \widehat{b_{0} S_{t}} I N V_{t}^{\text {low }}+f_{t} \widehat{b_{0} S_{t}} I N V_{t}^{\text {high }}+g_{t} \widehat{b_{0} S_{t}}$ econ $+u_{t} . R_{t}$ is the continuously compounded return of the $\mathrm{S} \& \mathrm{P} 500$ futures. The returns changes are computed from five minutes before to five minutes after a macroeconomic news release. $S_{i t}$ is the standardized surprise for announcement $i . I N V_{t}^{\text {low }}$ and $I N V_{t}^{\text {high }}$ are dummy variables equal to 1 on days when the investor sentiment measure is below the 25 th percentile and above the 75th percentile, respectively. Two different measures of the state of the economy are tested: the smoothed U.S. recession probability and the Chicago Fed National Activity Index (CFNAI). The CFNAI used in regression is revised in May 2016. The level of VIX, as a measure of implied volatility, is used as a control variable to measure the impact of market fear on market response. The regressions are estimated using OLS with White (1980) heteroskedasticity consistent covariance matrix. *, **, and *** denote significance at 10 percent, 5 percent, and 1 percent levels, respectively. 
